Revue des patrimoines

\title{
Maisons de maître et habitations coloniales dans les anciens territoires français de l'Amérique tropicale
}

\section{Christophe Charlery}

\section{(2) OpenEdition}

Journals

Édition électronique

URL : http://journals.openedition.org/insitu/2362

DOI : 10.4000/insitu.2362

ISSN : 1630-7305

Éditeur

Ministère de la Culture

Référence électronique

Christophe Charlery, « Maisons de maître et habitations coloniales dans les anciens territoires français de l'Amérique tropicale », In Situ [En ligne], 5 | 2004, mis en ligne le 19 avril 2012, consulté le 08 janvier 2020. URL : http://journals.openedition.org/insitu/2362 ; DOI : 10.4000/insitu.2362

Ce document a été généré automatiquement le 8 janvier 2020

\section{(c) $($ ) $\odot \ominus$}

In Situ Revues des patrimoines est mis à disposition selon les termes de la licence Creative Commons Attribution - Pas d'Utilisation Commerciale - Pas de Modification 4.0 International. 
Maisons de maître et habitations

coloniales dans les anciens territoires français de l'Amérique tropicale

Christophe Charlery

Evolution de la maison de maître

Définition 
Figure 1

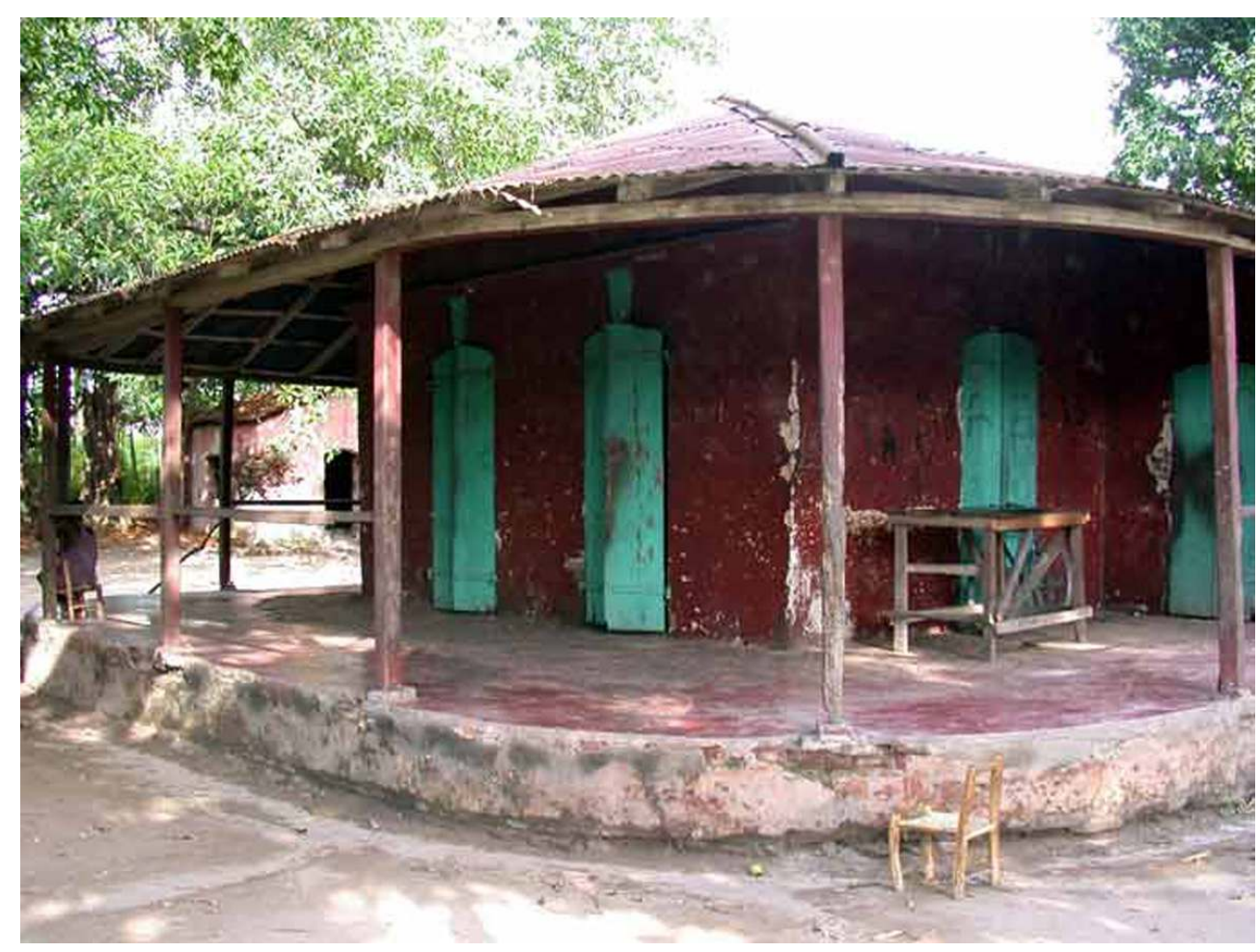

Maison de maître de l'ancienne habitation sucrerie Destreille, près du Cap-Haïtien (Haïti). Datant de la fin du XVIII siècle, cette maison de taille modeste est assez représentative de l'architecture des habitations sucreries dans la plaine du Cap-Haïtien

Phot. C. Charlery (c) C. Charlery, 2003

1 Selon les définitions anciennes, l'habitation coloniale est un bien possédé par un particulier aux colonies ${ }^{1}$ (fig. $n^{\circ} 1$ ). L'habitation ne se résume donc pas simplement à la maison de maitre ou à un édifice spécifique, mais comprend l'ensemble des bâtiments, domestiques et industriels, ainsi que les terres, les cultures, les esclaves, le bétail et tous les ustensiles nécessaires à la vie sur l'exploitation. On y cultive d'abord le tabac, puis l'indigo, la canne à sucre, le coton, le café et le cacao. En outre, il ne faut pas oublier qu'une multitude de petites exploitations produisait des vivres destinés à l'approvisionnement des marchés locaux. Enfin, quelques colons se lancèrent dans la production de matériaux de construction pour le marché local et il existait, dans presque toutes les colonies françaises, des habitations poteries produisant des formes à sucre, de la brique et des tuiles.

\section{Etablissement des premiers colons}

Dès l'établissement des premiers colons aux Antilles et en Amérique au XVII ${ }^{e}$ siècle, le principal objectif est de faire fortune afin d'acquérir une certaine aisance avant de revenir en France. Il faut donc se lancer dans la culture de produits de luxe exotiques dans l'espoir de produire rapidement des revenus tout en limitant les dépenses d'établissement. Dans les premiers temps coloniaux, les investissements de départ sont modiques, les constructions légères et provisoires, d'autant que charpentiers, maçons et menuisiers font alors défaut. Mais l'habitation est avant tout un lieu de travail et les premières maisons sommairement construites en matériaux périssables trouvés sur 
place. La plupart des colons projette de revenir en métropole une fois fortune faite. Tout au long de l'histoire, ce retour envisagé est une constante, comme le confirme Moreau de Saint-Méry : "La manie générale est de parler de retour ou de passage en France. Chacun répète qu'il part l'année prochaine, et l'on ne se considère que comme des voyageurs, dans une terre où l'on trouve si souvent son dernier asile"2. Il n'y a donc, a priori, pas de raison d'investir de grosses sommes dans la construction des maisons car les équipements industriels coûtent cher, surtout s'il s'agit d'une sucrerie. Enfin, il arrive fréquemment que le maître ne réside pas sur place et laisse la gestion de l'habitation à un géreur, ce qui ne l'incite pas à faire des frais. A la fin du XVII ${ }^{e}$ siècle, le père du Tertre donne une bonne description de ces maisons : "Celles des officiers et des riches habitants ne sont pour la plupart qu'une charpente revêtue de planches, avec un étage au-dessus de la salle, dont le plancher est d'ais ou de brique; elles sont couvertes de tuiles [...]. Les autres ne sont couvertes que de bardeaux de bois, en guise de tuiles [...]. Les maisons des simples habitants ne sont encore palissadées que de roseaux, particulièrement là où on ne craint pas les incursions des sauvages [...] celles des plus pauvres sont couvertes de feuilles de cannes, de roseaux, de latanier et de palmiste; celles-là sont incomparablement plus agréables que nos chaumines de France" ${ }^{3}$. Certaines régions plus pauvres conservent jusqu'à la fin de l'Ancien Régime un habitat précaire, comme en Guyane où le manque cruel d'artisans amena longtemps les premiers colons à avoir recours aux Indiens caraïbes pour construire ${ }^{4}$.

3 A cette époque, il n'y a pas de plan type pour l'aménagement intérieur des maisons de maitre. Elles s'agrandissent, comme les autres bâtiments de l'exploitation, en fonction des besoins et des revenus du colon. L'habitation coloniale ressemble alors à un "chantier permanent ". De plus, il n'y a pas vraiment de séparation entre l'espace d'habitation, les espaces de réserve et les magasins. En 1671, la description de la maison principale de l'habitation des Carmes, établie à Saint-Claude en Guadeloupe, est assez significative : "Sur l'habitation, il y une grande, forte et belle case bastie tout de neuf depuis deux mois laquelle contient une grande chambre pour le Rx; aux deux costés il y a un petit cabinet fort à propos et commode, une petite excyrie ; dans l'autre costé est un magazin ou es mit tous les ustensiles de l'habitation, les eaux de vie de cannes, les cassaves, les pois, les mils. $\mathrm{Au}$ bout du magazin est la chambre du commandeur et des blancs qui sont sur l'habitation"'.

\section{Evolution de la maison de maître au XVIII ${ }^{e}$ siècle}

4 Pourtant, dans une certaine mesure, l'usage et l'expérience tendent à instaurer des aménagements standard rudimentaires et il semble qu'à partir de la fin du XVII siècle, des plans type apparaissent dans l'ensemble des colonies françaises d'Amérique : Ces logements n'ont que des salles basses, séparées intérieurement en deux ou trois pièces, dont l'une sert de salle, l'autre de chambre à coucher, la troisième de garde-manger "? Enfin, avec l'enrichissement général des colons dans les années 1760-1770, la facilité du crédit et le développement d'une population créole blanche née aux Amériques et qui ne souhaite pas quitter les colonies, la construction des maisons de maître prend plus d'importance 8 . Le goût marqué pour le luxe et l'ostentation fait dire à Moreau de SaintMery à propos de la société coloniale de Saint-Domingue que : "Le luxe y a donc un culte très suivi et c'est du Cap, comme d'un centre, qu'il répand ses jouissances et ses maux. " 9 . 
Figure 2

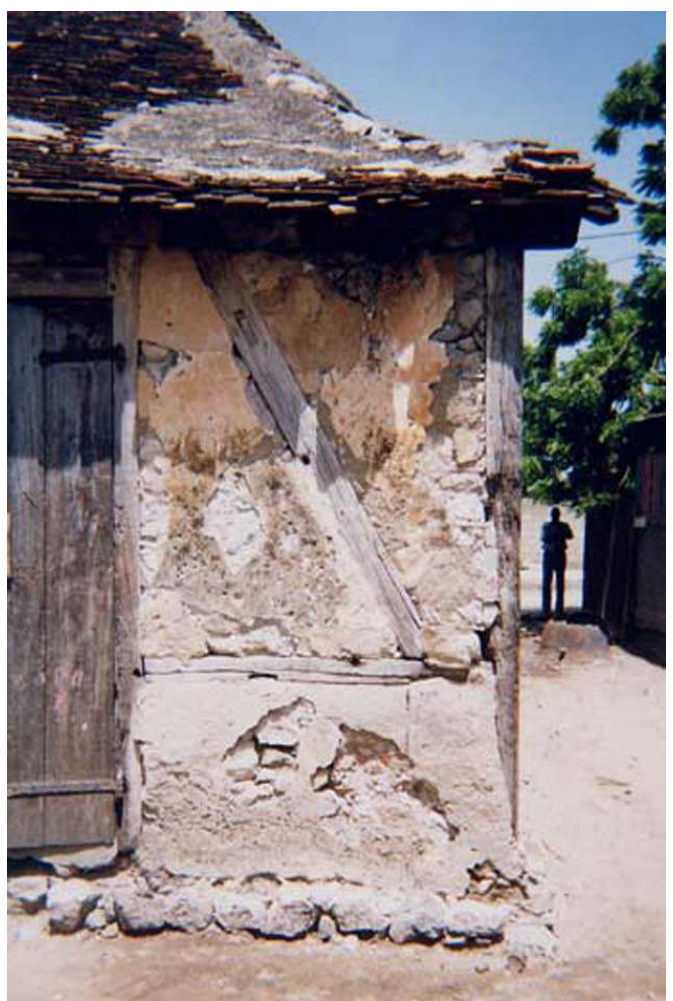

Maison de Claire-Heureuse, épouse de l'Empereur Jean-Jacques Dessalines, à Marchand-Dessalines (Haïti). Construite entre 1802 et 1806, cette maison conserve ses pans de bois, sa maçonnerie entre poteaux et des vestiges de badigeon ocre jeune typique du XVIII siècle

Phot. C. Charlery @ C. Charlery, 2003

5 C'est effectivement à Saint-Domingue que ce changement est le plus spectaculaire alors que la culture du café prend toute son extension sur les mornes et que de nombreuses habitations caféières sont construites sur des terrains vierges (fig. $\mathbf{n}^{\circ} \mathbf{2}$ ). 
Figure 3

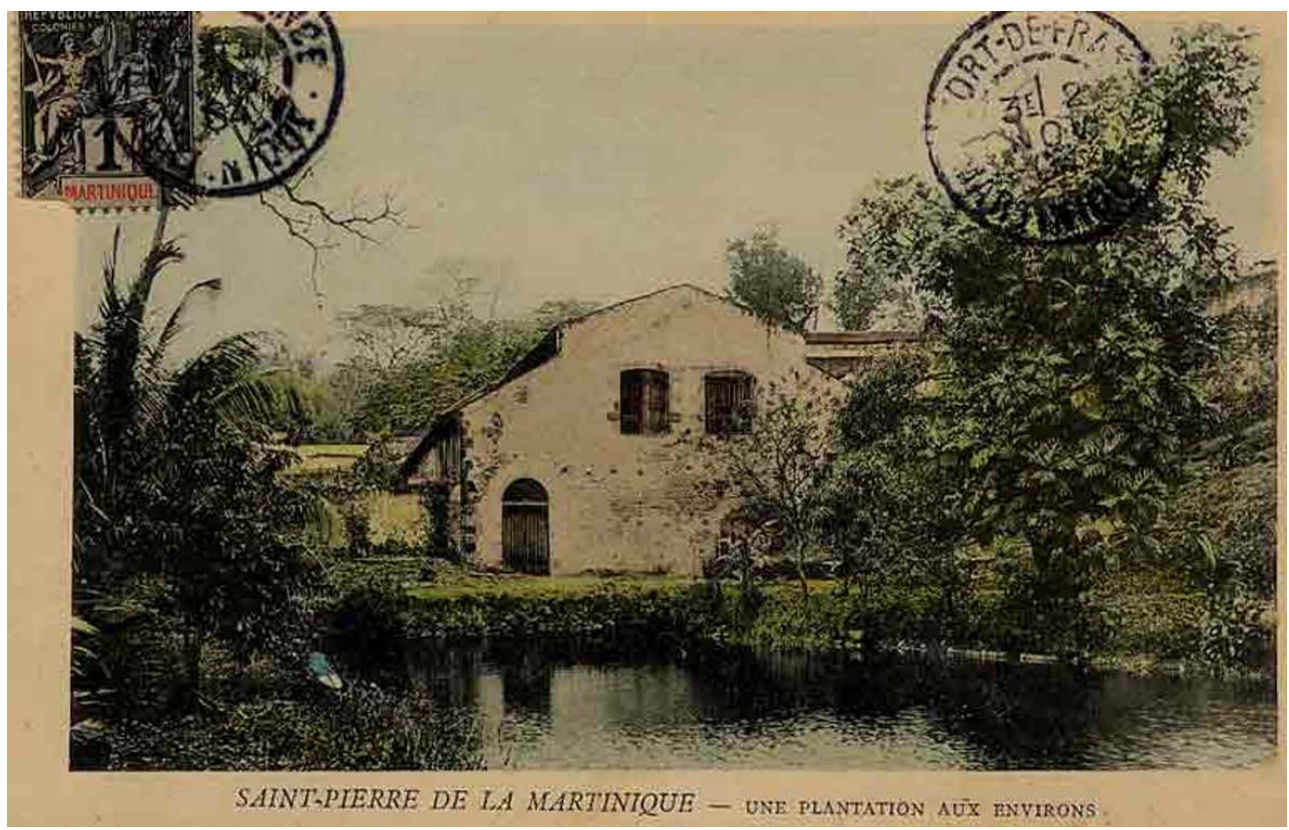

Carte postale ancienne représentant une habitation sucrerie dans les environs de Saint-Pierre de la Martinique. La maison de maître est en épais murs de maçonnerie

Repro C. Charlery (c) C. Charlery, 2003

6 A l'inverse des premiers établissements coloniaux du début du XVII ${ }^{\mathrm{e}}$ siècle, ces exploitations agricoles sont construites en maçonnerie, suivant un plan général prédéterminé. Cependant, dans les plaines où l'on cultive la canne à sucre et où la pierre manque, on continue à utiliser le bois ; les maisons sont sensiblement plus grandes mais restent rustiques. Après la révolte des esclaves et la perte définitive de la colonie en 1804, de nombreux colons s'installent dans la région de Santiago de Cuba (fig. $\mathbf{n}^{\circ}$ 3). Ils y bâtissent de grandes caféières, véritables répliques de ce que l'on avait édifié à SaintDomingue.

7 En Martinique et en Guadeloupe, les années 1770-1780 voient aussi la réalisation de nombreuses maisons de maître (fig. $\left.\mathbf{n}^{\circ} \mathbf{4}\right)$ en maçonnerie. 


\section{Figure 4}

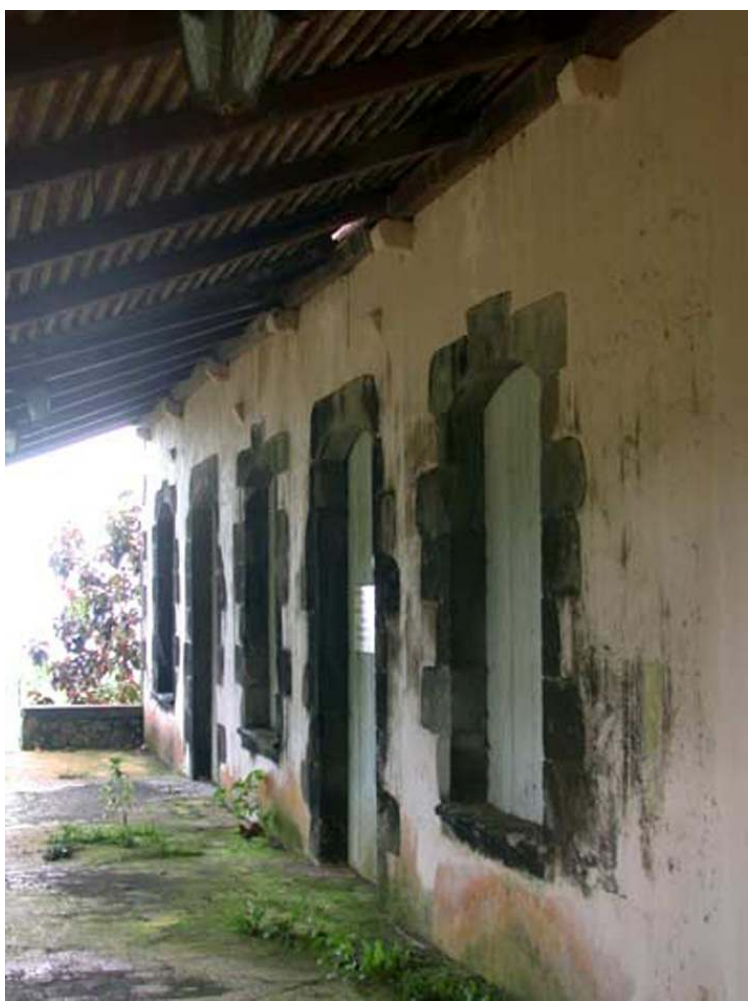

Maison de maître de l'Habitation sucrerie Leyritz à Basse-Pointe (Martinique). Cette maison est assez caractéristique des constructions en maçonnerie de la fin du XVIII e siècle, avec ses encadrements de baies en pierre de taille et ses linteaux en arcs surbaissés

Phot. C. Charlery @ C. Charlery, 1997 


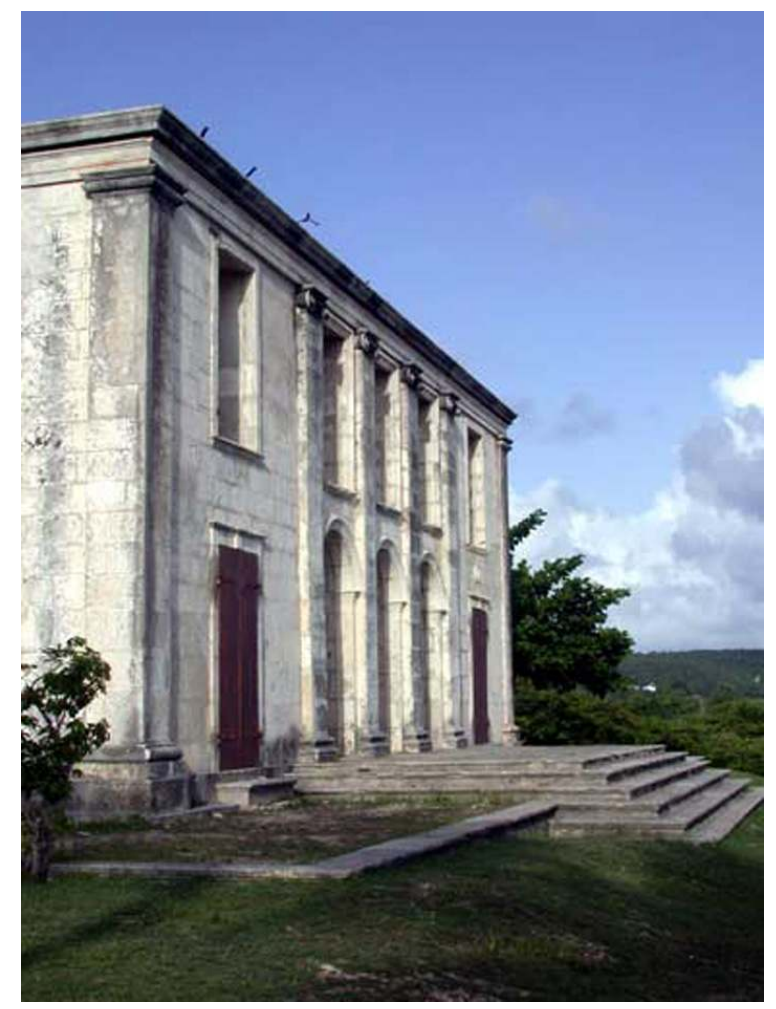

Maison de maître de l'habitation sucrerie Murat à Grand-Bourg (Marie-Galante). Exceptionnelle par sa taille et sa mise en œuvre en pierre de taille particulièrement soignée, cette grande maison de planteur fut probablement construite entre 1807 et 1814

Phot. C. Charlery @ C. Charlery, 2004

Pourtant, le bois n'est pas abandonné car beaucoup moins onéreux, y compris dans sa mise en œuvre. Cependant, comme à Saint-Domingue, les constructions sont désormais plus grandes ; la structure en bois repose sur un solage en maçonnerie qui limite les dégâts provoqués par l'humidité et les remontées capillaires. Le bardage est généralement laissé naturel et le bois prend souvent une couleur grise. Parfois, on passe une couche de gros rouge qui donne au bois une couleur d'acajou rouge. Lorsque les murs ne sont pas palissadés de planches, la maçonnerie entre poteaux est enduite à la chaux et peut même recevoir un badigeon, blanc ou ocre jaune. Ce traitement permet aussi de protéger la structure des insectes et des poux de bois. Souvent, les menuiseries sont peintes.

Pour autant, on ne peut pas parler d'élégance architecturale et de très nombreuses maisons de maître restent modestes (fig. $\mathbf{n}^{\circ}$ 5), surtout celles des "petits blancs". (fig. $n$ -5) En 1842, Victor Schoelcher rapporte que "Sur les nombreuses habitations vivrières [...], la maison [du maître] tombe en ruine, le toit percé laisse passer la pluie et il n'a pas littéralement de quoi acheter une essente pour le réparer" ${ }^{10}$. Il semble que le mauvais entretien des maisons soit une constante dans toutes les couches de la société coloniale ; une grande partie des dépenses est en effet consacrée à l'entretien et à l'amélioration de l'outil de production. Enfin, la rudesse du climat, l'incessant passage d'ouragans, mais aussi les ravages des insectes xylophages entraînent d'incessants travaux de réparation. Dans la catégorie des exploitations modestes rentrent aussi les petites habitations des gens de couleur libres, souvent mulâtres et anciens esclaves, qui ont acquis dès leur affranchissement une petite habitation caféière ou vivrière de quelques "carrés" 
seulement. Citons l'exemple du mulâtre Rémy, affranchi en 1816 et exerçant le métier de charpentier, qui a acheté en 1828 une petite habitation caféière dans la paroisse de Rivière-Salée à la Martinique, d'une superficie de quatre carrés de terre. La case à demeurer est en bois, " poteaux en terre, palissadée de planches, couverte en paille, devant laquelle se trouve un glacis carrelé " pour faire sécher le cafée ${ }^{11}$.

La présence de nombreuses petites propriétés tenues par des gens de couleur libres est attestée à Saint-Domingue à la fin du XVIII ${ }^{\mathrm{e}}$ siècle ${ }^{12}$, mais aussi à la Martinique et à la Guadeloupe, surtout à partir du début du XIX'e siècle (fig. $\mathbf{n}^{\circ}{ }^{6}$ ).

Si à Saint-Domingue les maisons sont rarement pourvues d'un second niveau, la construction à un étage carré est fréquente aux Antilles françaises (fig. $\mathbf{n}^{\circ} \mathbf{7}$ ).

12 Cependant, dans bien des cas, l'érection d'un niveau supplémentaire intervient ultérieurement, lorsque la famille s'agrandit (fig. $\mathbf{n}^{\circ} \mathbf{8}$ ).

\section{Figure 6}

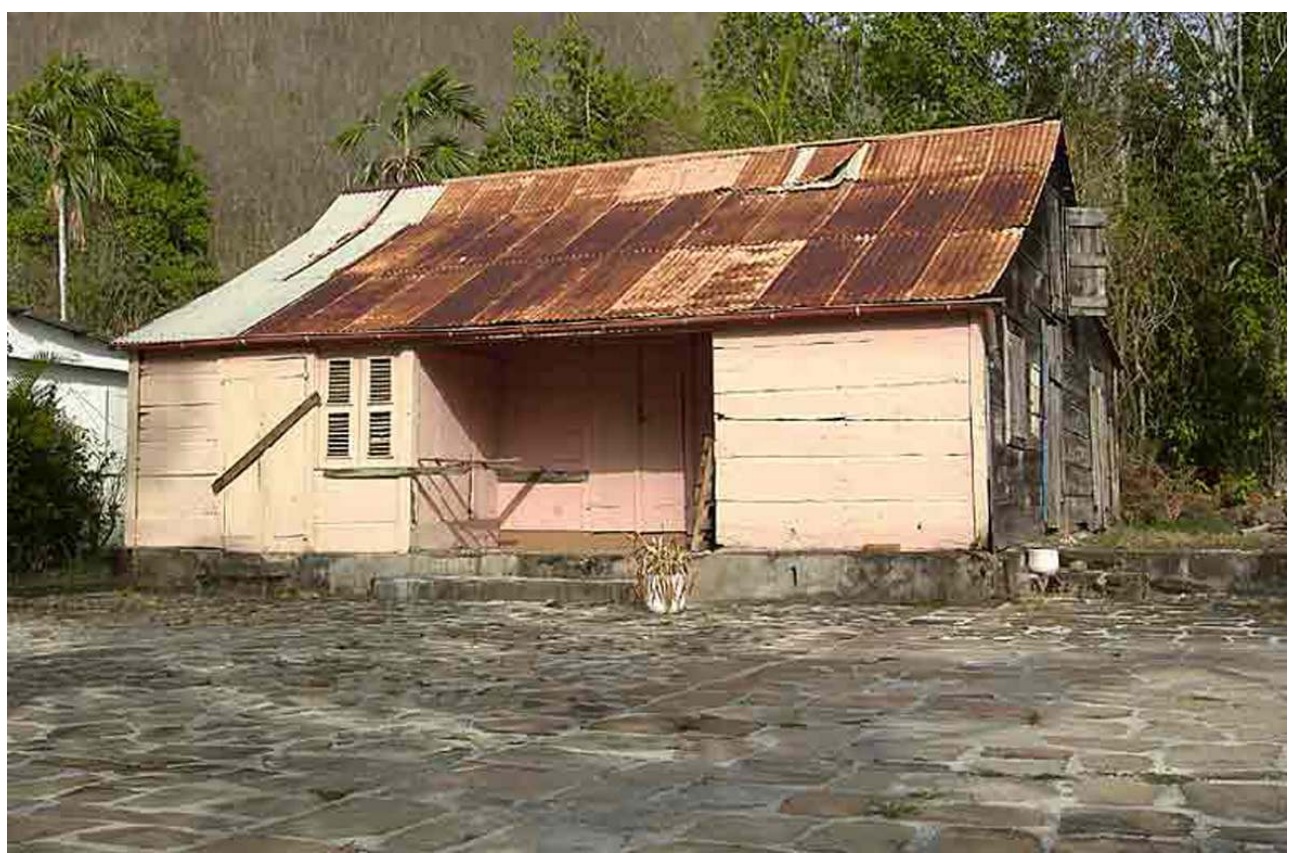

Ancienne maison de maître de l'habitation caféière Morendais à Vieux-Habitants dans la vallée de Beaugendre (Guadeloupe). De taille relativement modeste, cette maison en bois du milieu du XIX siècle était caractéristique de l'architecture coloniale de la côte sous le vent héritée du XVIIIe siècle. Peu avant la première guerre mondiale, elle fut transformée en boucan pour stocker le café lorsque les propriétaires décidèrent de construire à côté une nouvelle maison plus spacieuse

Phot. Inv. M. E. Desmoulins ( ) Inventaire général, ADAGP, 2002 
Figure 7

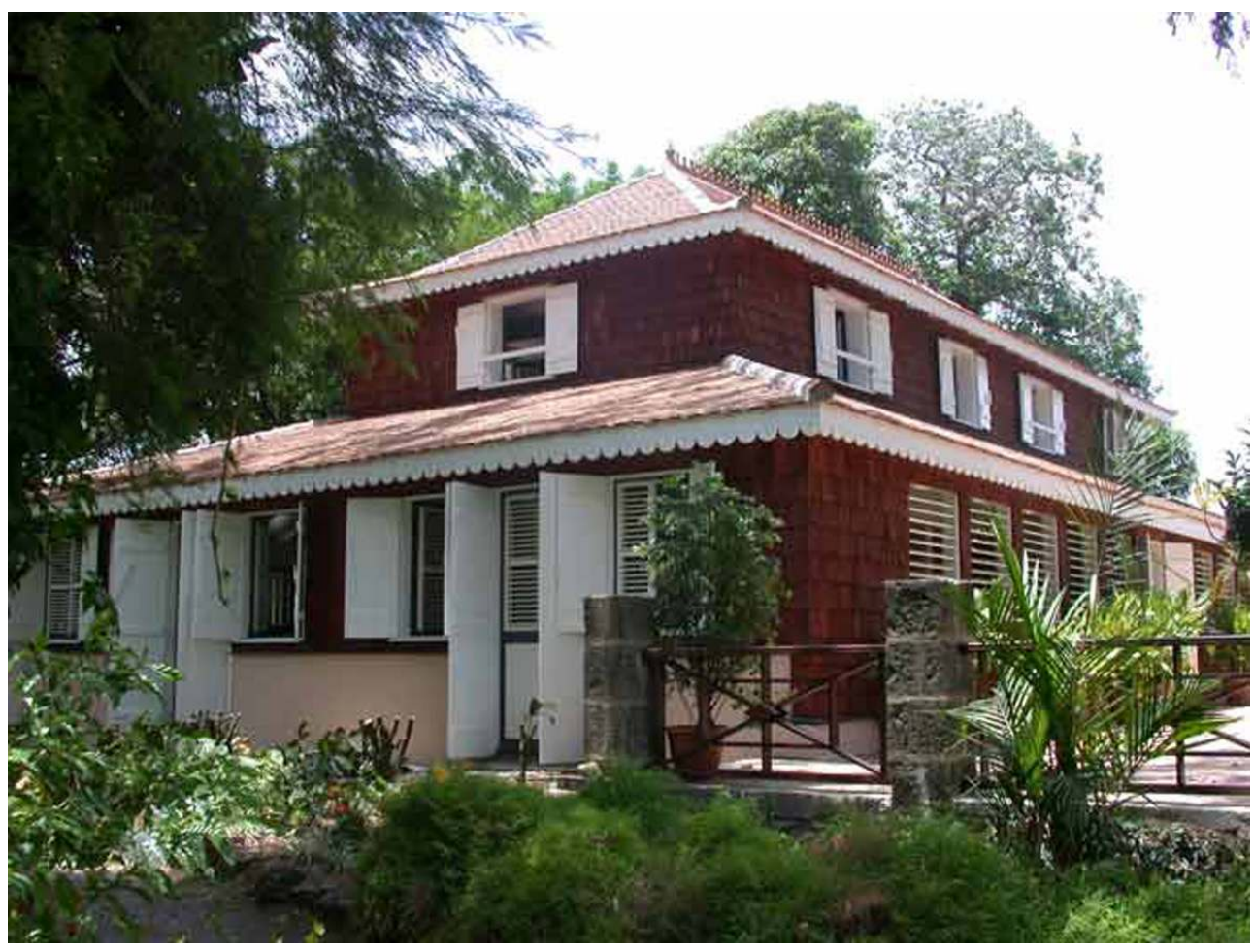

Maison de maître de l'habitation Acajou au François (Martinique). Le noyau central de cette maison en bois fut construit à la fin du XVIII siècle ; il existait déjà à cette époque une galerie pavée.

Considérablement agrandie vers 1842, un étage lui fut adjoint. Enfin, en 1887, la maison fut complétée par la construction d'une galerie supplémentaire sur la façade nord

Phot. C. Charlery (C) C. Charlery, 2003 


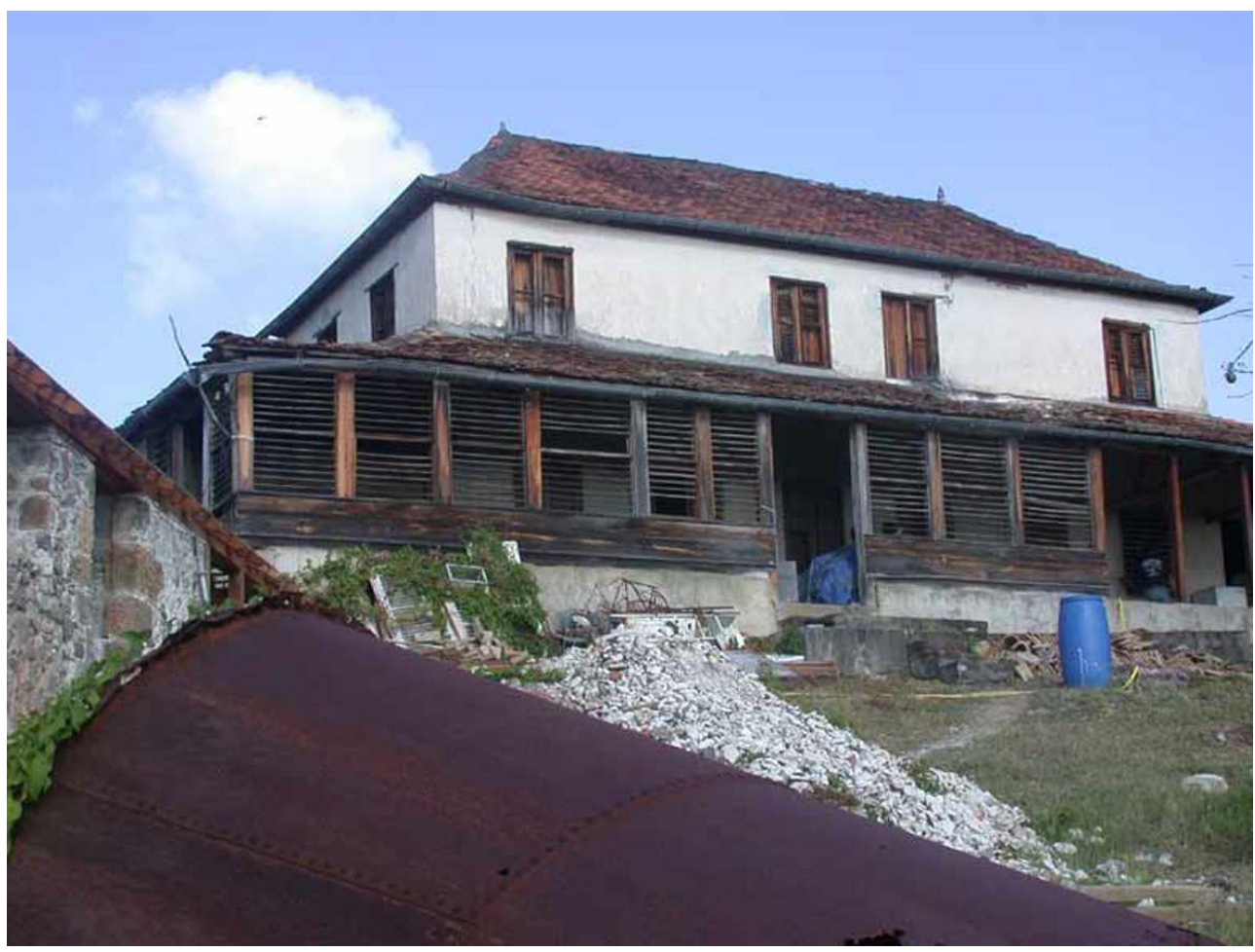

Maison de maître de l'habitation La Sucrerie aux Anses-d'Arlets (Martinique). En haut d'un morne et dominant un site magnifique, le noyau central de cette maison fut construit dans les années 1780. C'est probablement lorsque la famille Hayot en devint propriétaire en 1788, que des galeries furent adjointes et que l'étage fut élevé

Phot. C. Charlery (C) C. Charlery, 2004

\section{La maison de maître à trois pièces en enfilade}

L'étude de l'architecture domestique en milieu rural dans les anciennes colonies françaises d'Amérique permet de constater l'existence de types de maisons d'habitation que l'on retrouve partout, notamment celui dont le noyau principal se compose de trois pièces en enfilade. C'est le type le plus courant, on le rencontre dans toutes les anciennes colonies françaises, sans exception : en Guyane, à la Martinique, à la Guadeloupe, en Haïti, en Louisiane, mais aussi dans la région de Santiago de Cuba où sont venus s'installer de nombreux colons français ayant fui les révoltes d'esclaves qui survinrent à SaintDomingue à la fin du XVIII e siècle. Il est peu probable que cette distribution intérieure de la maison de maitre aux colonies résulte de l'“importation" d'un modèle régional métropolitain. Les colons étaient d'origines très variées et toutes les régions côtières de France ont envoyé d'importants contingents d'émigrants, du Havre à Bayonne, en passant par Nantes et Bordeaux, entre autres.

14 Plusieurs hypothèses peuvent être avancées, qui, sans se contredire, pourraient se compléter. 


\section{Une architecture de l'usage}

15 Dès la fin du XVII ${ }^{e}$ siècle, il semble que les maisons de colons répondent à au moins trois usages élémentaires : une salle, lieu de vie et de réception, un office, lieu de stockage, et une chambre, lieu de repos. Lorsque le révérend père Labat décrit la maison qu'il s'est fait construire au Macouba en Martinique, il précise qu'elle se compose d'une salle et d'une chambre ${ }^{13}$. Mais cette dernière est vite réduite pour installer, sur l'arrière, un office afin de "serrer" les provisions. Au couvent de Fond-Saint-Jacques, à Sainte-Marie, la maison comprend aussi une grande salle, deux chambres et un office ${ }^{14}$. L'existence de ces trois fonctions élémentaires a sans doute déterminé les distributions intérieures, d'autant que de nombreux colons sont célibataires et que leurs maisons sont avant tout fonctionnelles.

\section{Les artisans bâtisseurs}

Dans les colonies françaises, il n'y a pas d'architectes civils mais il n'est pas exclu que certains ingénieurs militaires aient réalisé quelques projets pour de riches particuliers, augmentant ainsi leurs revenus ${ }^{15}$. Cependant les interventions de ces " hommes de l'art " semblent être très rares. En revanche, le recours à un entrepreneur ou à un artisan, parfois maître compagnon, est courant. Dans un premier temps, l'artisan, qu'il soit maçon, charpentier ou menuisier, est le plus souvent originaire de France et dispose d'esclaves "à talent" qui l'aident dans son travail, puis, dans la seconde moitié du XVIII ${ }^{e}$ siècle, les hommes de couleur libres sont de plus en plus nombreux à s'établir à leur compte dans les métiers de la construction, même si dans de nombreuses habitations ce sont longtemps les esclaves "à talent" qui s'occupent directement des constructions, comme l'attestent de nombreux inventaires. Dans bien des cas, la demande du maître d'ouvrage concernant sa maison est assez simple, ce qui favorise sans doute la répétition de plans dont la grande capacité d'habitabilité n'est alors plus à démontrer.

Il est enfin intéressant de se demander quelle formation ont reçu les " maîtres artisans "; il n'est pas exclu qu'ils aient eu connaissance de livres et de traités publiés à leur intention. Plusieurs sources indiquent en effet que certains ouvrages spécialisés étaient en vente dans les colonies.

\section{Influence des traités d'architecture}

Parallèlement aux traités d'architecture et aux recueils de modèles publiés en France aux XVIIe et XVIII e siècles, il semble que les traités d'agronomie et les ouvrages relatifs à l'économie rustique aient aussi eu une très grande influence. Il est difficile d'évaluer avec précision l'impact qu'ils ont pu avoir sur les émigrants s'installant dans les colonies d'Amérique mais il faut relever que l'on trouve par exemple en 1776, dans le journal les Affiches Américaines ${ }^{16}$, imprimé au Cap Français à Saint-Domingue, des annonces publicitaires pour la La Nouvelle maison rustique de Louis Liger ${ }^{17}$, l'un des ouvrages les plus importants du XVIII e siècle dans ce domaine.

19 L'hypothèse d'une influence indirecte semble corroborée par le fait que d'autres ouvrages, inspirés de ces traités, s'adressent plus particulièrement au public résidant dans les colonies américaines et aux Indes orientales. Le premier, publié en 1776 par d'Aviler, présente une série de très belles maisons de maitre. Même si les projets 
d'influence palladienne semblent démesurés, pour ne pas dire utopiques, l'auteur adopte un discours tout à fait adapté aux réalités des Antilles: les recommandations techniques et architecturales tiennent toutes compte des réalités climatiques et géologiques de la région. Beaucoup plus pragmatique, l'ouvrage du chevalier de Préfontaine, publié en 1763 ${ }^{18}$, est un véritable guide pratique pour qui souhaite installer une habitation en Guyane et plus généralement, dans une colonie de l'Amérique tropicale ou subtropicale. Ce livre, intitulé La maison rustique, semble directement inspiré de Liger. Un long chapitre est d'ailleurs consacré à la construction et à la distribution de la maison de maître. Il connut sans doute un grand succès et en 1789, dans la relation de son voyage à Saint-Domingue, le baron de Wimpffen ${ }^{19} \mathrm{y}$ fait explicitement référence, le désignant comme un ouvrage de vulgarisation agronomique.

\section{Distributions type} sur le même plan; très peu ont un étage; ce ne sont que des rez-de-chaussée. En voici les proportions les plus ordinaires. Ce sont trois chambres de plain-pied : celle du milieu a 16 ou 18 pieds de long; les deux des côtés ont 16 pieds, le tout offrant une surface de 48 à 50 pieds, non compris les galeries autour du bâtiment, qui sont à jour et qui doivent être au moins de 6 à 7 pieds de large "20.

L'une des constantes de la distribution de ces maisons, est l'emplacement central du salon de compagnie. Le baron de Wimpffen, donnant une description précise de la "case américaine" à trois pièces, confirme : "Celle du centre est ordinairement la plus vaste. On sous divise, si l'on veut, les deux autres en plusieurs chambres" ${ }^{21}$. Le salon sert également d'entrée, tient lieu de vestibule et donne accès, de part et d'autre, aux chambres et pièces adjacentes. Cet usage n'est pas propre aux colonies : en 1791, François Cointeraux ${ }^{22}$ précise qu'en France, la salle est " habituellement occupée par la maîtresse du logis et par sa compagnie". Au début du XIX siècle, l'importance du salon se confirme: "Le salon est la pièce d'apparat où l'on reçoit les étrangers, et c'est elle qui doit déployer le plus de luxe et de richesses. Autrefois, lorsque les mœurs étaient plus simples, le salon n'existait que dans les palais et hôtels; dans la demeure modeste des particuliers, on disait salle de compagnie ; aujourd'hui, le plus petit bourgeois possède ce qu'il appelle pompeusement son salon ". ${ }^{23}$

Ainsi, les deux autres pièces, de part et d'autre du salon, servent ordinairement de chambres. Cette disposition est très commune lorsque la maison ne possède qu'un rez-dechaussée habitable, mais lorsque le galetas abrite des chambres supplémentaires, l'une des chambres du bas peut servir de salle à manger. Celle-ci, dit Cointeraux, "doit être carrelée et non parquetée, afin qu'on puisse la laver pour enlever les corps gras qu'on peut y laisser tomber pendant les repas" ${ }^{24}$. Aux Antilles, de nombreux inventaires confirment ces dispositions: un document exceptionnel daté de 1743 précise que la maison de maître de l'habitation Moulin-à-Eau, dans le quartier de Cousinière sur la paroisse de Vieux-Habitants (Guadeloupe), est divisée en trois chambres par des cloisons de planches et que celle du nord, servant de salle à manger, est "carrelée à carreaux de Provence "25. 


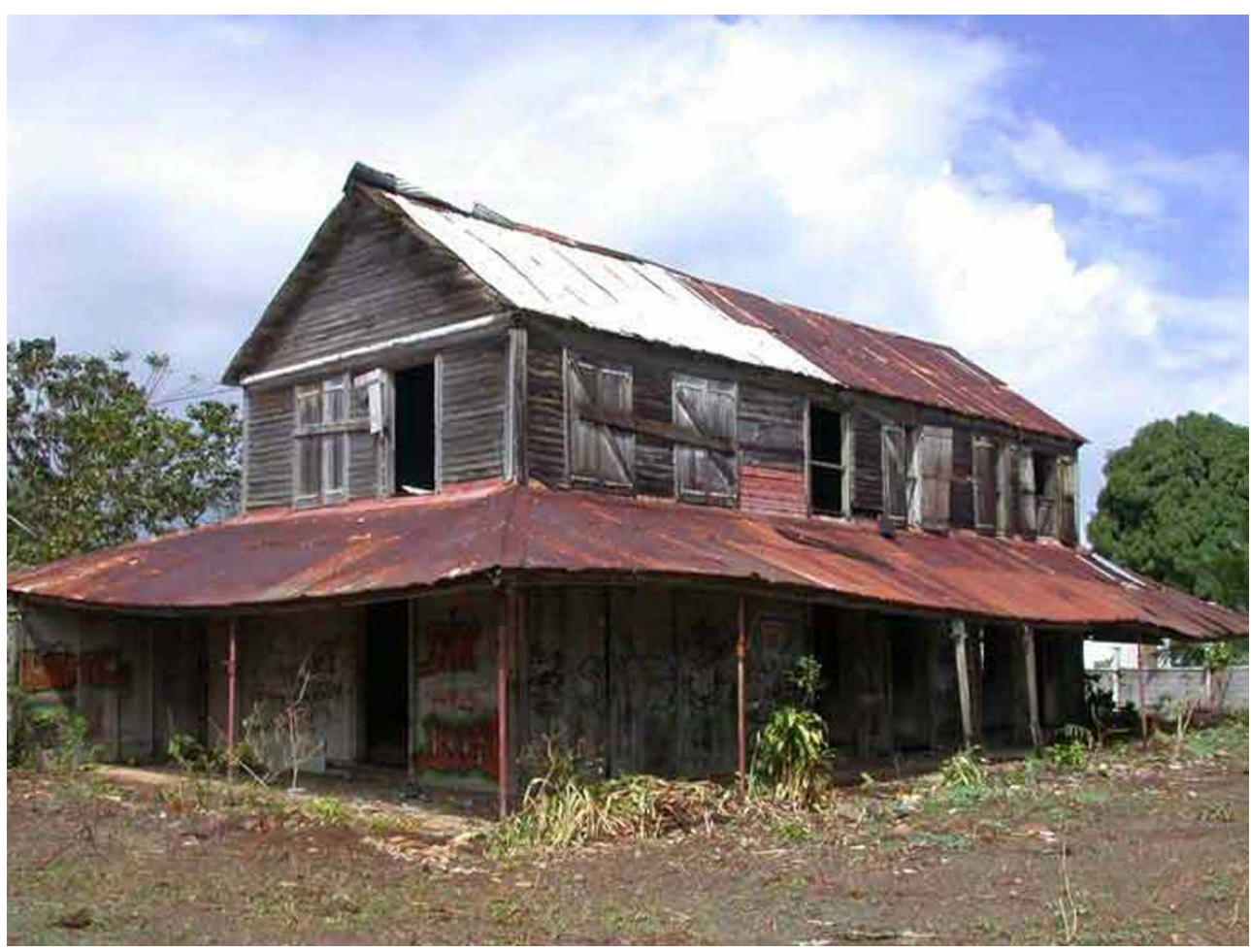

Maison de maître de l'habitation Desrosières-Nouy au Lamentin (Martinique). De facture récente, cette maison de maître en bois, datant de la fin du XIXe siècle, conserve un plan traditionnel de trois pièces en enfilade. Une large galerie, agrémentée de cabinets, en fait le tour

Phot. C. Charlery (c) C. Charlery, 2003

Lorsque les moyens du propriétaire le permettent, la maison est agrémentée de galeries et de cabinets (fig. $\mathbf{n}^{\circ}$ 9) qui augmentent considérablement la surface habitable. Mais beaucoup restent modestes, n'ayant "point de galerie, point de cabinets, point de jalousie, pas même de plancher" ${ }^{26}$.

En Guadeloupe, de nombreux exemples nous sont parvenus, les plus anciens étant tous conservés en Côte-sous-le-Vent ou sur les pentes du volcan de la Soufrière. La maison de maître de l'habitation-sucrerie L'Islet, sur la paroisse de Saint-Claude, existe déjà en 1699, date à laquelle un inventaire, exceptionnellement conservé, est dressé27. Il nous apprend que la maison en charpente, couverte d'essentes, consiste alors " en trois chambres, dont une coupée en deux". Quelques années plus tard, elle est reconstruite en maçonnerie et pierre de taille, mais conserve son plan à trois pièces en enfilade ainsi que sa toiture en essente, comme le suggère un second inventaire daté de $1731^{28}$. Par contre, en 1765 , la maison est couverte "de paille sur lattes et chevrons rond" ${ }^{29}$. Les archives livrent la description de nombreux autres édifices comme, en 1779, celle de la maison de l'habitation Veronne sur la paroisse de Morne-à-L'eau ${ }^{30}$, qui est “ divisée en une salle et deux chambres dans le bas ", ou celle de la veuve Bonneteau, à Vieux-Habitants ${ }^{31}$, qui en 1780 est " divisée par le bas en une sal, une chambre et un office et dans le haut en trois chambres, y compris celle où est l'escalier" (fig. $\mathbf{n}^{\circ} \mathbf{1 0}$ et 11). 


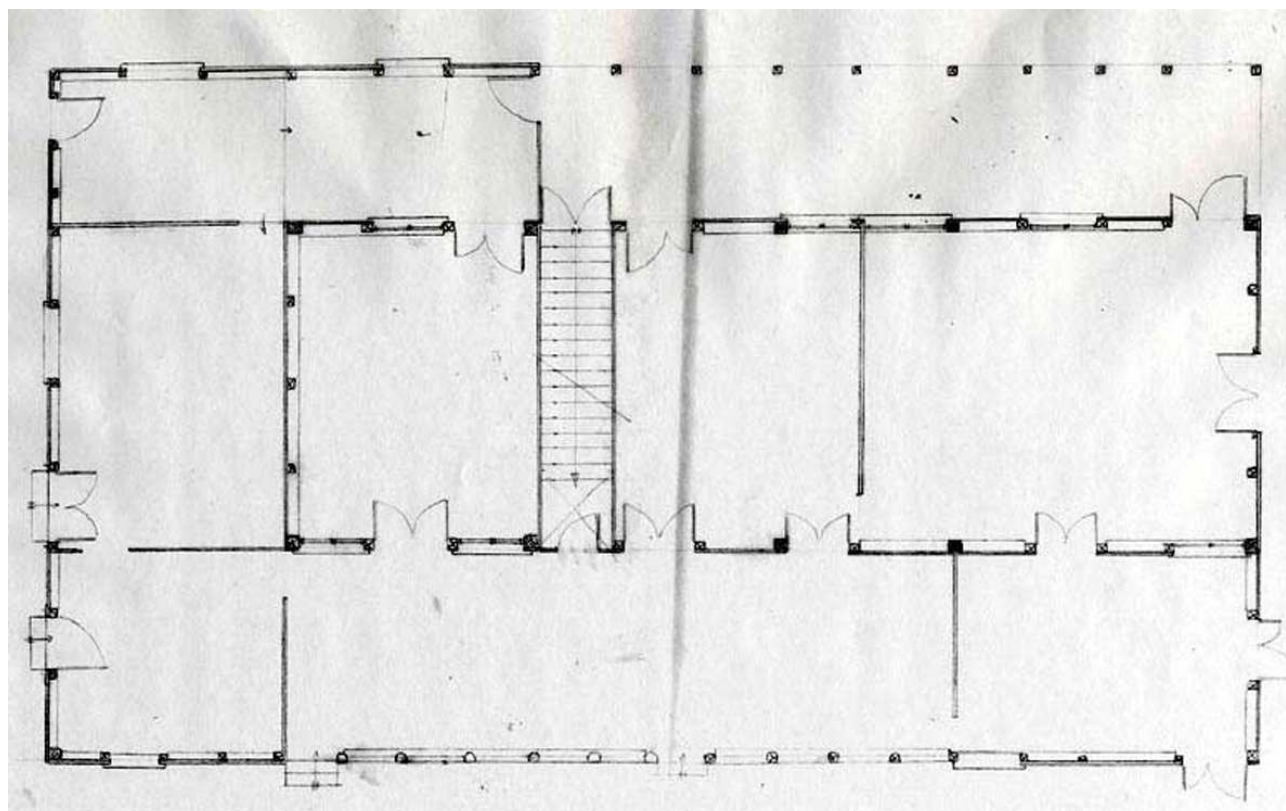

Plan du rez-de-chaussée de la maison de maître de l'habitation sucrerie Union au Lamentin (Martinique). Construite vers 1796, cette grande maison en bois, aujourd'hui très dégradée, a préservé sa distribution d'origine : trois pièces en enfilade et un escalier pour accéder à l'étage. Sur les façades principales, de larges galeries avaient été construites

Repro C. Charlery (c) C. Charlery, 2000

Figure 11

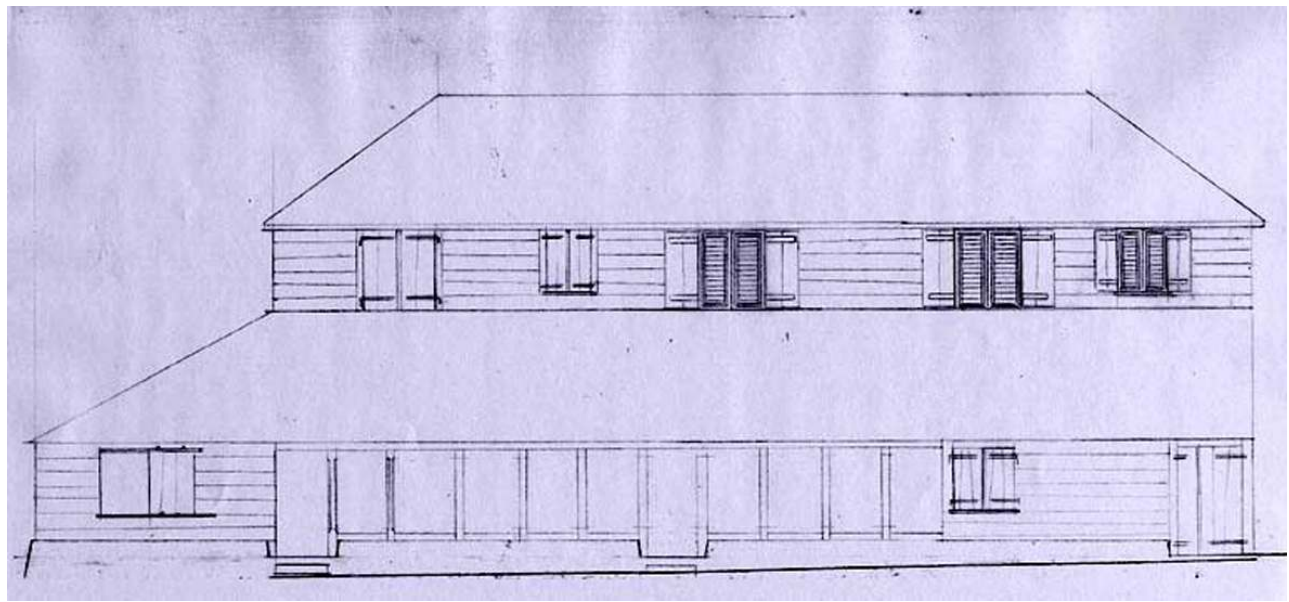

Elévation arrière de la maison de maître de l'habitation sucrerie Union au Lamentin (Martinique). Cette silhouette en "taille de guêpe ", obtenue avec les toitures à croupe de l'étage et les galeries du rez-dechaussée, est très caractéristique des maisons de maître de la Martinique. (voir aussi les figures 6, 7 et 11)

Repro. C. Charlery (c) C. Charlery, 2000

En Martinique, le presbytère de la paroisse du Carbet, construit en maçonnerie avant 1686 et remanié après le tremblement de terre de 1839, est sans doute l'un des plus anciens exemples qui nous soient parvenus. Notons qu'aux îles, les presbytères sont conçus comme des maisons et rien ne les distingue de l'architecture domestique. Cependant, la maison en simple rez-de-chaussée de l'habitation Duferret, sur la paroisse de Trinité, est 
plus représentative de cette architecture de la seconde moitié du XVIII ${ }^{e}$ siècle : les murs pignons sont en maçonnerie, le reste, en bois bardé de planches et les trois pièces en enfilade agrémentées par deux galeries, sur les façades avant et arrière.

Ce modèle à trois pièces devient en Martinique, plus que dans tout autre endroit, l'archétype de la maison créole et sert de modèle de base aux maisons des notables et aux villas périurbaines construites dans les quartiers bourgeois des villes et des bourgs (fig. $\mathbf{n}$ -12).

En témoigne la villa Those, construite dans le quartier de Balata à Fort-de-France, qui comme tant d'autres perpétue cette tradition (fig. $\mathbf{n}^{\circ} \mathbf{1 3}$ ).

Plusieurs fouilles archéologiques menées en Guyane ont permis de retrouver la trace d'anciennes maisons de maître d'une grande importance. L'habitation Macaye, construite vers 1735 dans le quartier de Rémire ${ }^{32}$, est sans doute la plus significative : les fondations montrent une longue maison rectangulaire, divisée en trois pièces carrelées de taille égale, et ceinte sur ses quatres façades d'une galerie tournante dont chaque angle est garni d'un cabinet (fig. $\left.\mathbf{n}^{\circ} \mathbf{1 4}\right)$.

Figure 12

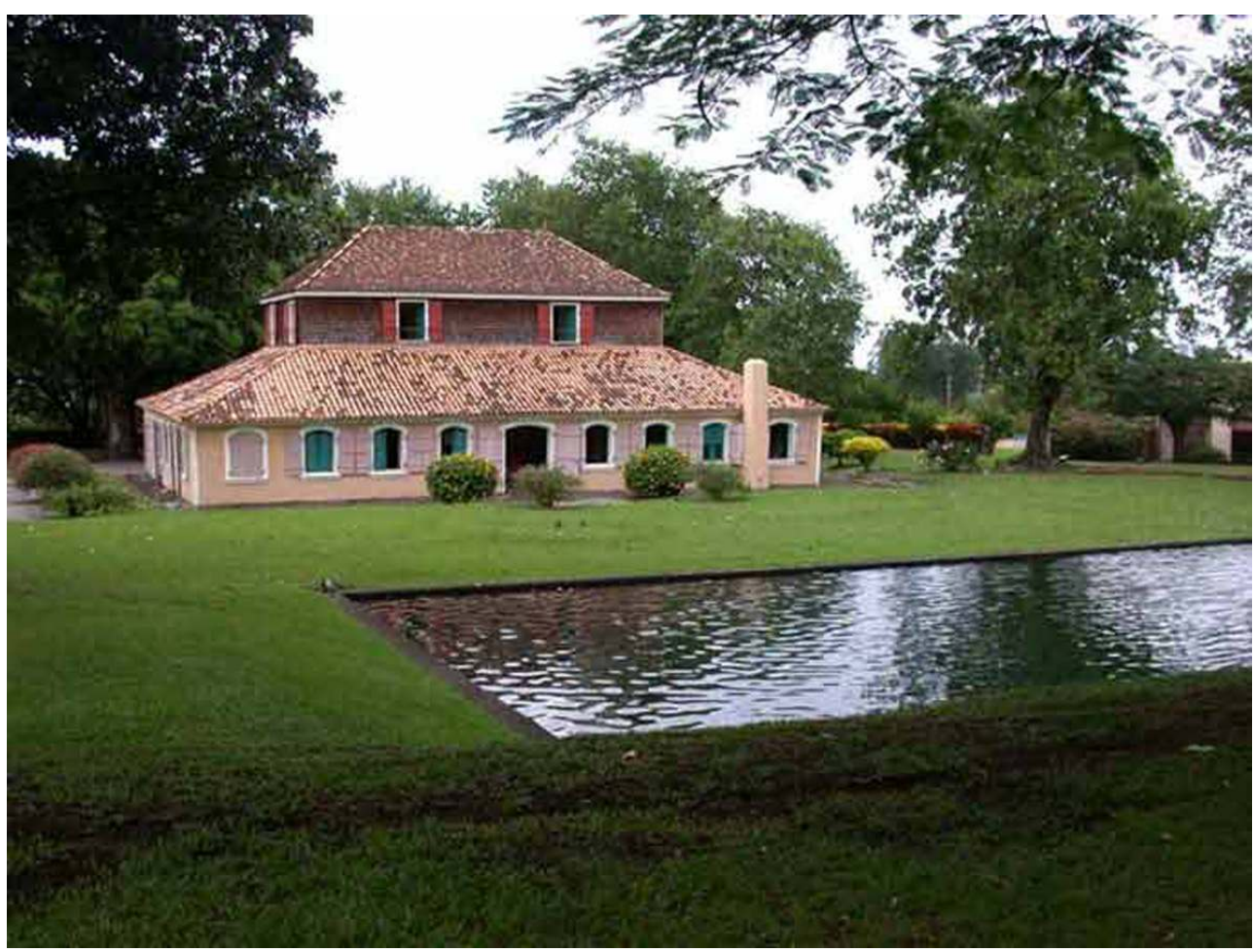

Maison de maître de l'habitation sucrerie Pécoul à Basse-Pointe (Martinique). Le noyau primitif de cette maison conserve aujourd'hui encore ses trois pièces en enfilade. Les galeries et l'étage auraient été construits dans une seconde phase de travaux, à la fin des années 1780

Phot. C. Charlery (c) C. Charlery, 2003 
Figure 13

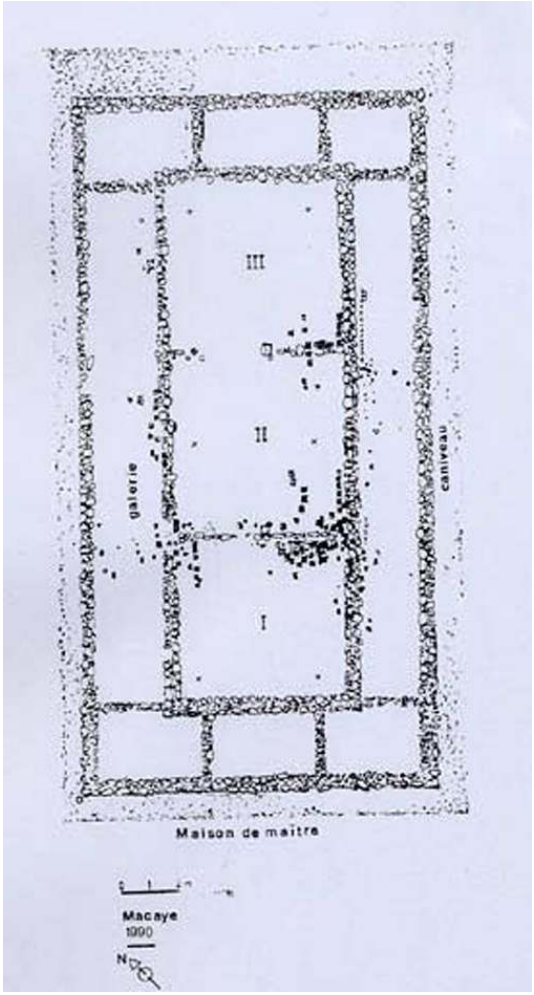

Extrait d'un plan des fondations de l'habitation sucrerie Macaye à Remire (Guyane). Construite vers 1735 , cette maison était très caractéristique dans sa distribution, avec ses galeries et ses cabinets aux quatre angles. Extrait de : Ministère de la Culture, UNE HABITATION EN GUYANE AU XVIIIE SIÈcLE, 1990

Repro. C. Charlery (c) C. Charlery, 2004 
Figure 14
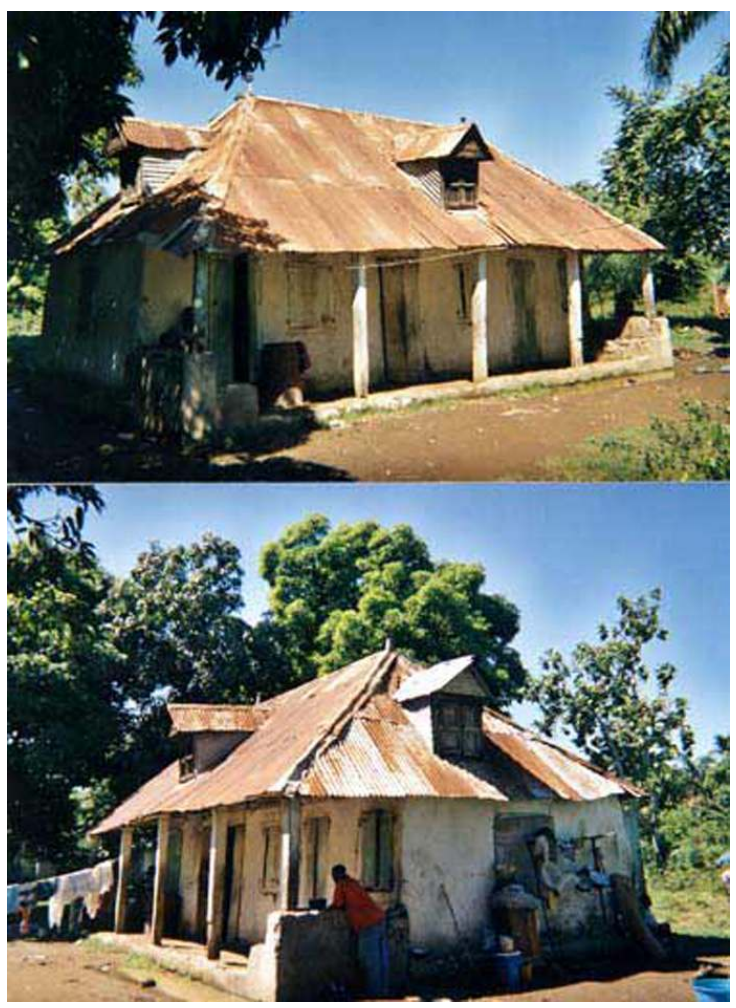

Ancienne maison d'un cultivateur aisé près de Léogane (Haïti). Probablement construite dans la seconde moitié du XIXe siècle, cette maison est néanmoins héritière de l'architecture française de l'époque coloniale. De taille modeste, elle est agrémentée d'une galerie sur sa façade antérieure, abritant aux extrémités deux banquettes en maçonnerie

Phot. C. Charlery (c) C. Charlery, 2002 


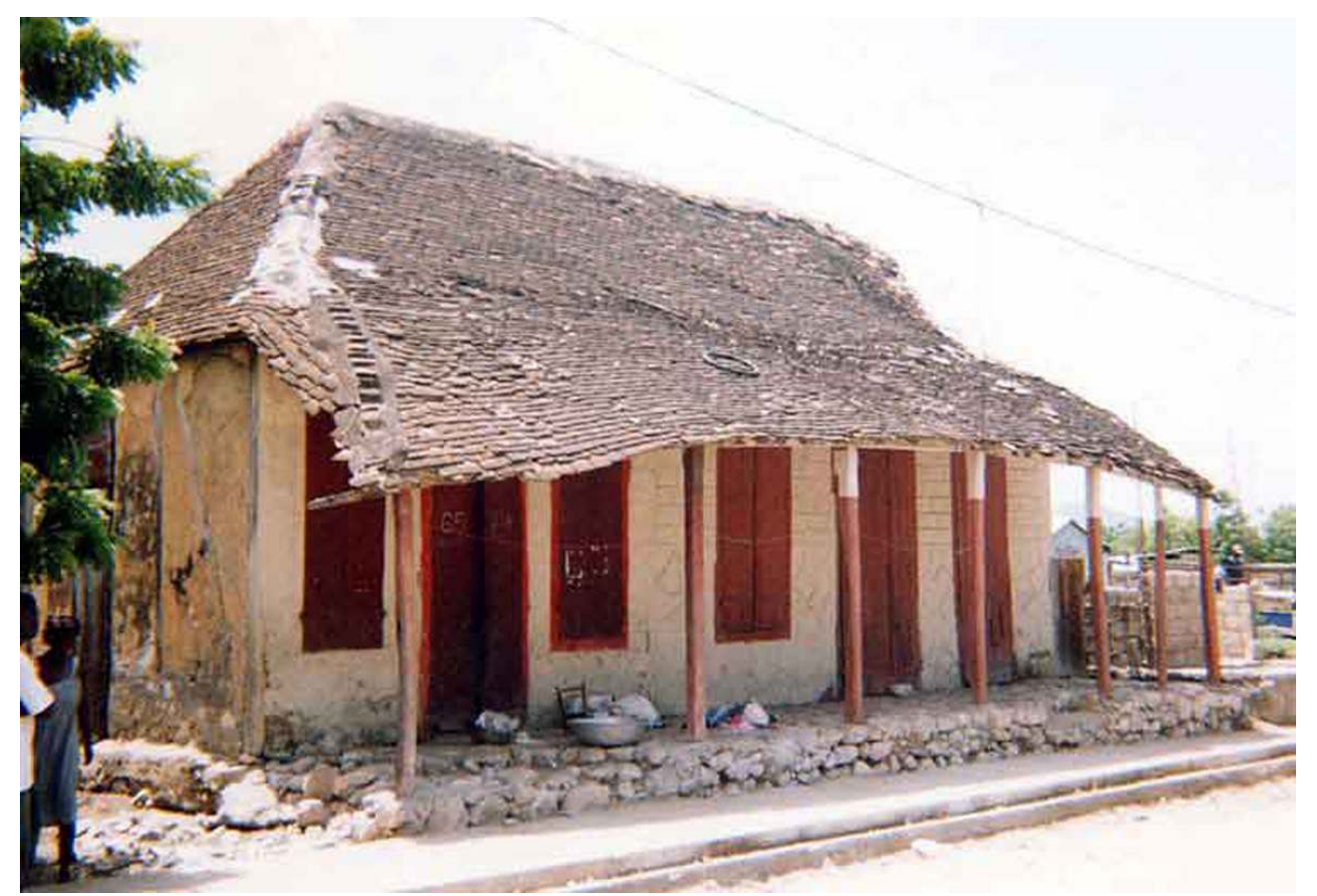

Maison de Claire-Heureuse, épouse de l'Empereur Jean-Jacques Dessalines, à Marchand-Dessalines (Haiiti). Construite au début du XIXe siècle, cette maison conserve toutes les caractéristiques de l'architecture coloniale françaises. L'une des trois pièces de l'enfilade a malheureusement été récemment détruite

Phot. C. Charlery (c) C. Charlery, 2003

Les archives de l'ancienne colonie française de Saint-Domingue confirment notre hypothèse : en 1780, au moment de la vente de l'habitation du comte d'Estaing, située sur les mornes du Cap, on sait que la maison principale, "construite en maçonnerie, est distribuée en une salle au milieu et une chambre de chaque côté" (fig. $\mathbf{n}^{\circ} \mathbf{1 5}^{15}$ ) Rares et souvent dans un état de conservation médiocre, les maisons de ce type aujourd'hui conservées en Haïti n'en demeurent pas moins des exemples des plus intéressants, car peu modifiés depuis leur construction. Bien qu'il n'en subsiste que les fondations, la maison de maître de l'habitation de Croix-des-Pères, dans la campagne de Léogane, détruite pendant la Révolution, présente un plan tout à fait emblématique: trois immenses pièces en enfilade agrémentées, sur la façade antérieure, d'une galerie encadrée de deux cabinets. Les maisons de la petite ville de Marchand-Dessalines comptent aussi parmi les exemples les plus anciens. Cette cité fut construite vers 1804 sur ordre de Jean-Jacques Dessalines, héros de l'indépendance haïtienne, pour devenir la capitale. La ville nouvelle se couvrit en peu de temps de maisons plutôt modestes, relevant toutes de modèles ruraux. Les maisons de Claire-Heureuse, épouse de JeanJacques Dessalines, et de Charlotin Marcadieux datent de cette époque et se composent toutes deux de trois immenses pièces avec salon central, d'une galerie ouverte sur la façade antérieure et d'une galerie dans œuvre sur l'arrière. Comme toutes les maisons anciennes du bourg, elles sont maçonnées entre poteaux, couvertes de tuiles plates et ont reçu, à l'extérieur, un badigeon ocre jaune. 
Figure 16

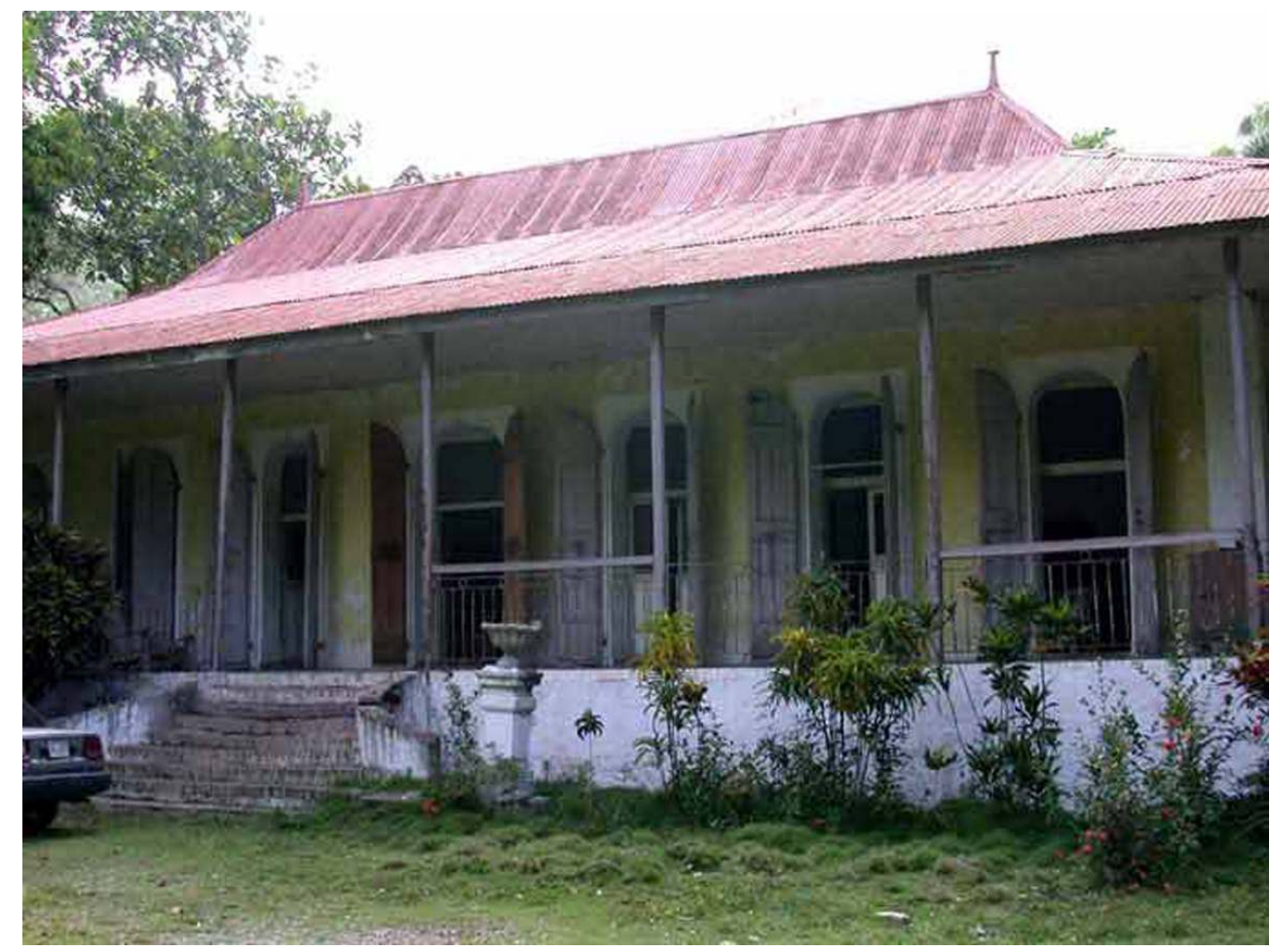

Maison de maître d'une habitation dans le quartier de Bel Air aux environs de Cap-Haïtien (Haïti). Reconstruite après le tremblement de terre de 1842, cette maison servit de résidence au président Cincinatus Lecomte au dèbut du XXe siècle. Elle conserve aujourd'hui encore sa trame de trois pièces en enfilade. Cependant, de grande taille, les chambres ont été redivisées chacune en deux

Phot. C. Charlery @ C. Charlery, 2003

Plus au nord dans la plaine du Cap-Haïtien, il faut citer la maison de maître de l'habitation Leconte, l'une des rares à avoir échappé aux incendies de la révolution de 1802 (fig. $\mathbf{n}$ - 16). De taille modeste, elle semble très représentative des maisons de maître d'habitations-sucreries de la fin du XVIII e siècle, avec sa galerie et ses linteaux de baie en arcs segmentaires.

31 Après l'indépendance, d'autres maisons de ce type furent construites. Parfois immenses, comme la maison de l'habitation Goyard, près du Cap-Haïtien, ou plus modestes, comme cette petite maison de campagne bourgeoise (fig. $\mathbf{n}^{\circ}{ }^{17}$ ) construite près de l'habitation de la Croix-des-Pères sur la paroisse de Léogane. 


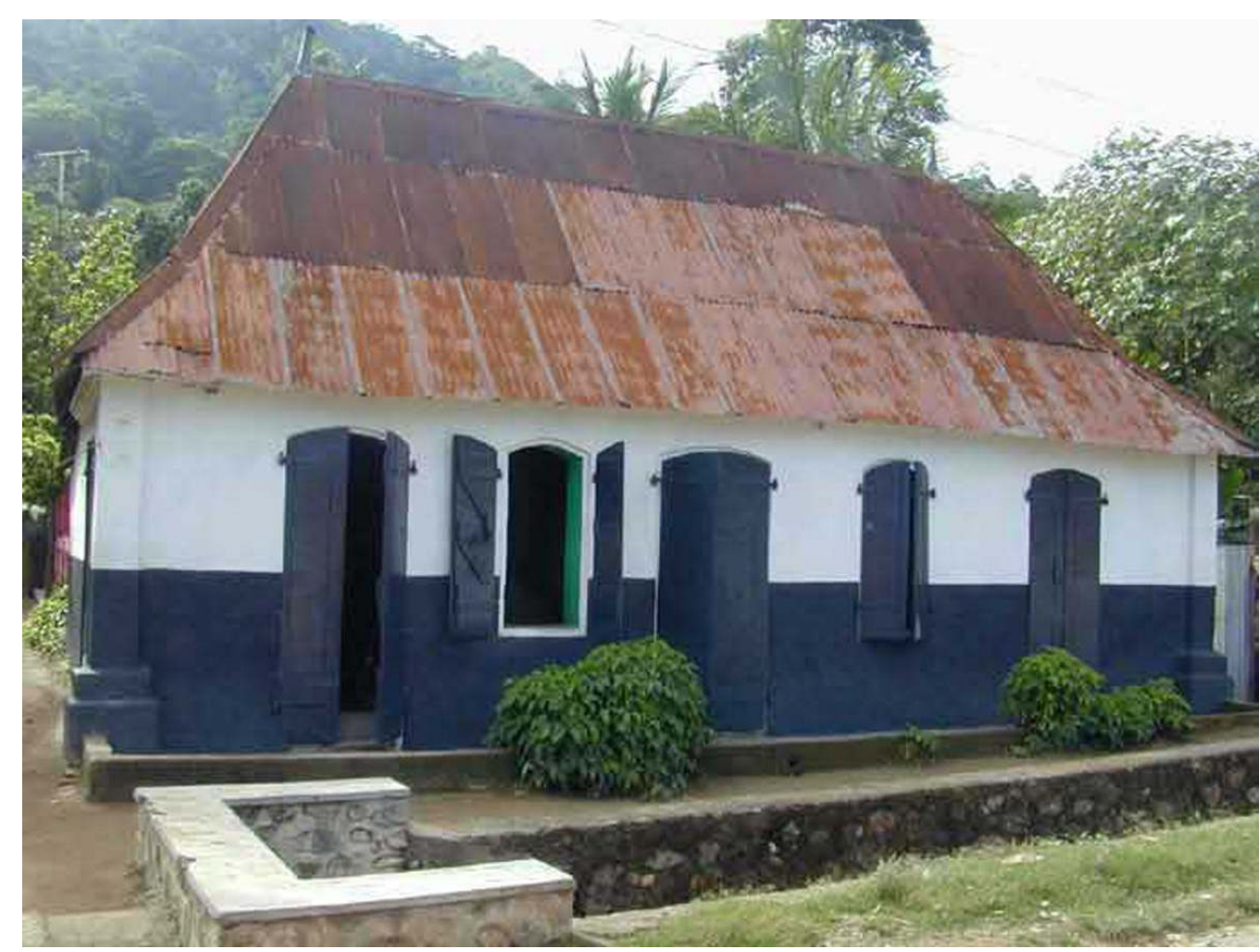

Maison dans la plaine du Cap-Haïtien (Haïti). Probablement reconstruite après le tremblement de terre de 1842, cette maison reprend tous les éléments de l'architecture du XVIII siècle : trois pièces, toiture pentue avec croupe et linteaux de baies en arcs surbaissés

Phot. Inv. H. Maheux ( ) Inventaire général, ADAGP, 2002

La Louisiane conserve elle aussi plusieurs exemples de cette architecture. La maison Troxler, édifiée à la Nouvelle-Orléans avant 1782, en est un témoin précieux : construite en bois, et couverte d'essentes, elle possède trois pièces identiques et une galerie encadrée de deux cabinets sur sa façade antérieure. Beaucoup plus imposante, la maison Pitot, bâtie vers 1799 par Barthelomé Bosque près de la Nouvelle-Orléans, est très caractéristique : deux niveaux distribués de la même façon, consistant en trois pièces et une galerie tournant sur trois façades, agrémentée de cabinets. Au rez-de-chaussée, les galeries sont soutenues par une série de colonnes en briques enduites, éléments traditionnels pour les maisons à étage de cette partie de la Louisiane. En 1800, un plan presque similaire avait été retenu pour la maison de maître de la plantation-sucrerie Labatut, sur la paroisse de Pointe-Coupée (fig. $\mathbf{n}^{\circ} \mathbf{1 8}$ ).

Encore plus imposante, la maison de l'habitation Whitney reprend le même plan initial, mais les galeries des pignons sont closes et forment des pièces supplémentaires (fig. $\mathbf{n}$ -19). 
Figure 18

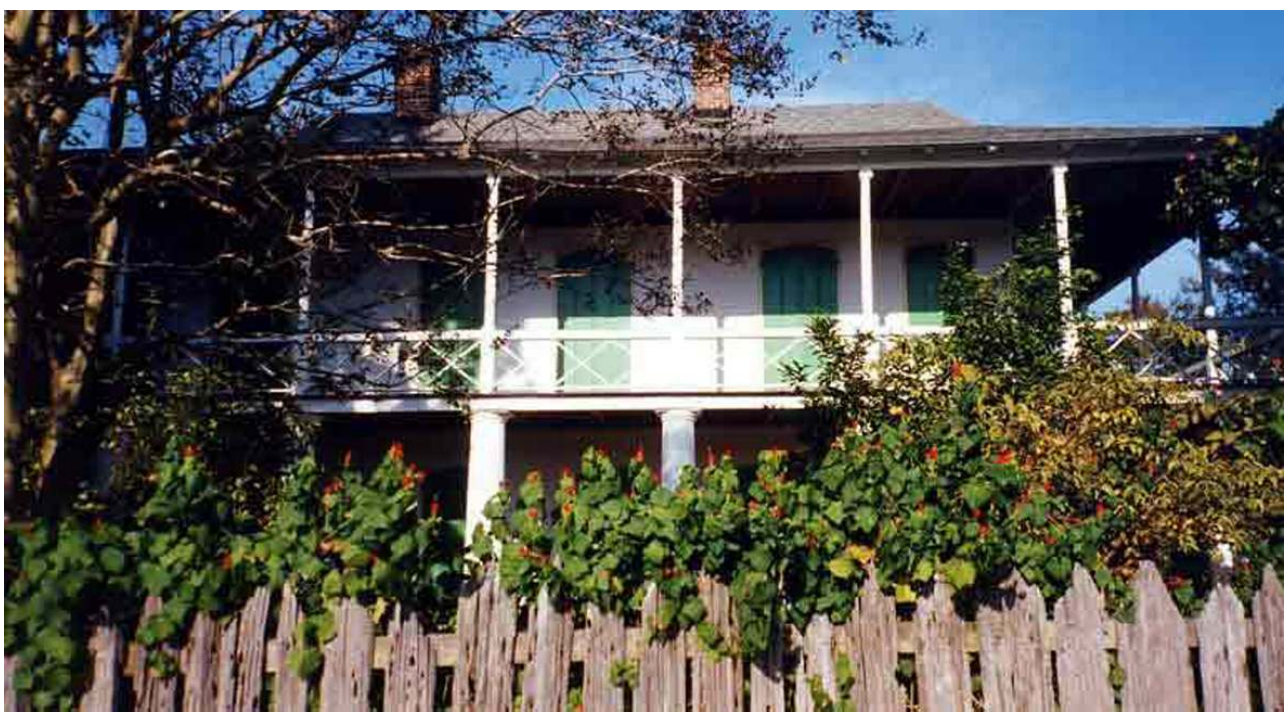

Maison de maître de l'habitation sucrerie Pitot à la Nouvelle Orléans (Louisiane). Cette grande maison à deux niveaux, construite à l'extrême fin du XVIII e siècle, fut acquise en 1810 par James Pitot, né en Normandie et ancien colon de Saint-Domingue naturalisé américain en 1796. Le rez-de-chaussée est en maçonnerie et l'étage en pan de bois bardé de planches

Phot. C. Charlery (c) C. Charlery, 2000

Figure 19

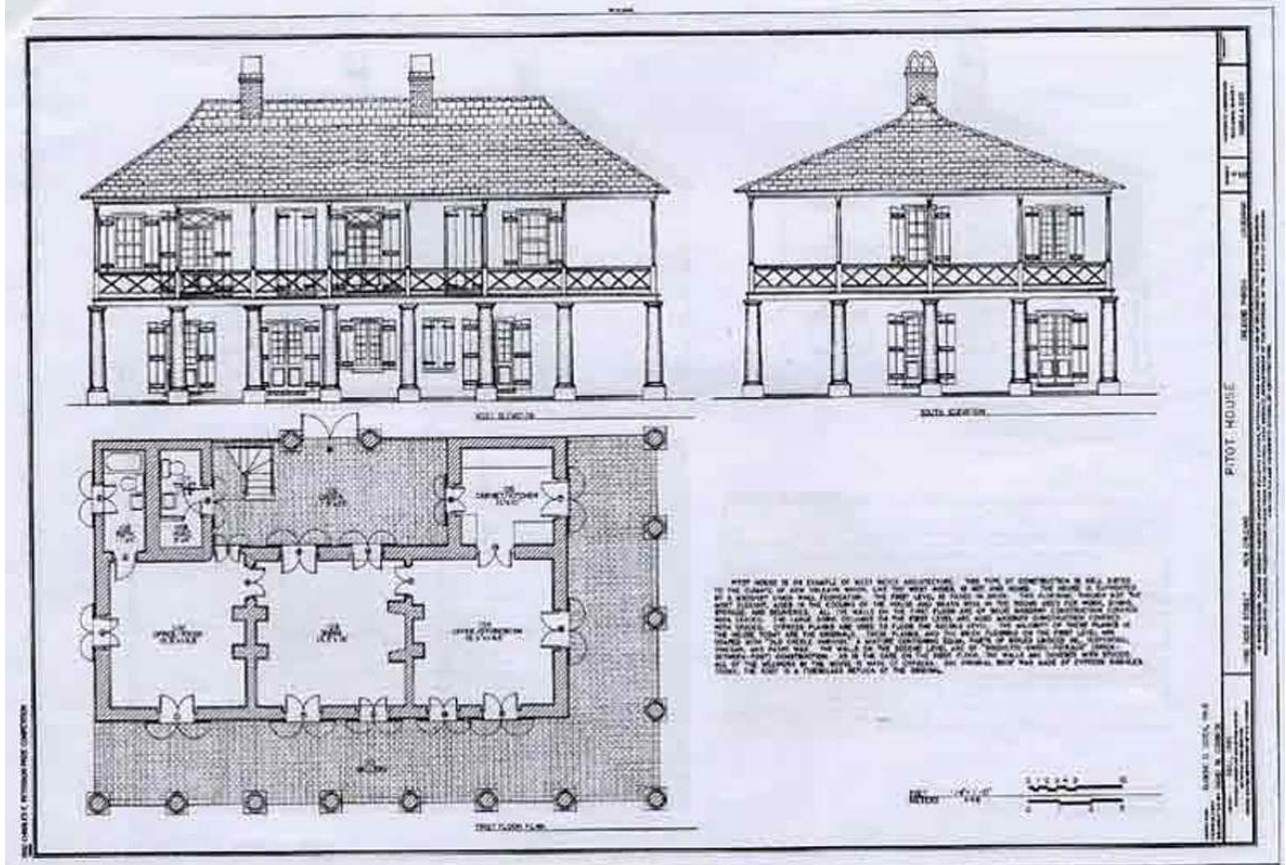

Relevé et élévations de la maison de maître de l'habitation sucrerie Pitot à la Nouvelle Orléans (Louisiane). Maison caractéristique avec ses trois pièces en enfilade et ses galeries. Extrait: Historic American Building Survey

Repro. C. Charlery @ C. Charlery, 2003

Enfin, dans les années 1810-1820, de nombreux colons français, qui avaient fui les révoltes d'esclaves de la fin du XVIII ${ }^{e}$ siècle, s'établissent dans la région de Santiago de Cuba, après 
avoir été expulsés de la partie espagnole de Saint-Domingue où ils avaient d'abord trouvé refuge. C'est principalement dans les montagnes de la Grand Pietra qu'ils édifient des centaines de caféières dont l'architecture est en tout point similaire à celles de SaintDomingue. Les maisons de maître des habitations Los Naranjos, ou San Sebastian, empruntent leur langage décoratif et structurel au vocabulaire de l'architecture coloniale française : charpente et pan de bois bardé de planches ou maçonnerie entre poteaux, croupes ou demi croupes, galerie sur les façades avant ${ }^{33}$. La maison de l'habitation caféière La Isabelica, construite vers 1815 par Victor Constantin Cuz, émigré de la partie française de Saint-Domingue, est sans doute la plus représentative : un rez-de-chaussée en épaisse maçonnerie, divisé en trois pièces et ceint d'une galerie à arcades, abrite les espaces de stockage, un étage carré dont les murs sont maçonnés entre poteaux, abrite l'espace d'habitation. A l'arrière, une galerie dans œuvre augmente la surface habitable alors que sur les autres côtés, un large auvent protège les façades.

\section{La maison de maître à deux pièces principales avec galerie}

Figure 20

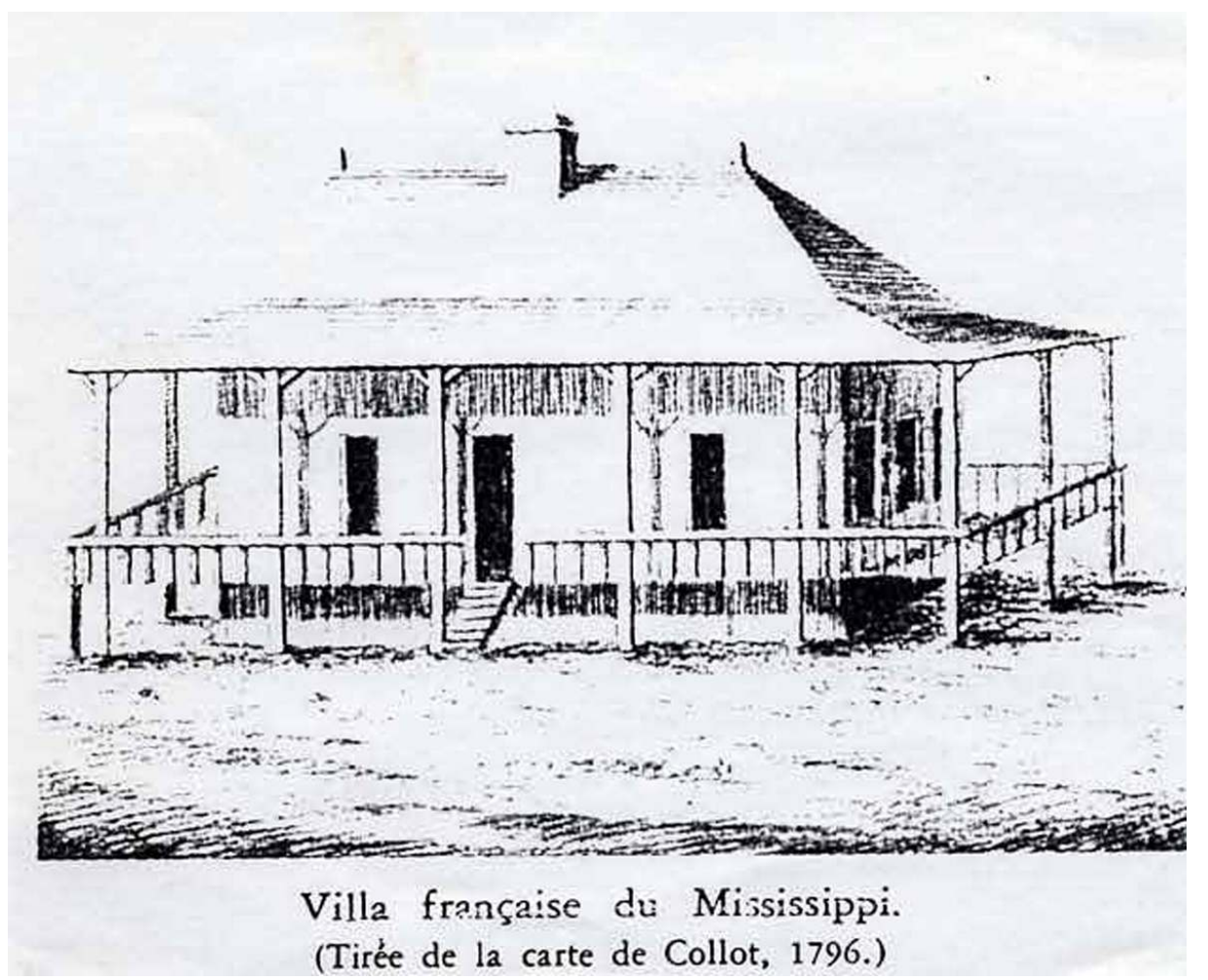

Villa française sur les bords du Mississippi, dans l'Illinois (Missouri). Cette maison de deux pièces est typique des constructions françaises au nord des possessions françaises sur les bords du grand fleuve (voir également la figure 31). Extrait de la carte de Collot, 1796

Repro. C. Charlery (c) C. Charlery, 2003

Ce modèle est particulièrement présent sur le continent américain, depuis le nord de la Louisiane jusque dans la région de Saint-Louis dans le Missouri. (fig. $\mathrm{n}^{\circ} 20$ ) Cependant, on le retrouve aussi sur la côte Atlantique dans les anciens territoires anglo-américains. Remontant le Mississippi en bateau au début du XIXe siècle, Robin fait une description précise des habitations présentes sur la rive du fleuve (fig. $n^{\circ} 20$ ) : le corps principal des 
maisons de maître n'est ordinairement "que de deux grandes pièces "34. Il en subsiste plusieurs exemplaires. A Sainte-Geneviève, dans le Missouri, au cœur d'une région qui compta une importante population française, la maison de Louis Bolduc, construite vers 1793, et celle de Jean-Baptiste Bequet, construite vers 1808, sont toutes deux magnifiquement restaurées. Elles ne comportent que deux pièces, l'une servant de salon, l'autre de chambre, et une galerie ouverte qui tourne sur les quatre côtés. Plus au sud (fig. $n^{\circ}$ 21), à Baton Rouge, dans l'Etat de Louisiane, la maison Kleinpeter, bâtie vers 1787, possède elle aussi deux pièces, mais seules les façades avant et arrière ont une galerie, celle de derrière possédant un cabinet à chacune de ses extrémités. (fig. $\left.n^{\circ} 21\right) \mathrm{Au}$ sud du grand fleuve, dans les zones plus prospères proches de la Nouvelle-Orléans, les maisons peuvent être de plus grande taille. Le corps principal conserve deux grandes pièces, mais la galerie est en partie fermée, créant une multitude de petites pièces annexes. Ainsi, la maison initiale de la plantation Yuca, construite à la fin du XVIII e siècle sur la paroisse de Natchitoches ou celle de la plantation Holden, (paroisse de Rougon) sont exactement identiques (fig. $\mathrm{n}^{\circ} 22$ ). La majorité des maisons citées sont bousillées entre poteaux, c'est-àdire qu'un torchis, à base de boue, de chaux et de mousse végétale, a été appliqué sur un lattis de bois disposé entre la structure en bois de cyprès de l'édifice.

Figure 21

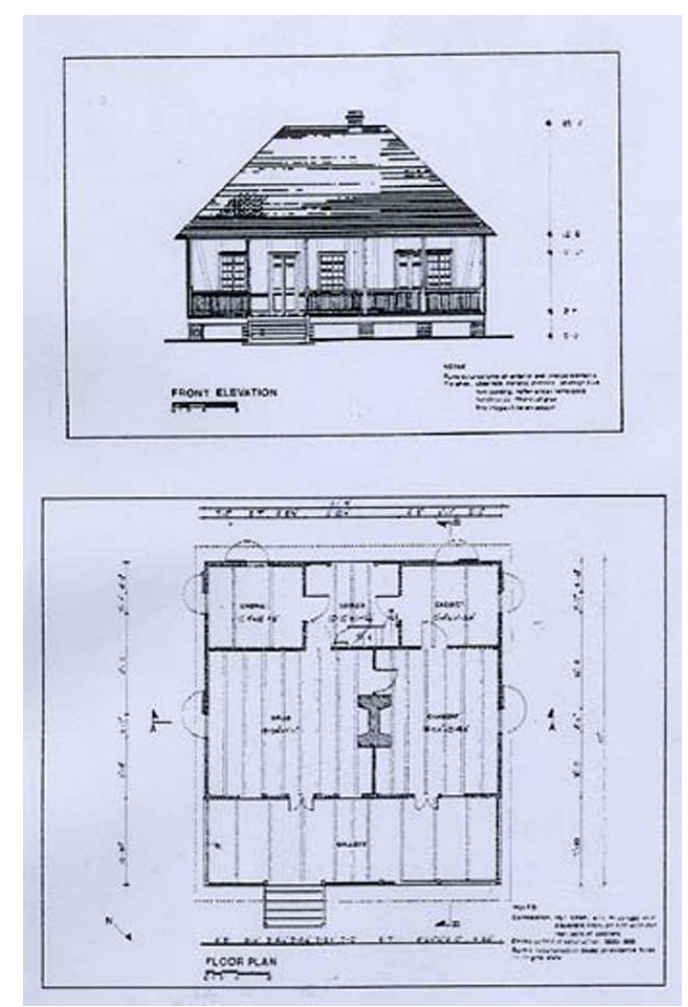

Relevé et élévations de la petite maison de maître de l'habitation sucrerie Kleinpeter à Bâton Rouge (Louisiane). Cette maison à deux pièces, bousillée entre poteaux, fut construite en 1787 par Joseph Kleinpeter. Extrait de Historic American Building Survey

Repro. C. Charlery (c) C. Charlery, 2003 


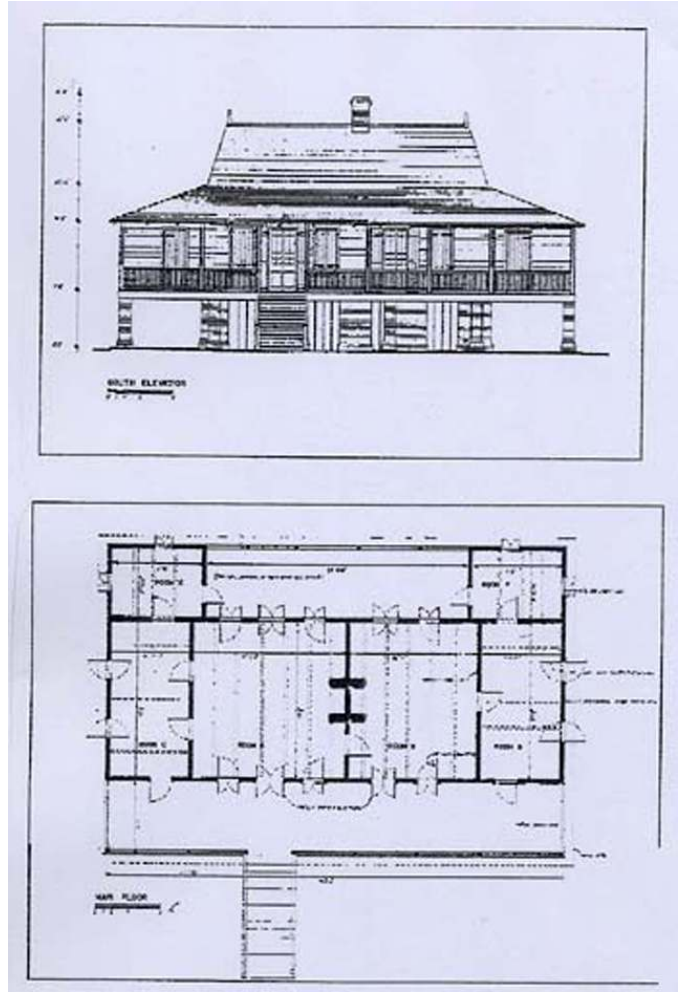

Relevé et élévations de la maison de maître de l'habitation sucrerie Holden à Rougon (Louisiane). Cette maison en pan de bois et bardée de planches, fut construite vers 1790. Elevée sur des plots maçonnés en briques, la maison était ainsi à l'abri des crues du Mississippi. Ce dispositif était courant sur les bords du grand fleuve. Extrait de Historic American Building Survey

Repro. C. Charlery (c) C. Charlery, 2003

En Haïti, c'est dans le bourg de Marchand-Dessalines, au centre du pays, que l'on peut encore voir deux maisons de ce type, probablement construites entre 1804 et 1806. (fig. $n$ -22) La première, aux épais murs de maçonnerie, possède une galerie ouverte sur la façade antérieure et conserve sur ses contrevents des pentures métalliques anciennes. La seconde, dont les murs sont maçonnés entre poteaux, présente une galerie ouverte sur deux côtés. A l'arrière, une autre galerie dans œuvre augmente l'espace de vie. Les archives livrent de nombreuses descriptions qui laissent penser que ces maisons n'étaient pas rares. Une annonce passée en 1766 dans les Avis divers pour la vente d'une habitation située à la pointe du Bec-Marsoin du Petit Trou, dans le quartier de Nippes, propose : "une maison principale [...], clissée et bousillée entre poteaux équarris, garnie de ses portes et fenêtres, couverte en paille, divisée en une salle, une chambre et deux cabinets " 35 .

En Guadeloupe, plusieurs maisons de ce type sont encore visibles, mais elles menacent ruine. La maison de maitre de l'habitation caféière Tarare, sur la commune de VieuxHabitants en Côte-sous-le-vent, toute en bois, semble dater du début du XIXe siècle (fig. $\mathrm{n}$ - 23). La distribution intérieure consiste en deux pièces identiques, agrémentées d'une galerie dans œuvre ouvrant sur la terrasse à sécher le café et au bout de laquelle un cabinet est aménagé. (fig. $n^{\circ} 23$ ) On retrouve le même plan à l'étage qui conserve des traces d'essentage sur toutes ses façades. Sur la commune de Trois-Rivières, la maison de maitre de l'habitation Sapotille, réalisée probablement dans les années 1850 sur un rez- 
de-chaussée plus ancien, possède un étage au plan identique et deux galeries ouvertes haute et basse, tournées vers la terrasse à sécher le café.

Figure 23

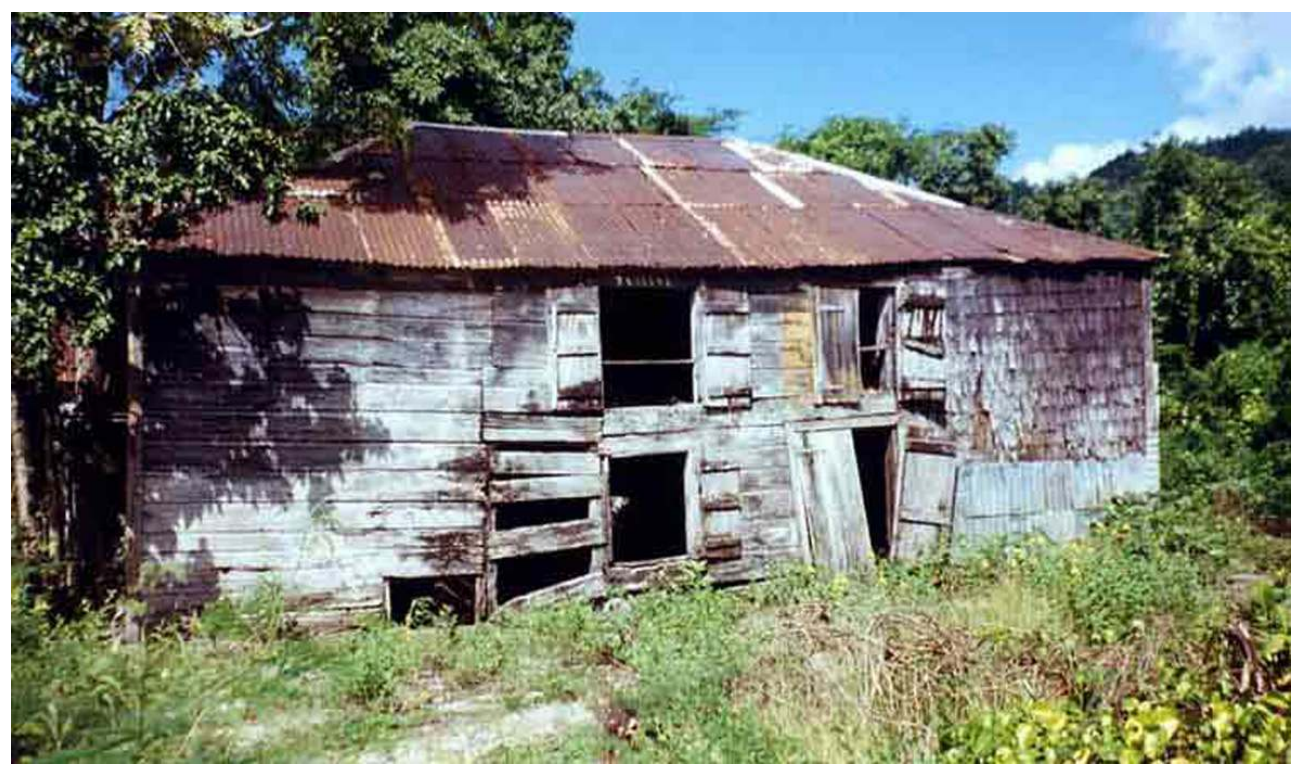

Ancienne maison de maître de l'habitation caféière Nicolas dans la vallée de Tarare à Vieux-Habitants (Guadeloupe). Cette maison en bois, construite au début du XIXe siècle, avait à l'origine ses murs couverts d'essentes. La maison, aujourd'hui en ruine, possède toujours ses deux pièces identiques et une galerie dans œuvre donnant sur la terrasse où séchait jadis le café

Phot. C. Charlery (c) C. Charlery, 2002

En Martinique enfin, le plus bel exemple est sans conteste la maison de maître de l'habitation La Sucrerie dominant le bourg des Anses d'Arlet. Elle est aujourd'hui très étendue, mais une étude attentive de ses maçonneries permet de comprendre son évolution. Le noyau primitif, entièrement en maçonnerie et peut-être construit vers 1760-1770, consistait en deux pièces de même taille, séparées par une cloison en bois (fig. $\left.\mathrm{n}^{\circ} 24\right)$.

Une galerie dans œuvre agrémentait la façade postérieure de la maison. C'est peut-être lorsque la famille Hayot en devint propriétaire, dans le courant des années 1780, que l'édifice fut considérablement agrandi d'un étage et d'une galerie périphérique, en maçonnerie, qui donnèrent à la maison sa physionomie actuelle (fig. $n^{\circ} 25$ ). 
Figure 24

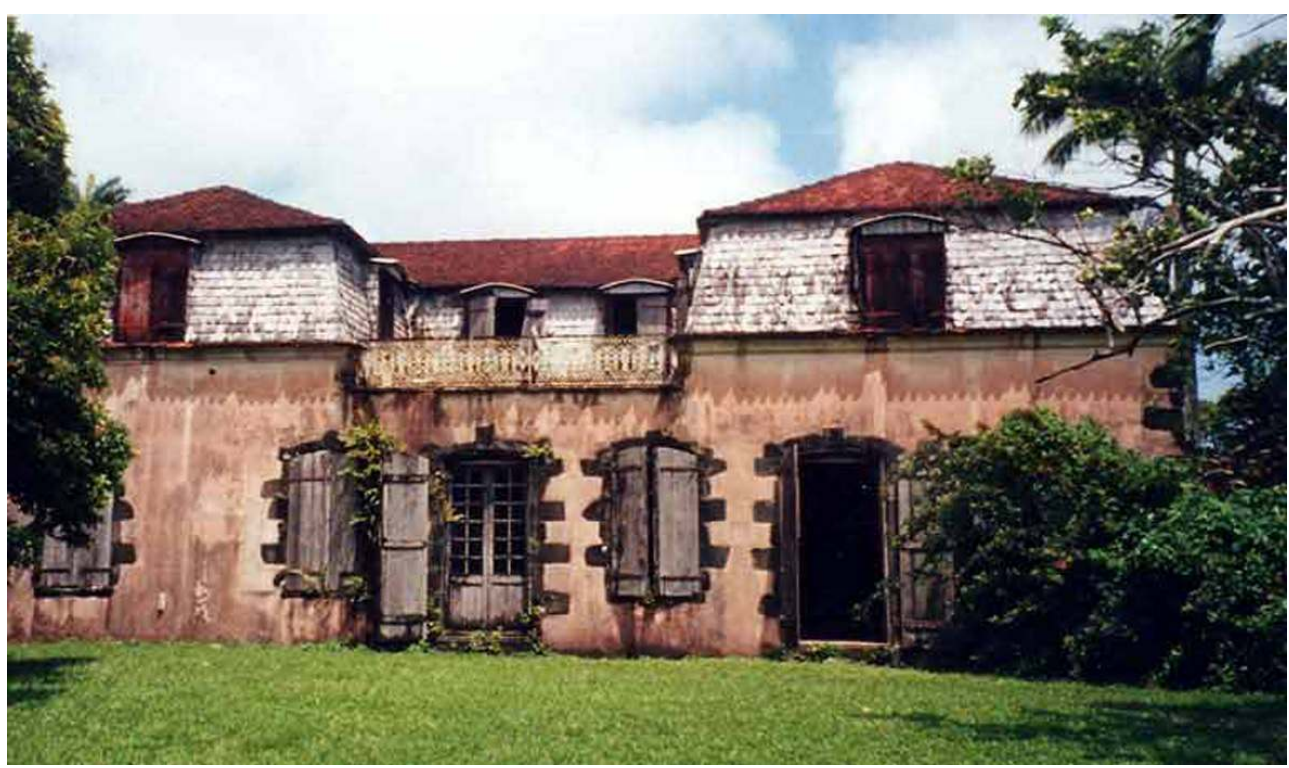

Maison de maître de l'habitation sucrerie Leyritz à Basse-Pointe (Martinique). La maison prit certainement son aspect actuel dans le courant des années 30, date à laquelle elle fut agrandie.

Cependant, à l'intérieur, le noyau primitif du XVIII e siècle, à deux pièces, est parfaitement identifiable. II était agrémenté d'une galerie dans œuvre, ornée d'un très bel escalier pour mener à l'étage. La forme de la toiture à pan brisé aurait pu exister dès l'origine

Phot. C. Charlery @ C C. Charlery, 2000

\section{Figure 25}

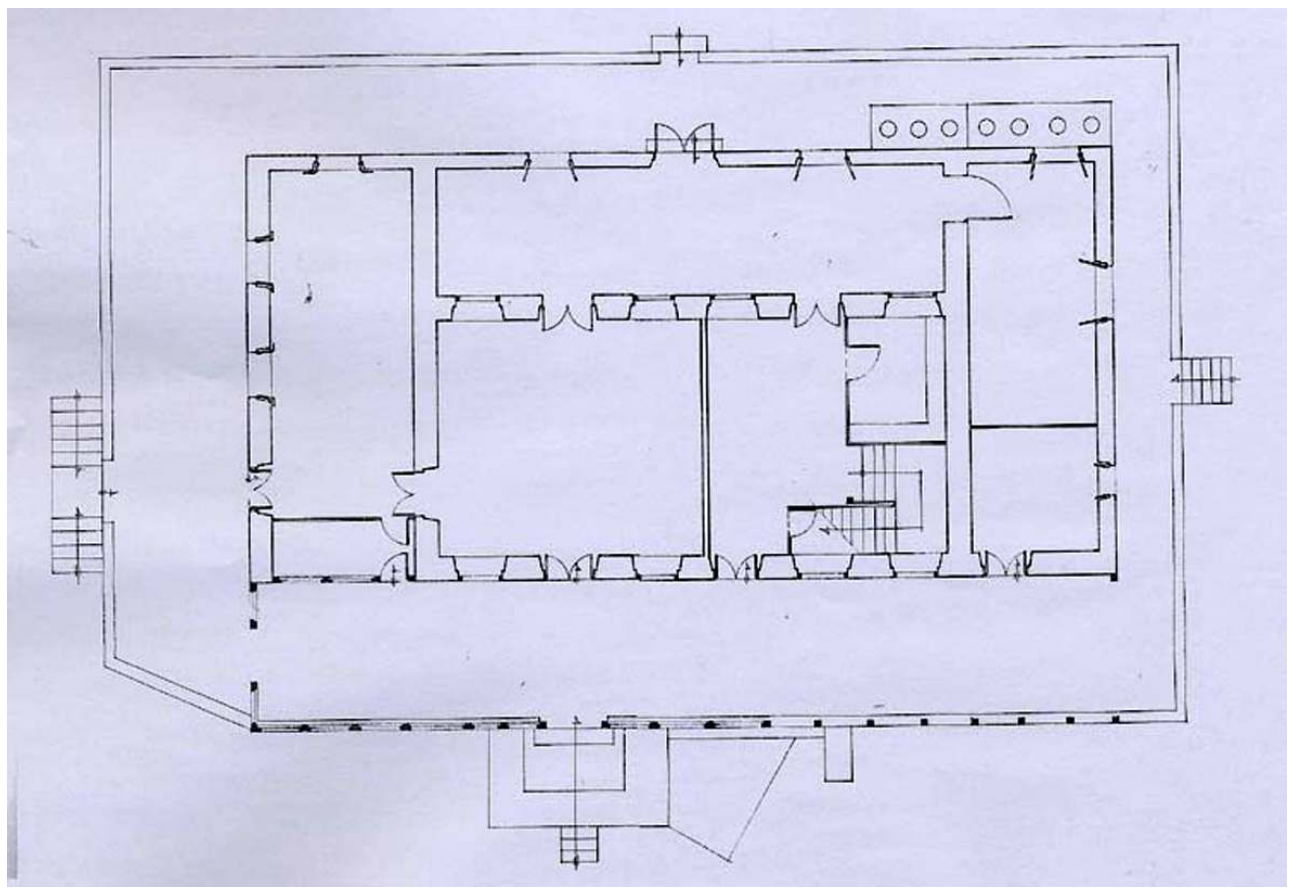

Plan de la maison de maître de l'habitation La Sucrerie aux Anses-d'Arlets (Martinique). Au centre, on distingue le noyau principal à deux pièces, ainsi que la galerie dans œuvre sur la façade arrière, datant probablement du début des années 1780. Les galeries hors œuvre de la façade antérieure et des pignons furent adjointes vers 1788

Repro. C. Charlery (c) C. Charlery, 2004 


\section{Hypothèse sur l'origine de la maison à deux pièces} Wood $^{37}$ dont l'ouvrage traite largement des maisons dont le plan de base est constitué de deux pièces identiques, agrémentées à l'arrière d'un appentis formant une sorte de petite galerie dans œuvre abritant la cuisine et les toilettes. On sait l'importance de cette publication pour l'architecture coloniale de l'Amérique du Nord et des colonies angloaméricaines aux Antilles, et le phénomène de standardisation qu'elle entraîna à partir des années 1790, particulièrement en ce qui concerne le logement des esclaves ${ }^{38}$. Cependant, John Wood ne traitait pas uniquement de l'habitat des masses laborieuses; il proposait aussi, sur les mêmes modèles de base standardisés, des maisons plus élaborées. Il est probable que ces travaux ont influencé la distribution de nombreuses maisons coloniales de l'aire américaine. Les conclusions de Charles Peterson sur l'architecture française de la région de Sainte-Geneviève vont dans ce sens: à partir des années 1760, l'influence anglaise et anglo-américaine fut particulièrement intense dans la région, de l'autre côté du fleuve, sur la rive gauche du Mississippi ${ }^{39}$.

En Guadeloupe, dans l'architecture urbaine ancienne, on peut constater la présence d'un plan tout à fait semblable à deux pièces et galerie dans œuvre à l'arrière. Basse-Terre compte encore aujourd'hui un grand nombre de ces maisons datant pour la plupart de la fin du XVIII ${ }^{\mathrm{e}}$ siècle et du début du XIXe siècle. Cette distribution est encore utilisée à la fin du XIX ${ }^{\mathrm{e}}$ siècle dans la maison Romana, au cœur de la ville du Moule. Ce modèle urbain aurait-il influencé la distribution de certaines maisons de maître construites sur les plantations, ou est-ce le contraire ? Aucun recueil d'architecture français du XVII ${ }^{\mathrm{e}}$ ou du $\mathrm{XVIII}^{\mathrm{e}}$ siècle ne propose rien de tel et seul l'ouvrage de John Wood aurait pu servir de référence. Ce dernier précise d'ailleurs dans le titre que les modèles présentés peuvent être construits " aussi bien à la ville qu'à la campagne ".

\section{La maison a couloir central}

43 Il existe un dernier type de maison de maître, peu représenté sur les îles françaises d'Amérique. Il s'agit de maisons importantes, disposant d'un étage carré et dont la distribution intérieure, double en profondeur, se compose de quatre pièces souvent de même taille, séparées par un couloir axial traversant. 


\section{Origine de la maison à couloir central}

44 C'est un type architectural présent dans la presque totalité des régions françaises. Le plan au sol présente quatre pièces largement éclairées par de grandes baies et distribuées par un couloir central. La disposition centrale du couloir est déjà très ancienne et Charles Estienne la préconise dès $1583^{40}$. Il contient souvent l'escalier qui donne accès à l'étage carré. Cette centralité favorise une distribution efficace et limite la perte d'espace. Bien qu'adaptée aux matériaux et aux techniques propres à chaque région, cette architecture, ultime réduction de la distribution des châteaux classiques, marque dans un certain sens "la fin du vernaculaire" "41. En effet, un goût nouveau pour le confort et une maîtrise plus grande du second œuvre permettent de ne plus tenir compte des usages locaux qui favorisent certaines orientations ou limitent, dans certaines régions, le nombre et la taille des ouvertures. Si ces maisons sont déjà assez répandues à la fin du XVIII ${ }^{\mathrm{e}}$ siècle, c'est surtout au siècle suivant qu'elles se multiplient à très grande échelle dans toutes les campagnes françaises.

\section{Développement aux colonies françaises}

Dans les îles françaises d'Amérique, ce type semble avoir connu son heure de gloire dans la seconde moitié du XIX ${ }^{e}$ siècle. Agrémentés de galeries, ces édifices de grande taille étaient réservés aux couches les plus élevées de la société coloniale.

Figure 26

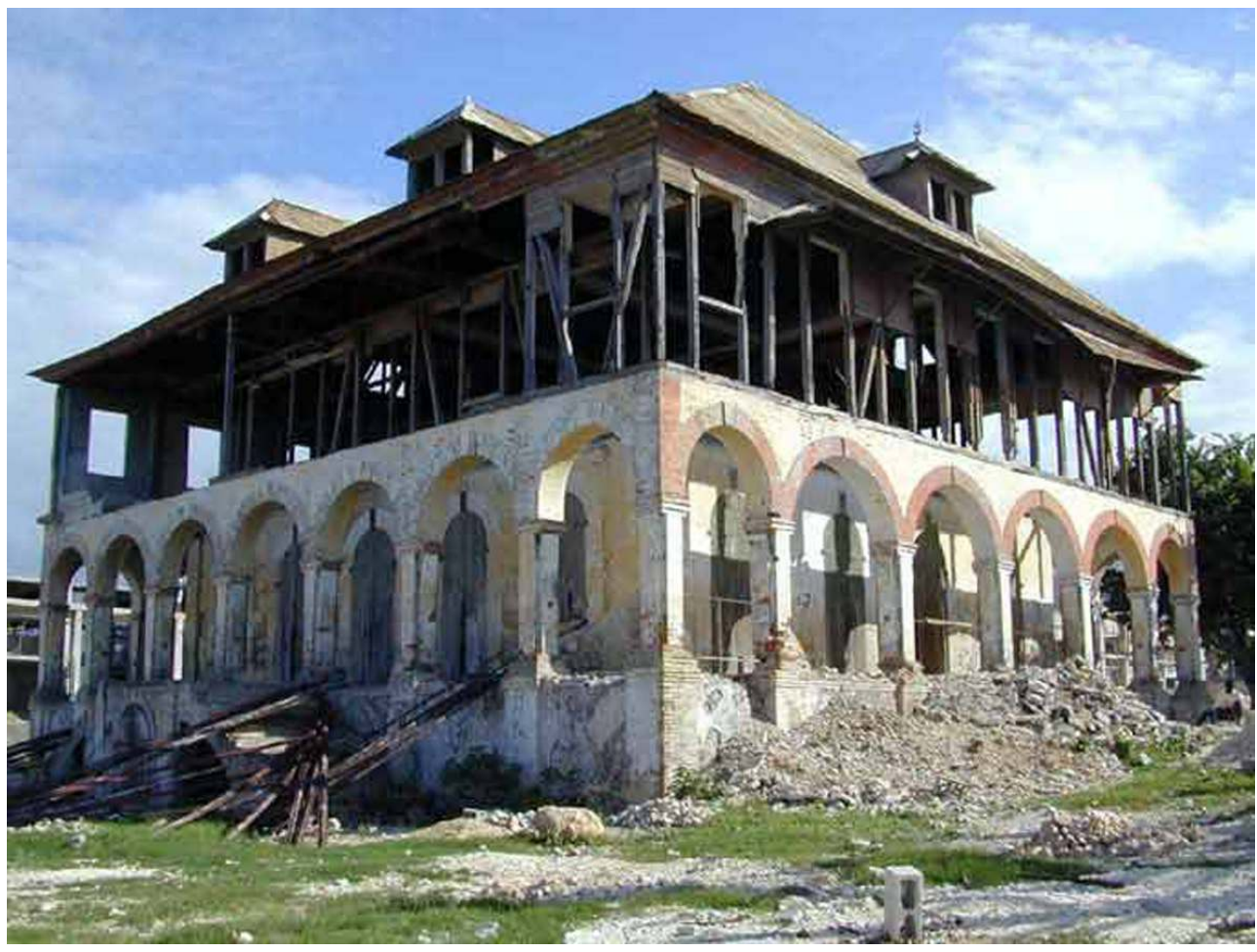

Maison de maître de l'habitation sucrerie Bon Repos à Carrefour, près de Port-au-Prince (Haïti). Le rezde-chaussée en maçonnerie de cette immense maison fut construit au milieu du XIX ${ }^{e}$ siècle, alors que l'étage, en bois, fut adjoint en 1879. Aux deux niveaux, la distribution était identique : quatre pièces de part et d'autre d'un couloir central et une galerie tournante sur toutes les façades

Phot. Inv. H. Maheux (c) Inventaire général, ADAGP, 2002 
En Haïti, la maison principale de l'habitation Bon Repos, dans le quartier de Carrefour (fig. $\mathbf{n}^{\circ}$ 26) près de Port-au-Prince en est l'un des exemples les plus représentatifs. Le rezde-chaussée en maçonnerie de cette immense maison est construit au milieu du XIX ${ }^{\mathrm{e}}$ siècle, l'étage carré en bois lui est adjoint en 1879, lorsque le président Hippolyte, récemment élu, en fait sa résidence privée. Au rez-de-chaussée, de part et d'autre du couloir traversant dans lequel se trouve l'escalier donnant accès à l'étage, les pièces s'alignent : sur la droite, deux salons, sur la gauche, une salle à manger, le dernier quart étant divisé en deux pièces plus petites servant d'office et de débarras. Tout autour se développe une large galerie hors œuvre. L'étage comporte lui aussi un long couloir et quatre chambres autour desquelles tourne une galerie ouverte agrémentée aux angles de cabinets.

Figure 27

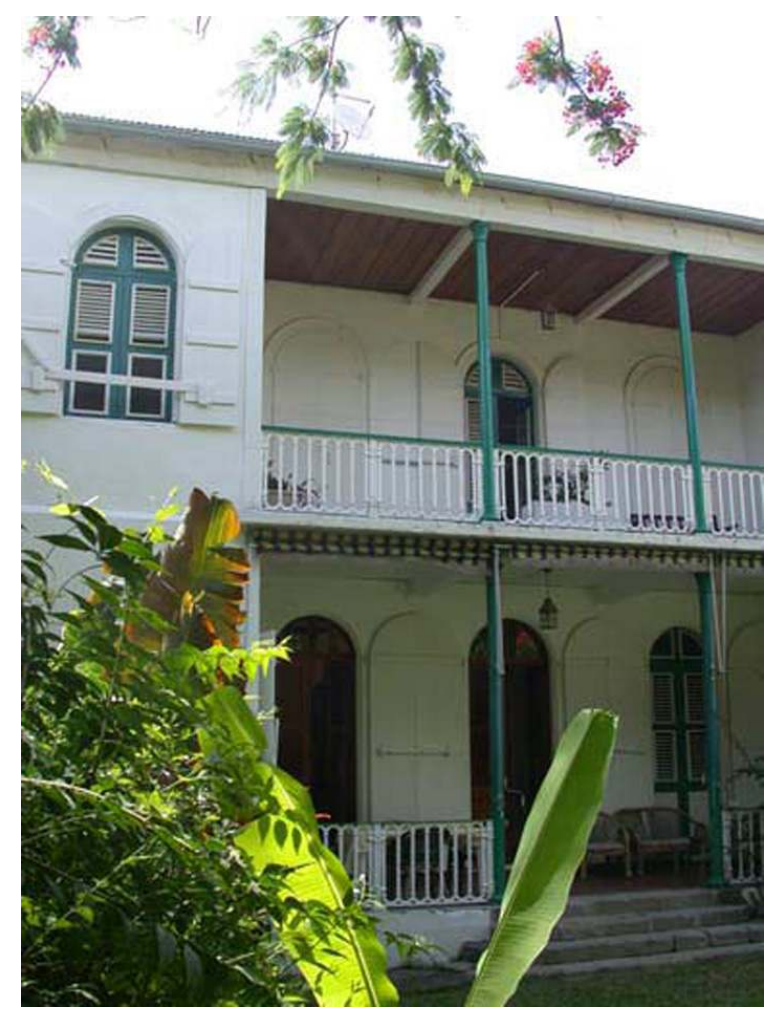

Maison du directeur du Génie à Basse-Terre (Guadeloupe). Détail de la façade arrière Phot. C. Charlery (c) C. Charlery, 2003

En Guadeloupe, la maison construite vers 1865 à Basse-Terre par l'armée pour loger le directeur du Génie, bien que située en ville, reprend pratiquement cette disposition (fig. $\mathbf{n}^{\circ}$ 27). En effet, on trouve au rez-de-chaussée, de part et d'autre d'un large couloir axial, un salon et une salle à manger d'un côté, un cabinet de travail et un petit office de l'autre. Le reste de la surface est occupé, de ce côté, par l'escalier qui n'est pas disposé dans le couloir. A l'avant, une galerie hors œuvre agrémente la façade, alors que la galerie arrière présentait à ses extrémités des cabinets qui augmentaient l'espace habitable. Divisé par un couloir central, l'étage se compose de quatre grandes chambres ayant chacune leur cabinet $^{42}$. (fig. $\left.n^{\circ} 27\right)$ 
Ce modèle se retrouve dans d'autres colonies françaises, par exemple en Afrique. L'hôtel du Gouverneur de Conakry (Guinée), construit sur ce plan en 1889, fut le premier édifice imposant de la ville, conçu pour représenter la grandeur de France ${ }^{43}$.

\section{Développement en Angleterre et dans les colonies anglo- américaines}

49 Il est intéressant de constater qu'en Angleterre et dans les colonies anglo-américaines, un phénomène tout à fait similaire se développe tout au long du XVIII ${ }^{e}$ siècle. En effet, le style Georgien, puise, lui aussi, ses sources dans la Renaissance italienne. La traduction anglaise de 1716 des Quatre Livres d'Architecture de Palladio a sans doute favorisé ce mouvement.

Figure 28

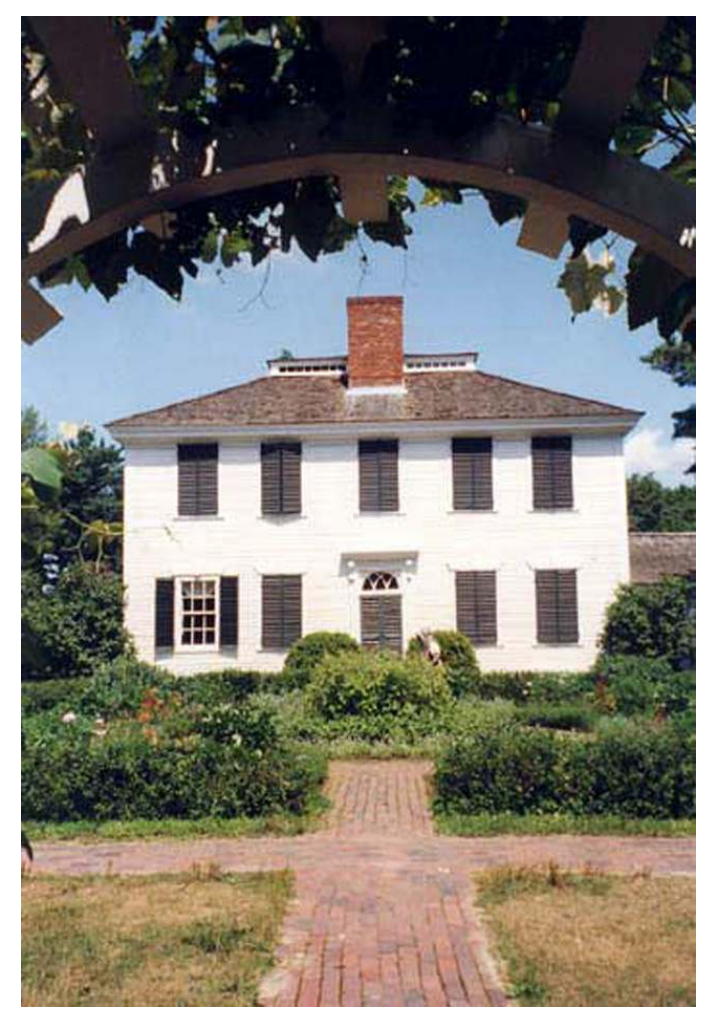

Maison de maître à Oldsturdbridge (Massachusetts). Probablement construite à la fin du XVIIIe siècle, cette grande maison en bois était directement inspirée de l'architecture de style georgien. Son plan à quatre pièces et couloir central était caractéristique

Phot. C. Charlery (c) C. Charlery, 1999

Dans ces colonies, plusieurs autres ouvrages exercèrent une grande influence sur la production architecturale. Celui de James Gibbs ${ }^{44}$, publié à Londres pour la première fois en 1728, eut une importance considérable. Comme le précise l'architecte, ce livre fut initialement conçu à l'intention des propriétaires souhaitant faire construire des maisons dans des régions reculées, où l'assistance d'un architecte n'est pas possible ${ }^{45}$. Cependant, il ne faut pas négliger les ouvrages destinés aux charpentiers, car en Amérique, le manque d'architectes pousse les propriétaires à faire directement appel aux artisans. Les 
publications procurent à ces derniers des modèles de distribution intérieure et de façades.

Dès 1700, le style Georgien est d'abord importé à Boston, en Nouvelle-Angleterre, mais il faut attendre les années 1745-1750 pour qu'il trouve sa pleine maturité sur toute la côte Est, jusqu'à Charleston. L'un des plans les plus communs présente, comme en France, quatre pièces desservies par un couloir central. Notons qu'au début du XIX ${ }^{e}$ siècle, ce modèle se retrouve jusqu'en Louisiane, mais uniquement dans la communauté angloaméricaine (fig. $\mathbf{n}^{\circ} \mathbf{2 8}$ ).

\section{Adaptation au climat : galeries et persiennes}

52 A l'instar de tous les étrangers implantés aux Antilles, les Français ont tout d'abord tendance à construire des maisons dont le style rappelle celui de la métropole. Puis vient le temps de l'adaptation aux matériaux locaux disponibles, et surtout au climat tropical. Dans ces contrées chaudes, souvent humides et aux pluies parfois abondantes, la recherche d'ombre et plus encore la ventilation, deviennent une priorité, mais restent souvent un luxe, comme nous l'indique Robin ${ }^{46}$ : "Il faut de l'air, c'est le besoin renaissant de tous les moments de l'homme, surtout inactif. Tout dans ces espèces de maisons, est ordinairement sacrifié pour l'obtenir: pièces grandes, percées de larges ouvertures, galeries, escaliers extérieurs, pour rendre plus libre cette si nécessaire circulation de l'air et défendre les appartements de l'action du soleil. Dans le petit nombre de ces demeures particulières, l'homme aisé y jouit vraiment d'un air plus frais et plus salubre. En France, la maison du riche ne se distingue de celle de la fortune modique que par les inutilités du luxe [...] Mais dans les colonies, le charme de respirer un air pur et libre, de jouir d'une ombre fraîche, semble être le privilège de l'opulence".

\section{Les galeries, un espace intermédiaire}

53 Aux Antilles françaises, la galerie hors œuvre, soutenue par une série de poteaux et largement ouverte sur l'extérieur, est un élément essentiel de l'architecture créole car elle procure une ombre agréable et limite la hausse de température qui résulte de l'échauffement des murs par le rayonnement direct du soleil. Elle offre en outre un espace de vie supplémentaire, à l'abri des pluies. La maison possède aussi parfois une longue pièce dans œuvre à l'arrière que l'on appelle aussi galerie, comme en témoignent de nombreux actes notariés, mais qui s'apparente à une véritable pièce intérieure.

\section{Origine de la galerie ouverte dite hors œuvre}

Les galeries hors œuvre existent dans les civilisations anciennes, particulièrement autour de la Méditerranée et en Orient. Au Maghreb et en Andalousie, l'architecture maure des X ${ }^{e}$ et $\mathrm{XI}^{\mathrm{e}}$ siècles a aussi laissé quelques beaux exemples de palais agrémentés de portiques formant des galeries ou loggias.

En France, il faut attendre la Renaissance pour voir se généraliser les galeries ouvertes, d'abord dans les demeures seigneuriales et les châteaux, puis dans l'architecture bourgeoise et enfin dans l'architecture vernaculaire. 


\section{Apparition des galeries hors œuvre aux Antilles}

Figure 29

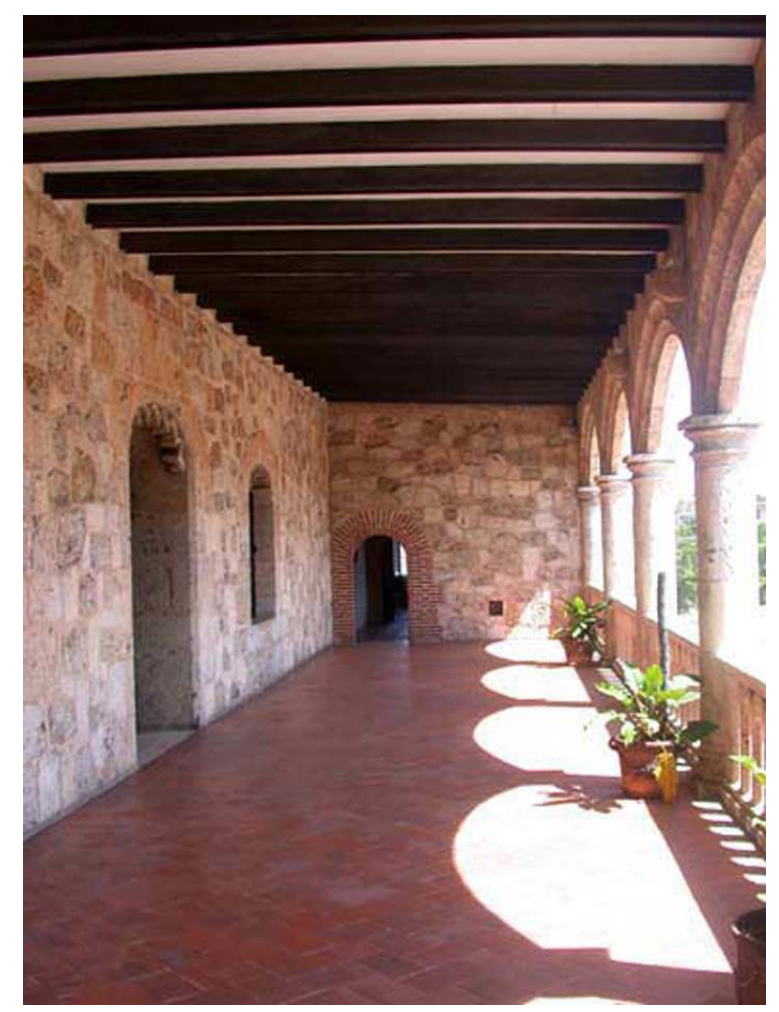

Détail de la galerie du palais de l'Alcazar à Santo-Domingo (République Dominicaine)

Phot. C. Charlery @ C C. Charlery, 2004

Il est difficile de retracer l'apparition et le développement de la galerie ouverte dans l'aire caribéenne. Cependant, il semble que ce soit dans les colonies espagnoles, et plus précisément à Santo Domingo, que les premières galeries (fig. ${ }^{\circ} 29$ ) ont été construites, dès l'installation des premiers colons à la fin du $\mathrm{XV}^{\mathrm{e}}$ siècle. Eugenio Pérez Montas ${ }^{47}$ précise à ce sujet que les galeries de l'Alcazar, palais édifié en 1510 pour le fils de Colomb alors gouverneur de l'île, sont les éléments les plus caractéristiques qui marqueront durablement l'architecture de la ville et plus généralement de l'île. Il est par exemple encore possible aujourd'hui d'observer les ruines de deux maisons principales sur d'anciennes habitations sucrières construites aux premiers temps de la colonisation : la maison de Palavé et celle d'Engomble possèdent toutes deux des galeries soutenues par de grandes arches en plein cintre, encadrées de cabinets et formant une sorte de loggia. Cependant, les Espagnols ont reproduit des éléments qui étaient utilisés dans l'architecture de leur métropole, comme le patio et les galeries.

Dans les colonies anglaises, hollandaises, danoises ou françaises, il n'existe aucune tradition de cette sorte et il semble que l'apparition des galeries soit beaucoup plus tardive. Un certain nombre de documents iconographiques indique que les galeries ouvertes apparurent à la fin du XVII ${ }^{e}$ siècle ou au début du XVIII siècle, au moins dans les colonies néerlandaises, comme en témoigne une série de gravures conservée au Cabinet des Estampes du Rijksmuseum d'Amsterdam. (fig. $n^{\circ} 30$ ) Réalisées en Guyane hollandaise (Surinam) en 1708 par Dirk Valkenburg, qui exerçait la fonction d'économe et de peintre, 
ces dessins sont d'une grande précision. Sur la vue (fig. $\mathrm{n}^{\circ}$ 30) de la plantation Waterland, construite sur les bords du fleuve Suriname, figure au premier plan le bâtiment de la sucrerie. Deux galeries en appentis sont parfaitement visibles de part et d'autre du bâtiment. La légende précise la présence d'une "galerie donnant sur le fleuve " et d'une "galerie arrière, donnant sur les champs ". De même, sur une vue de la maison de maître de la plantation Palmeniribo, elle aussi construite sur les bord du fleuve, on distingue deux galeries, l'une à l'“ arrière de la maison de maître " et l'autre " de façade ", toutes deux notées en légende. Enfin, une gravure datée de 1718, sur laquelle figure une vue de la ville de Paramaribo, semble indiquer que la " maison du gouverneur", probablement en maçonnerie, possède une galerie en bois, peut-être dans œuvre, mais couverte par une toiture en appentis comme en témoigne une brisure de pente.

Figure 30

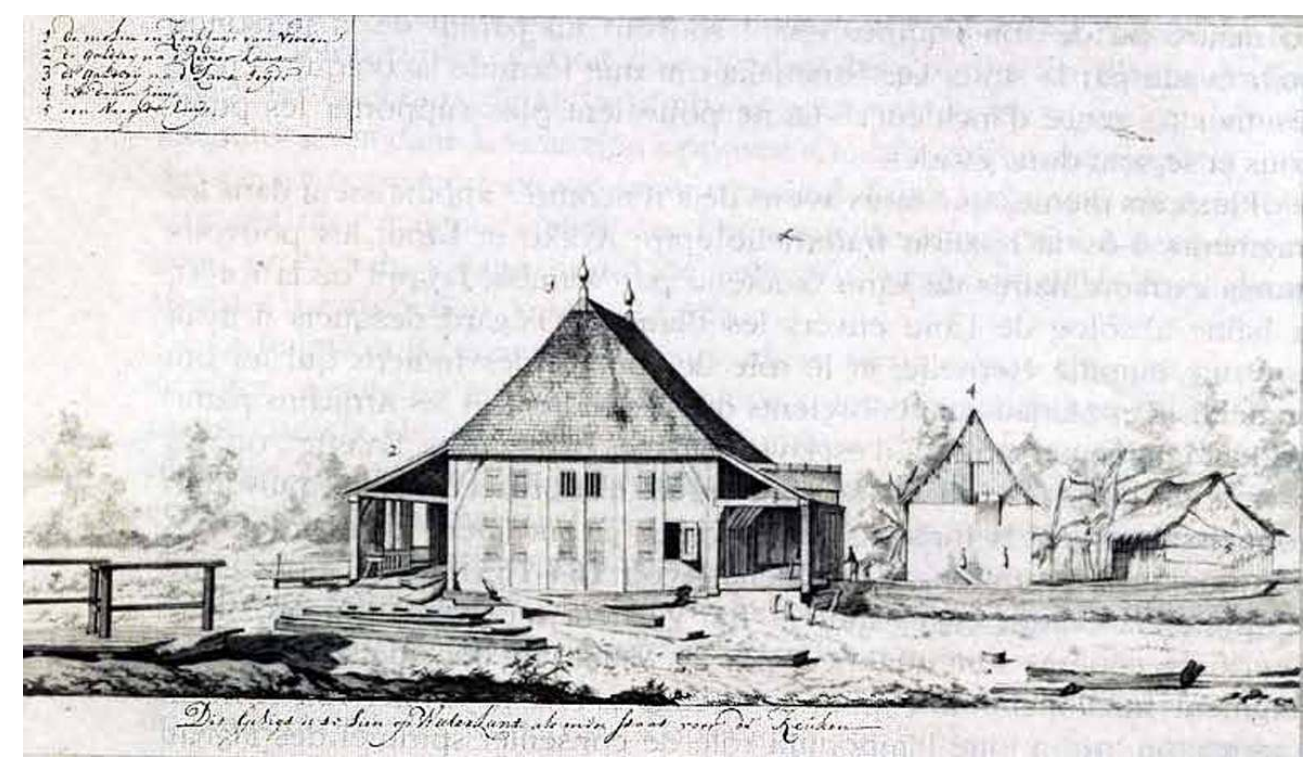

Vue de la Plantation Waterland (Suriname), réalisée en 1708 par Dirk Valkenburg. Au centre, la sucrerie, agrémentée de deux galeries sur les façades principales. Cabinet des Estampes, Rijksmuseum (Amsterdam)

Repro. C. Charlery (c) C. Charlery, 2004 
Figure 31

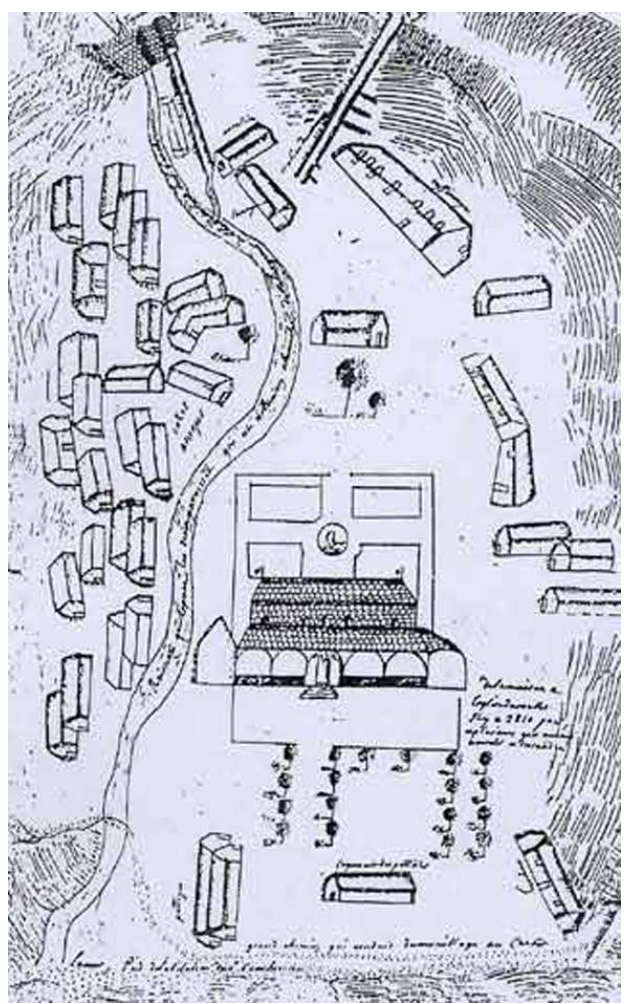

Vue de l'habitation du Sieur Banchereau au Carbet (Martinique) en 1726. Au centre, la maison comporte une galerie qui semble soutenue par une série de poteaux surmontés d'arches probablement en bois. ADM

Repro. C. Charlery @ C. Charlery, 2004 tardivement, peut-être à Saint-Domingue dans un premier temps sous l'influence des colonies espagnoles voisines. Lors de son voyage à la fin du XVII ${ }^{e}$ siècle, le révérend père Labat ne mentionne aucune galerie ouverte. Par la suite, pour de nombreux chroniqueurs de passage, cet appendice architectural semble demeurer un élément parfaitement nouveau, preuve qu'il n'était pas directement un héritage de la France et ce n'est que dans le second quart du XVIII e siècle qu'il se propage dans les colonies. Le plan de l'habitation du Sieur Banchereau (Anse Latouche, paroisse du Carbet en Martinique) dessiné en 1726 (fig. $n^{\circ}$ 31), est la plus ancienne représentation de galerie connue à ce jour : au centre des divers bâtiments, la maison du maître possède une grande galerie à arcades. (fig. $n^{\circ} 31$ ) cartouche une vue cavalière de l'habitation Loyola, dans le quartier de Rémire, où l'on voit que la maison de maître, au premier plan, possède une galerie encadrée de deux cabinets.

Enfin, en Louisiane, la première représentation d'une galerie date de 1734. Elle apparaît, en forme de " $L$ " sur un plan dessiné par Bernard Devergues pour le projet d'une maison de garde avec sa prison. Rapidement, la galerie devient l'un des éléments les plus utilisés dans l'architecture française domestique le long du Mississippi, principalement en milieu rural, pour les maisons des planteurs. Lorsqu'en 1806 Robin arrive en bateau à l'entrée du bayou Saint-Jean, aux portes de la Nouvelle-Orléans, il est frappé par l'omniprésence de 
cet élément architectural ${ }^{49}$ : “Alors les rives défrichées découvrent de distance en distance de jolies maisons de campagne, les unes en bois, entourées de galeries dans le goût chinois (fig. $\mathrm{n}^{\circ} 32$ ) ; d'autres, bâties en briques, sont couronnées de galeries à l'italienne; plusieurs ont des colonnades [...] (fig. $\mathrm{n}^{\circ}$ 32) La chaleur du climat rend nécessaire des galeries. Toutes [les maisons] en ont, les unes qui tournent tout autour de la maison, d'autres aux deux façades seulement, et rarement à une seule. Ces galeries sont formées par le prolongement de la couverture qui se relève au lieu de s'abaisser en toit brisé en sens contraire de nos mansardes. Ces toits brisés et relevés sont soutenus par de petites colonnes en bois d'un effet agréable à la vue. On donne ordinairement 8 à 9 pieds de profondeur à ces galeries ". La grande largeur de ces dernières permet aux occupants d'y dresser une table pour y prendre les repas. Parfois même, deux petites pièces, appelées cabinets, sont aménagées à chaque extrémité pour servir de petites chambres d'appoint.

Figure 32

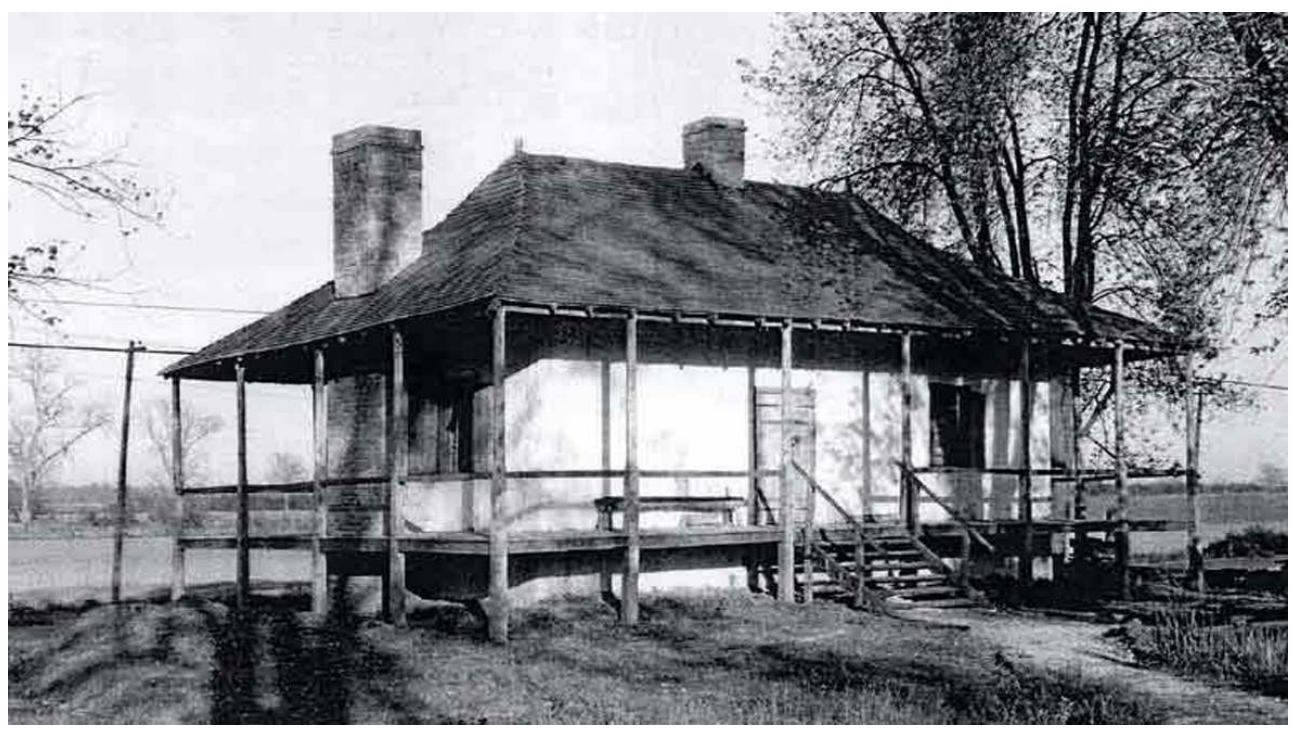

Vue de la maison Bequet-Ribault à Sainte-Geneviève (Missouri). Construite vers 1808, cette maison est caractéristique de l'architecture coloniale française sur le bord du fleuve Mississippi, avec sa galerie tournante sur quatre côtés. On remarquera un surhaussement du rez-de-chaussée qui met la maison hors d'eau en cas de crues. Extrait de Historic American Building Survey

Repro. C. Charlery (c) C. Charlery, 2004 


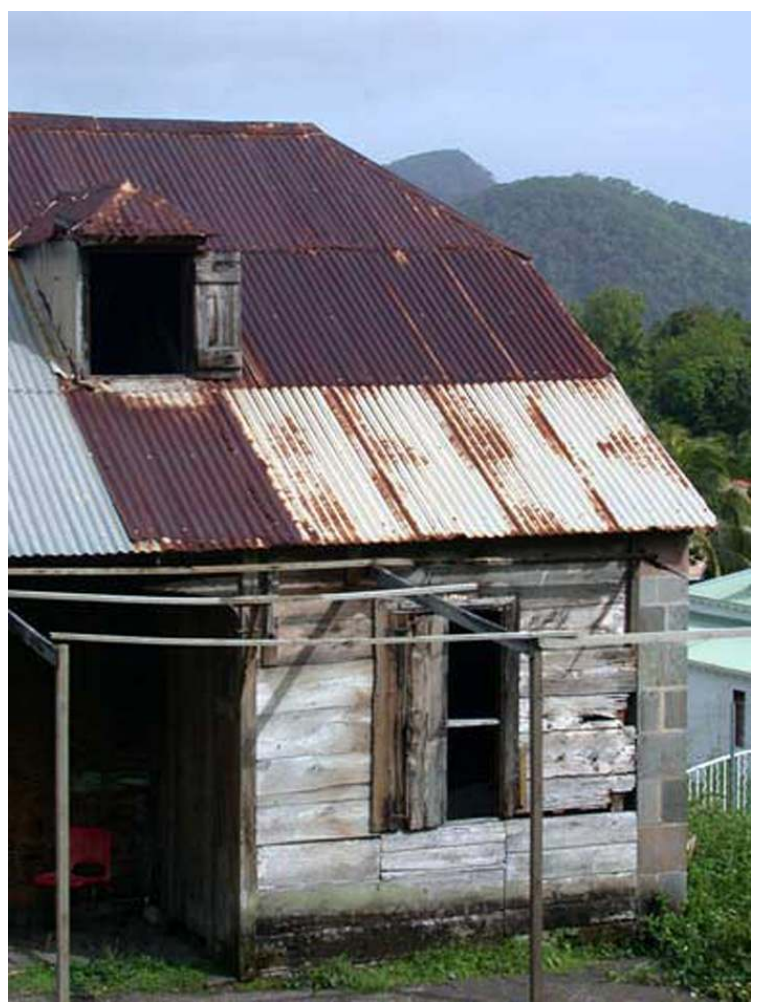

Détail d'un cabinet en bout de galerie d'une maison de maître sur une petite habitation caféière à Saint-Claude (Guadeloupe)

Phot. C. Charlery (c) C. Charlery, 2003

61 Probablement inspirés par les anciennes maisons des puissants colons espagnols installés à Santo Domingo depuis le XVI ${ }^{\mathrm{e}}$ siècle, les deux cabinets extrêmes sont présents (fig. $\mathrm{n}$ - 33) dans la plupart des colonies françaises de l'Amérique, puisqu'on les retrouve à SaintDomingue bien sûr, mais aussi en Guadeloupe et en Martinique, comme le confirment de nombreux documents d'archives comme cet "Etat de mes biens de l'Amérique " ${ }^{50}$ dans la paroisse de Sainte-Anne, en Guadeloupe, rédigé en juin 1776 par un colon revenant en France.

Dans ce document exceptionnel, ce dernier fait une description de sa maison et précise la présence de “ deux petites chambres à chaque extrémité de la gallerie " (fig. n 34 ).

La plupart du temps, les galeries étaient soutenues par des poteaux en bois, mais il pouvait arriver que ces derniers soient en maçonnerie de briquettes lorsque ce matériau était facilement disponible ou que l'on souhaitait donner meilleure allure à sa maison. Citons l'exemple de l'habitation située à Brochetage, dans le quartier de Dondon à SaintDomingue, “ dans laquelle il y a une belle grand'case [...], galerie tournante sur pillier de maçonnerie, avec quatre cabinets, le tout bien palissadé et planchéié " 51 (fig. n 35 et 36). 


\section{Figure 34}

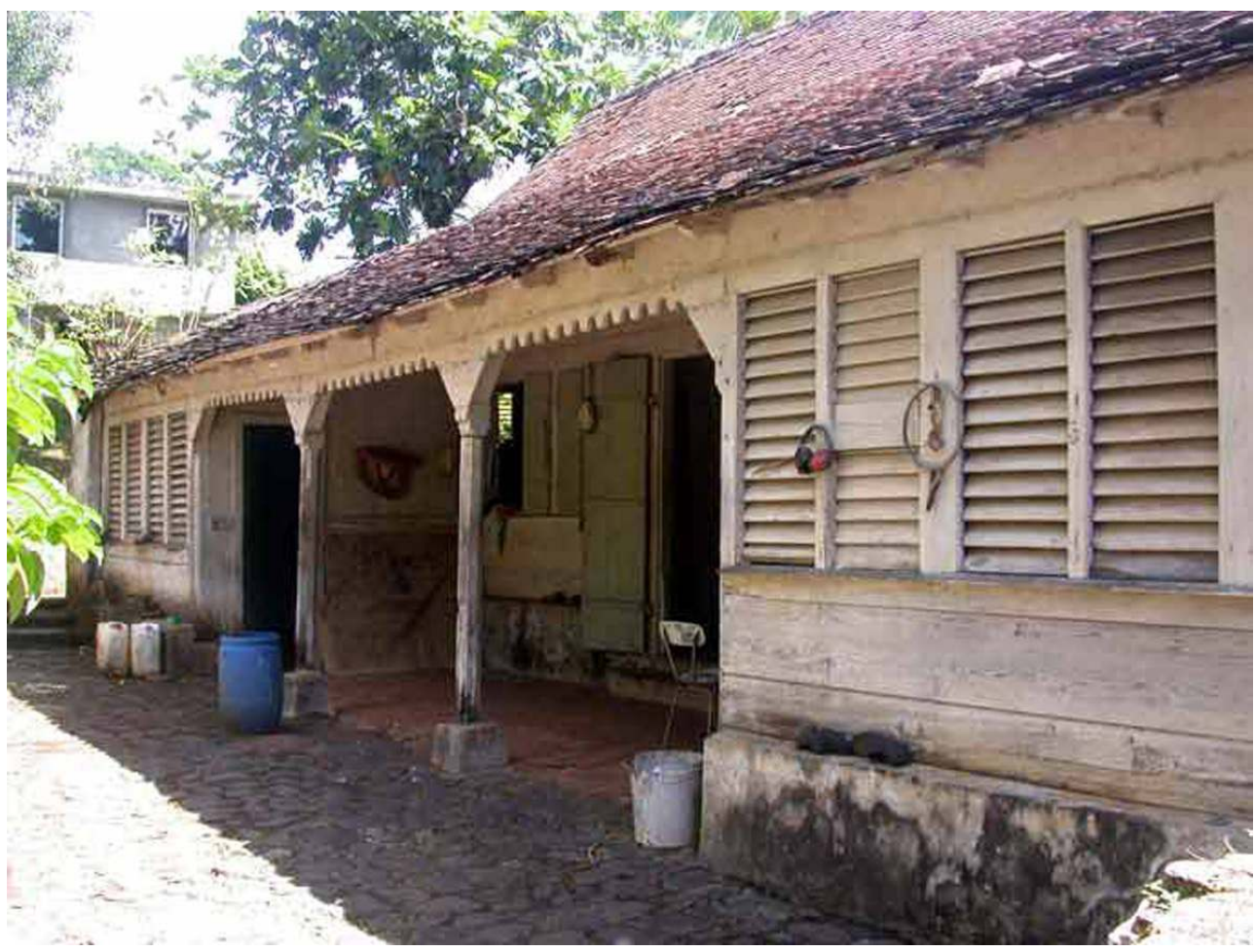

Maison de maître de l'habitation sucrerie Dufferet à Trinité (Martinique). Construite à la fin du XVIII siècle, mais réhabilitée au XIXe siècle, cette maison a tout de même conservé ses galeries hors œuvre agrémentées d'un cabinet à chaque extrémité

Phot. C. Charlery @ C. Charlery, 2003 
Figure 35

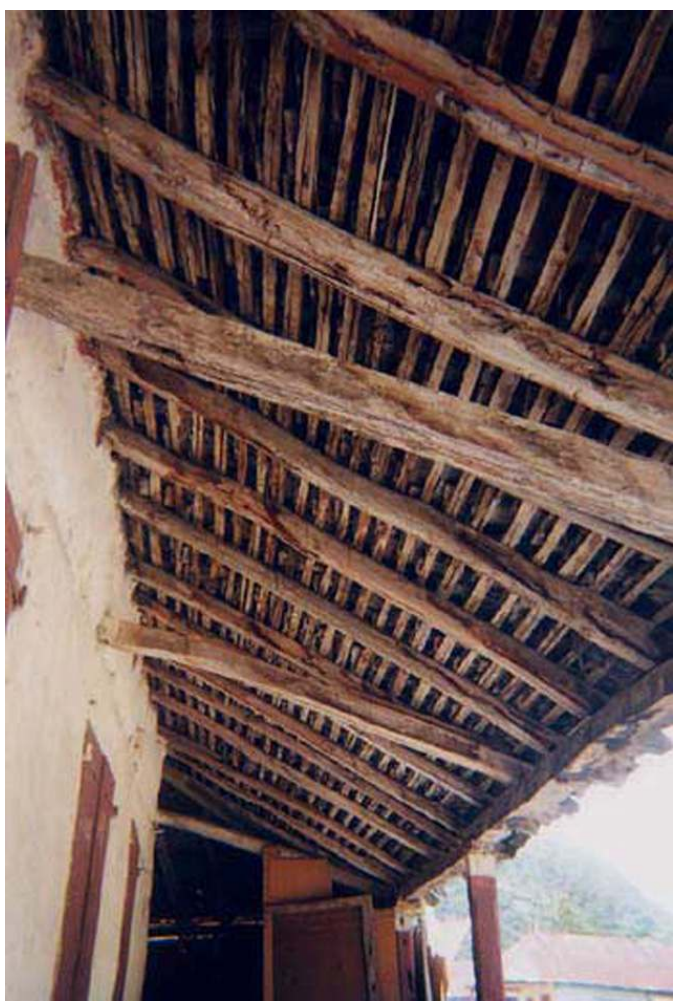

Détail de la galerie d'une maison construite à Marchand-Dessalines (Haïti) au début du XIXe siècle Phot. C. Charlery (c) C. Charlery, 2003 
Figure 36

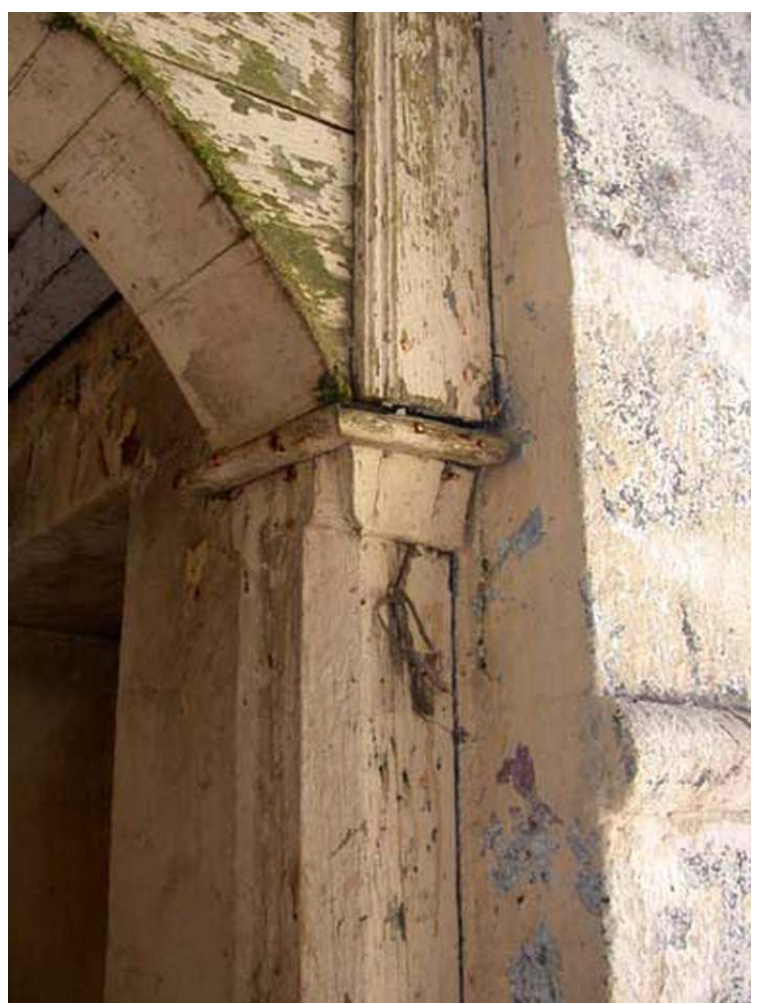

Détail d'un poteau chanfreiné de la galerie de la maison de maître de l'habitation caféière Sapotille à Trois-Rivières (Guadeloupe), construite au milieu du XIXe siècle

Phot. C. Charlery (c) C. Charlery, 2003

Plus rarement enfin, la galerie peut astucieusement cacher, sous son plancher, des tiroirs où l'on stocke le café et que l'on peut tirer afin de le faire sécher. Lors de la vente d'une habitation caféière en 1785 sur la paroisse de la Rivière-Salée à la Martinique, il est précisé que la maison a " des galeries sur les quatre faces, dans lesquelles se trouvent des planchers pour loger le café, avec huit caisses roulantes " 52 .

\section{Origine de la galerie dans œuvre}

65 Pour de nombreux historiens, l'étymologie du terme galerie ne serait pas d'origine italienne, mais plutôt française, comme le suggère déjà l'architecte Sebastiano Serlio (1475-1554) lui-même dans ses livres d'architecture. Le terme aurait été initialement utilisé dans le milieu naval pour désigner la coursive extérieure le long du poste d'équipage ou des cabines de navire ${ }^{53}$ puis introduit dans le vocabulaire de l'architecture domestique : la galerie désignait alors une longue pièce dans œuvre, régulièrement percée de grandes baies et dont le grand côté donnait généralement sur le jardin ou sur une cour intérieure. Comme le rapporte J.-P. Babelon ${ }^{54}$, Louis Savot écrivait en 1624 : "Il semble que les François ont esté les premiers autheurs des galleries". En effet, si quelques exemples précoces existent dès le XVe siècle, à l'hôtel Saint-Pol et à l'hôtel des Tournelles à Paris, c'est la galerie François Ier du château de Fontainebleau, commencée en 1528, qui fit référence dans l'architecture des palais et hôtels urbains. 


\section{Apparition des galeries dans œuvre aux colonies françaises}

C'est peut-être avec la construction des couvents que les premières galeries dans œuvre sont construites à la fin du XVII ${ }^{e}$ siècle dans les colonies françaises d'Amérique. (fig. $\mathrm{n}$ - 37) Il s'agit alors de longues pièces, closes de murs et garnies de baies, qui se trouvent souvent à l'arrière du bâtiment et dont la sobriété n'a rien à voir avec les luxueuses galeries que l'on trouve à cette époque dans des châteaux français. Lorsque le père Labat, résidant aux Antilles françaises à la fin du XVII siècle, décrit les couvents de Basse-Terre en Guadeloupe et de Saint-Pierre en Martinique, il fait référence à des galeries dans œuvre.

Figure 37

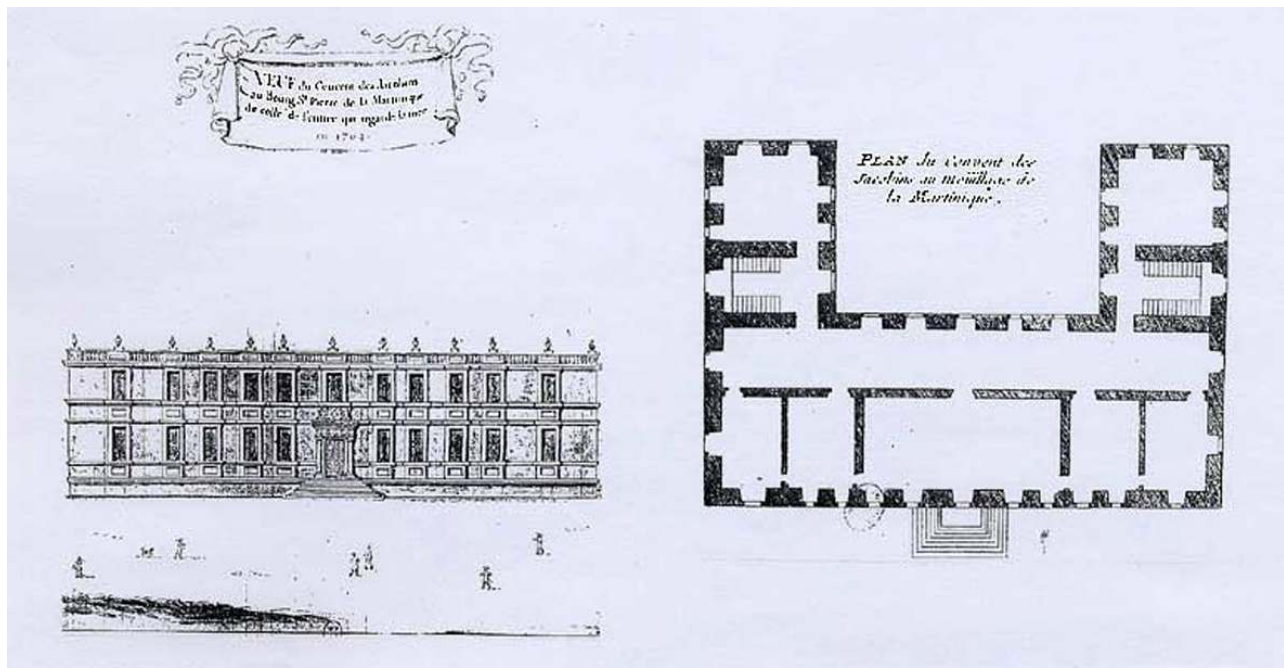

Vue du couvent des jacobins à Saint-Pierre (Martinique), construit en 1704 par le père Labat. On distingue parfaitement, à l'arrière, une longue galerie dans œuvre. Extrait de : Labat, NOUVEAU voYAgE AUX ISLES DE L'AMÉRIQUE, édition de 1742

Repro. C. Charlery (C) C. Charlery, 2004 
Figure 38

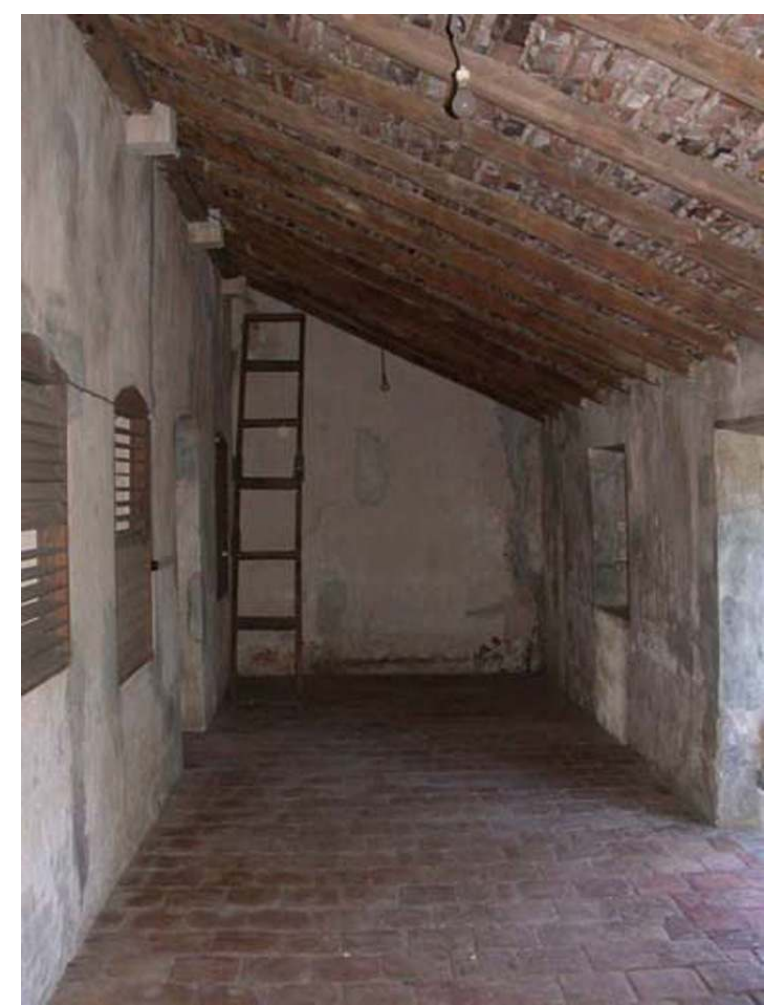

Maison de maître de l'habitation la Sucrerie aux Anses-d'Arlets (Martinique). Détail de la galerie dans œuvre (voir aussi figure 24)

Phot. C. Charlery (c) C. Charlery, 2004

Le couvent des capucins de Basse-Terre, construit dans les années 1680, est un bâtiment qui se développe sur plusieurs terrasses successives. Le niveau le plus haut abrite, outre un salon carré et quelques chambres, une galerie dans œuvre de 15 pieds de large qui se développe sur toute la longueur du bâtiment ${ }^{55}$.

Le couvent des jacobins (fig. $\mathbf{n}^{\circ}$ 37) de Saint-Pierre est lui construit dans les années 1690. C'est d'ailleurs le père Labat lui-même qui en dresse les plans. Il prévoit à l'arrière du bâtiment une large galerie dans œuvre ${ }^{56}$. L'ensemble disparaît lors de l'éruption de la montagne Pelée en 1902, mais des fouilles archéologiques ont permis de mettre au jour les fondations de l'édifice. La galerie y est parfaitement identifiable, même si sa largeur est bien moins importante que sur le projet proposé dans l'ouvrage du père Labat.

\section{Usage des galeries ouvertes et dans œuvre}

Bien plus qu'un simple élément d'abri, la galerie ouverte devient au XVIII ${ }^{e}$ siècle un espace de vie à part entière (fig. $\mathbf{n}^{\circ}$ 38). Déjà en 1763 , le chevalier de Préfontaine précise : "Les galeries dont le bord extérieur sera soutenu par des poteaux de huit pieds en huit pieds, servent à respirer le frais dans les grandes chaleurs, facilitent la promenade à couvert en temps de pluie ; elles garantissent les murs \& la maison de l'humidité ; \& on à même encore l'attention, dans cette vue, de creuser tout autour de la maison, à quelque distance, des rigoles qui favorisent l'écoulement des eaux dans la saison des pluies" ${ }^{57}$. Quelques années plus tard, le baron de Wimpffen écrit à son tour : "une ou deux galeries 
règnent en avant de l'une ou des deux faces [de la maison]. Elles restent ouvertes, ou sont fermées par des jalousies à coulisse, mais seulement à hauteur d'appui. L'une est la salle à manger, l'autre le salon de compagnie, quant on ne veut pas se tenir dans celle du milieu". Il précise enfin que dans les maisons les plus importantes, des cabinets sont aménagés aux extrémités, afin de servir d'office, de buffets, de garde meuble ou bien de chambres à coucher " que l'on destine ordinairement aux étrangers" 58 .

Parfois, les galeries sont construites a posteriori, sur des maisons dont le noyau existait déjà. En 1766, celle de la veuve Bonneteau en Guadeloupe, qui mesure 12 pieds de large sur toute la longueur de la maison, est neuve, n'est pas encore achevée, ses portes et ses fenêtres ne sont pas encore posées ${ }^{59}$.

\section{La ventilation}

\section{Figure 39}

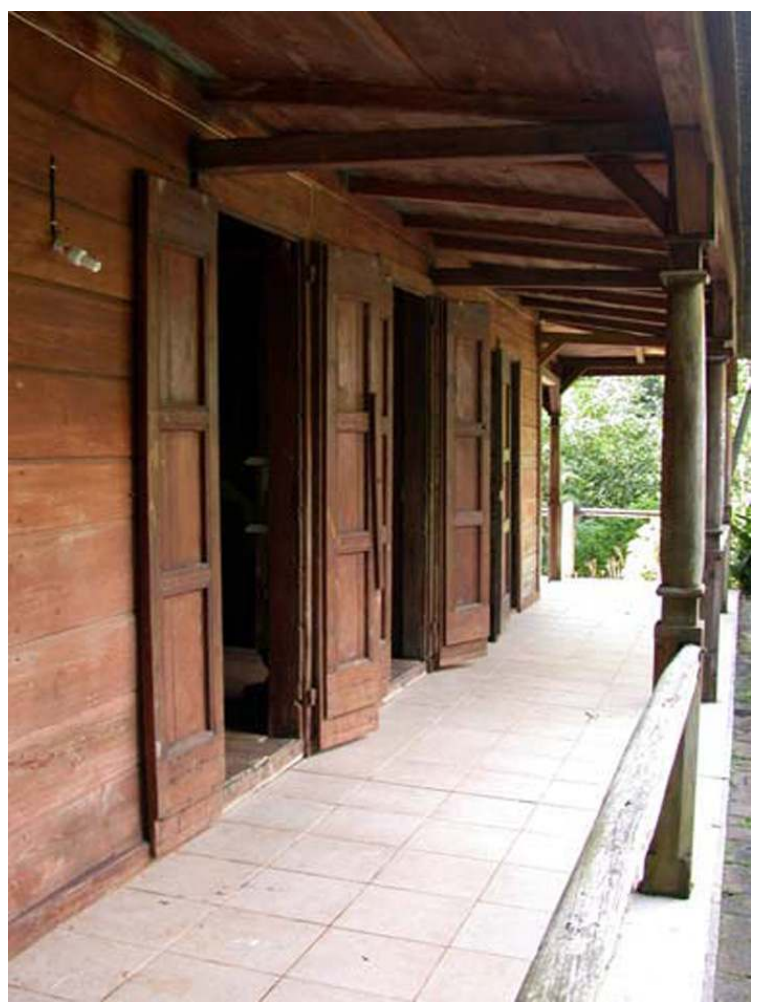

Maison de maître de l'habitation caféière Thomas-Ermitage à Bouillante (Guadeloupe). Détail des baies : les menuiseries consistent uniquement en contrevents en bois avec faux panneautage. Ce type de contrevents se retrouve dans toutes les anciennes colonies françaises de l'Amérique, jusqu'en Louisiane

Phot. C. Charlery @ C. Charlery, 2003

Le climat chaud de l'Amérique tropicale autorise à ne pas vitrer les baies qui, dans de nombreux cas, ne sont garnies que de simples contrevents (fig. $n^{\circ} 39$ ). Le chevalier de Préfontaine rapporte d'ailleurs à ce sujet : “ Il n'y a point ordinairement de fenêtres ; on y supplée en choisissant de chaque côté de la maison l'intervalle du milieu de chaque chambre pour en faire deux portes. L'une peut se fermer quand l'autre reste ouverte "60. Cependant, dès le XVII ${ }^{e}$ siècle, il existe plusieurs manières de garnir ses baies. Comme le précise le père du Tertre, “je n'ai vu des vitres qu'aux fenêtres des maisons des 
gouverneurs, tous les particuliers n'en ont point, soit parce que le verre est trop fragile, soit que l'usage n'en est pas pratique: vu les chaleurs du pays, on est obligé de tenir toujours la porte et les fenêtres ouvertes pour laisser passer la brise, afin de rafraîchir la case, mais on ferme la nuit à cause de la trop grande fraîcheur "61.

Cent ans plus tard, les choses n'ont pas changé et comme le précise Robin, les baies garnies de vitrerie sont réservées à quelques rares salons de maisons opulentes. En Louisiane et tout au long du fleuve du Mississippi, l'emploi du verre est aussi exceptionnel : importé d'Europe, il demeure en effet fort onéreux. Ce n'est qu'à partir de 1767 qu'il est directement produit dans la région, dans la ville de Saint-Louis ${ }^{62}$ (fig. $\mathrm{n}^{\circ} 40$ ).

A défaut, on garnit les menuiseries de papier huilé ou mieux, d'un canevas en lin qui favorise une meilleure ventilation. Il est aussi possible de monter des balustres formant des barreaux dans l'embrasure des fenêtres, comme le faisaient très couramment les Espagnols (fig. $n^{\circ} 41$ ).

Enfin, dans les îles, un caillebotis en bois imitant les moucharabiehs, est parfois installé entre les petits bois des menuiseries et forme des croisées ou même des parois dites en claire-vüe. A Saint-Domingue par exemple, l'annonce de la vente de l'auberge de SaintMarc dans Les Affiches Américaines du 7 mai $1766^{63}$, précise qu' “ A l'est et à l'ouest il y a deux galeries en claire-vüe à hauteur d'appui, de 12 pieds chacune, et des portes de bois de chène, neuves et en bon état, aussi en claire-vüe ". Ce système, utilisé en Europe depuis l'Antiquité, est connu en France, au milieu du XVIII ${ }^{e}$ siècle, sous le nom de jalousie (fig. n $\left.{ }^{\circ} 42\right)$.

\section{Figure 40}

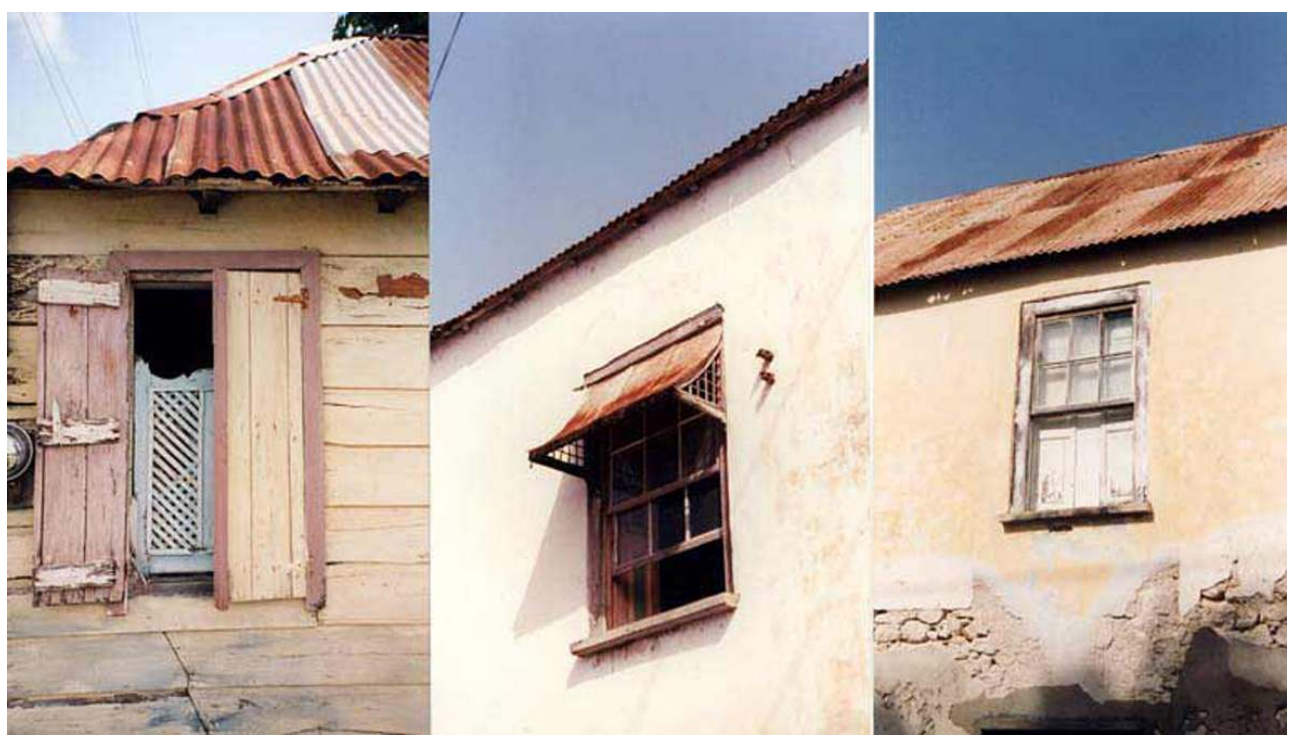

Détails de menuiseries dans les îles anglophones. De gauche à droite : fenêtre avec caillebotis à Pigeon (Sainte-Lucie), fenêtre à petits bois et guillotine avec auvent extérieur à Bridgetown (Barbade), fenêtre à petits bois et guillotine avec volets intérieurs à Bridgetown (Barbade)

Phot. C. Charlery @ C. Charlery, 1998 
Figure 41

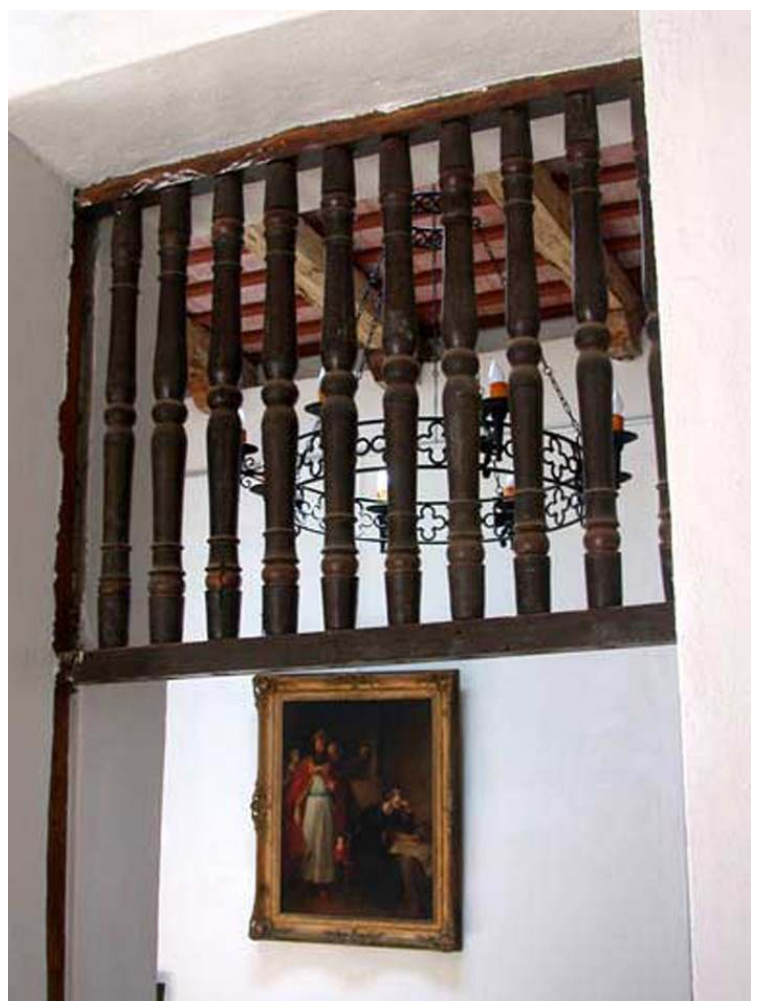

Détail d'une imposte en balustres de bois tourné à Santo-Domingo (République Dominicaine). Ce système avait aussi été utilisé aux îles françaises au XVIIe siècle

Phot. C. Charlery (c) C. Charlery, 2004 


\section{Figure 42}

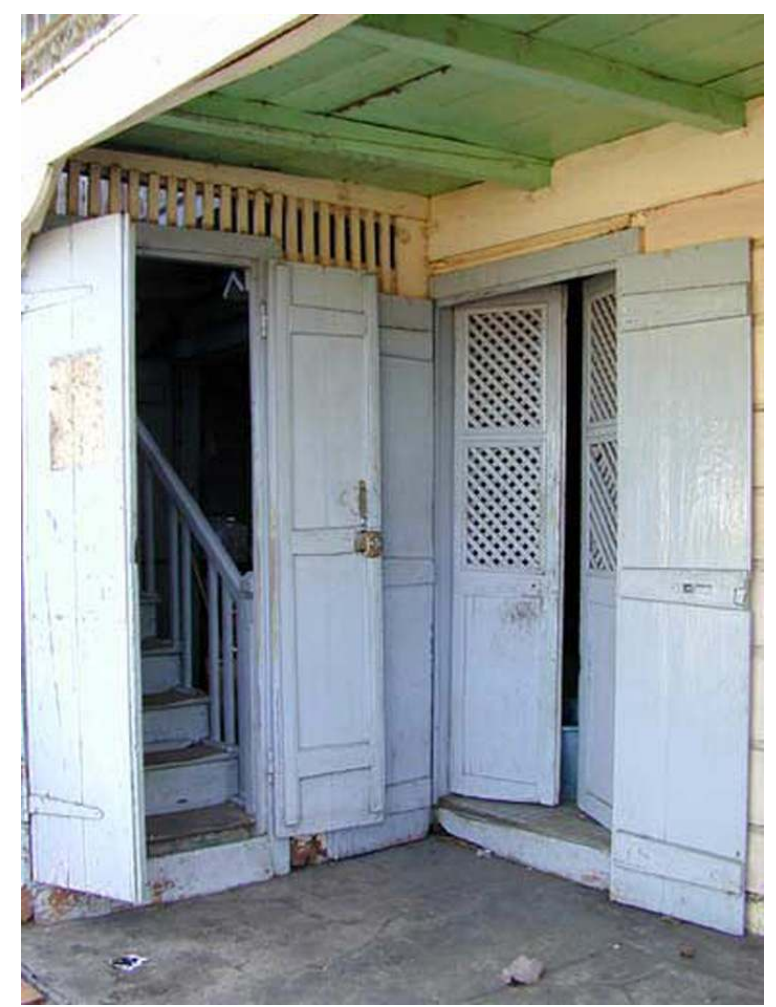

Détail d'une baie garnie de caillebotis en bois dans une maison à Bouillante (Guadeloupe). Ce système est aujourd'hui très rare à la Martinique ou en Guadeloupe. Il est encore couramment utilisé en Haïti Phot. Inv. M. E. Desmoulins (c) Inventaire général, ADAGP, 2002 


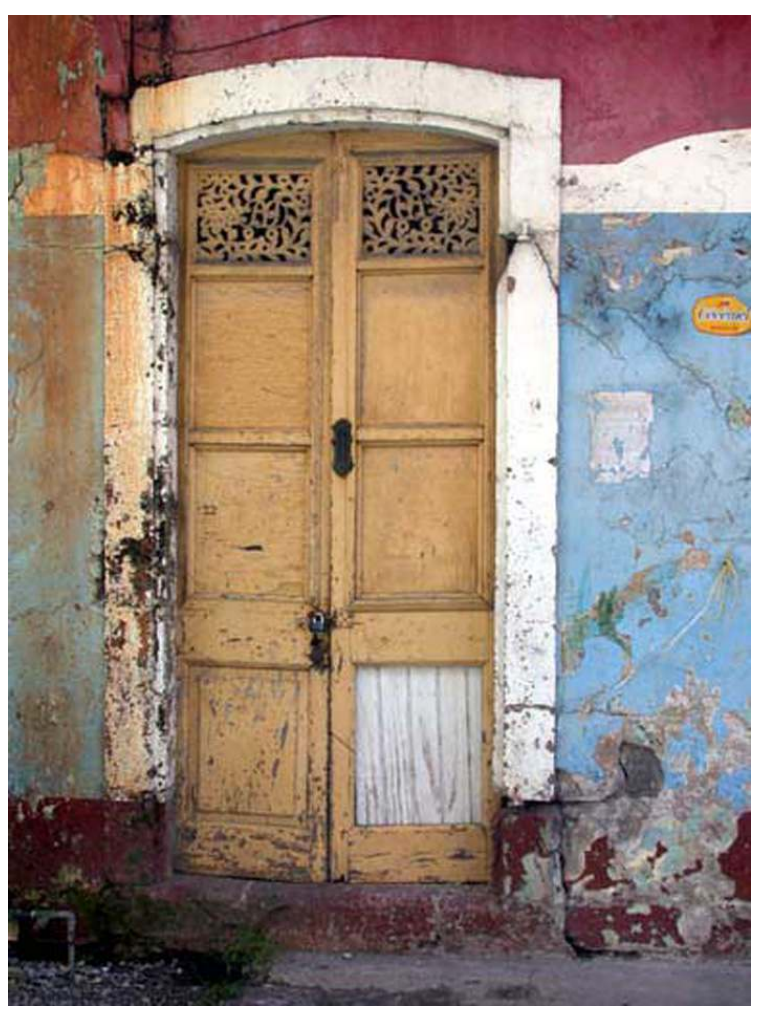

Détail d'une porte garnie d'impostes ajourées à Roseau (Dominique)

Phot. C. Charlery (c) C. Charlery, 2004

D'Aviler en donne une description précise dans son Dictionnaire de l'Architecture ${ }^{64}$ : "fermeture de fenêtre, faite de petites tringles de bois, croisées diagonalement, qui laissent des vuides en losange, par lesquels on peut voir sans être apperçu. Les plus belles jalousies se font de panneaux d'ornements de sculpture évuidés. Elles servent (fig. $\mathbf{n}^{\circ}{ }^{43}$ ) dans les églises aux jubés, tribunes et confessionnaux, dans les écoles ou salles publiques, aux écoutes, lanternes ". Ce système, moins coûteux que les persiennes, fut longtemps utilisé. En Haïti, il reste un élément traditionnel du second œuvre, alors qu'en Martinique et en Guadeloupe, il a presque disparu.

\section{Porte-ombre, jalousies et persiennes : des inventions françaises}

L'origine de la persienne est encore incertaine. D'après le Grand Dictionnaire Universel Larousse de $1866^{65}$, le terme persienne trouverait son étymologie du vieux français persien ou persan, sous-entendant fenêtre persane. L'usage de celle-ci, évoquant les moucharabiehs, serait "une importation de l'Orient". D'après d'autres sources ${ }^{66}$, le terme aurait pour origine l'évocation des raies horizontales si caractéristiques des tissus persans... Notons qu'en Louisiane, les persiennes sont parfois désignées sous le terme french louvers et à Cuba persianeria francesa. Dans les deux cas, il faut traduire par persiennes françaises, expression favorable à l'hypothèse d'une origine française. 
Figure 44

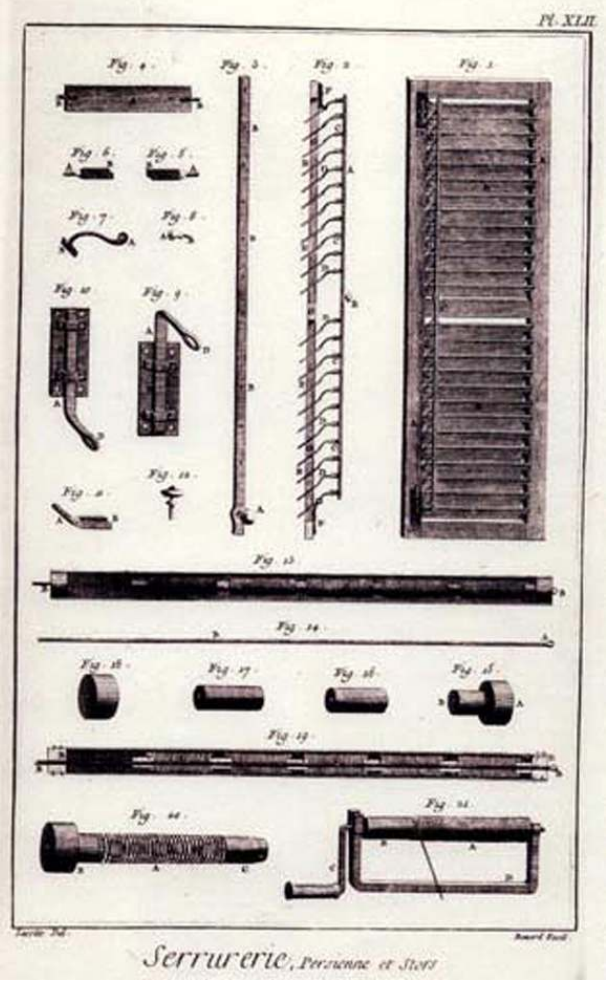

Extrait d'une planche sur la fabrication des persiennes. Extrait de : Diderot et d'Alembert, I 'ENCYCLOPÉDIE, TOME 12, 1765

Repro. C. Charlery (C C. Charlery, 2003 
Figure 45

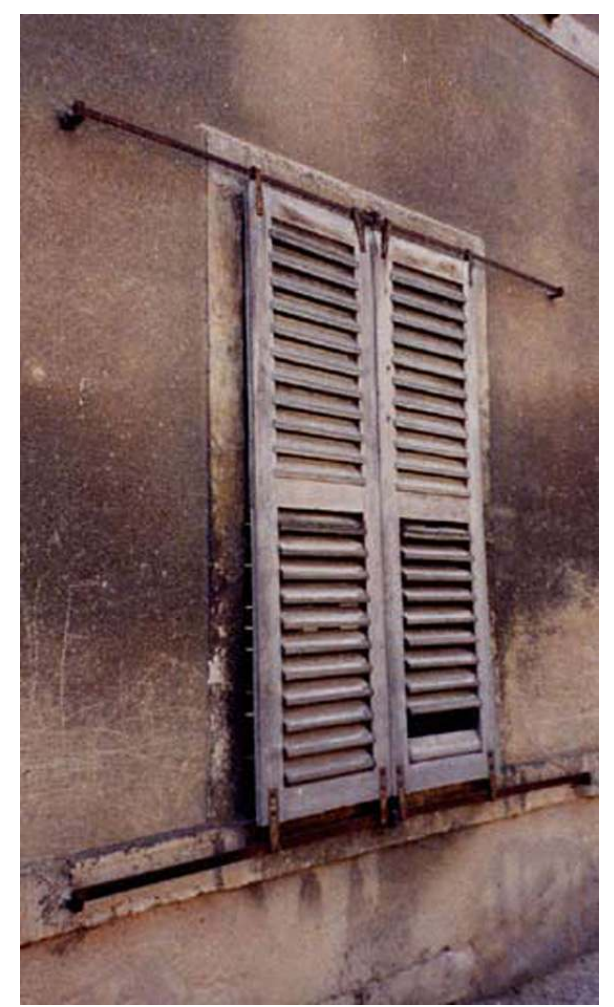

Détail d'un volet coulissant à persiennes à Besançon (Doubs)

Phot. C. Charlery @ C. Charlery, 2002

En France, il semble que le premier dispositif de persiennes fixes soit mis au point en 1726, par Antoine Duchesne à Versailles. En 1741, l'architecte Gabriel fils, contrôleur du château de Versailles, reprend l'invention pour l'installer aux fenêtres de l'appartement du Dauphin, futur Louis XV, et la baptise, pour l'occasion, par le terme de persiennes, ou sultanes, en référence à l'Orient. Cependant, il a pris soin de perfectionner l'invention : il coupe le châssis en deux battants, qu'il fait gonder et plaquer contre le mur ${ }^{67}$.

Il faut ainsi attendre les années 1760 pour en voir les premières mentions dans les traités d'architecture ou de menuiserie. Le douzième tome de l'Encyclopédie (fig. $n^{\circ} 44$ ) de Diderot et d'Alembert, édité en 1765 , en donne la première définition ${ }^{68}$ : “Jalousies ou chassis de bois qui s'ouvrent en dehors comme contrevents (fig. $n^{\circ} 45$ ), et sur lesquels sont assemblés à égale distance des tringles de bois en abat-jour qui font le même effet que les stores, rompent la lumière et donnent entrée à l'air dans un appartement ".

\section{Apparition des persiennes aux Antilles}

En 1776, l'architecte parisien d'Albaret publie un curieux recueil de modèles de maisons de maître destinés aux habitants des Indes Occidentales ${ }^{69}$. Dans l'un de ses projets, il précise que "Les jalousies fixes dont on garnit aux Indes les piazzas et croisées, peuvent s'adapter aisément dans chaque entre colonne; ce qui produira une ombre et une fraîcheur agréable. Les croisées sont garnies de petites colonnes, auxquelles on peut de même adapter des jalousies ". Ainsi, à cette date, l'usage des persiennes est connu dans les îles des Antilles. 

le manque de documents rend les recherches difficiles. Jusqu'au début des années 1770, elles ne semblent pas encore utilisées dans les colonies françaises, ni d'ailleurs dans aucune autre île étrangère. Il faut attendre l'année 1776 pour trouver les premières mentions de persiennes dans la colonie. Notons qu'à cette époque, elles sont abusivement désignées par le terme de jalousies. Ainsi, le 4 mai 1776, une annonce est passée pour la vente d'une maison dans la ville du Cap Français avec " des jalousies à toutes les fenêtres " ${ }^{70}$. C'est probablement dans cette ville, la plus importante de toutes les colonies françaises en Amérique, que sont installées les premières persiennes.

81 A la suite de son passage au Cap Français, Moreau de Saint-Méry relève que "Depuis 1776, le goût des jalousies aux fenêtres \& même aux portes, s'est singulièrement étendu. On en voit presque partout de mobiles \& d'immobiles, de celles qu'on élève, de celles à chassis. Les galeries en sont garnies, \& il faut avouer que c'est une des idées les plus heureuses qu'on ait pu avoir dans ce climat, où les jalousies diminuent l'éclat du jour, le modèrent à volonté, \& augmentent l'action du vent, en l'obligeant de se comprimer pour passer entre les palettes " ${ }^{71}$. C'est peut-être sur un bâtiment officiel, comme la maison du Gouverneur, que les premières persiennes furent installées avant d'être copiées dans l'architecture privée. Décrivant cette dernière, le même auteur précise que les fenêtres "avaient des jalousies à battants, comme toutes celles de cette maison ". ${ }^{72}$

Il semble que la mode s'en développe rapidement dans d'autres villes de l'île, comme Port-au-Prince où Moreau de Saint-Méry relate que "Partout les jalousies de différents genres défendent contre la chaleur et servent à ménager le jour et les effets de l'air" ${ }^{73}$. Dans le nouveau bâtiment du Gouvernement, “ Après le salon est une magnifique galerie servant de salle à manger [...]. Cette galerie garnie de jalousies est d'autant plus fraîche qu'abritée du soleil à l'ouest par la maison elle-même, elle l'est à l'est par une seconde galerie en appentis, carrelée en marbre " ${ }^{74}$. Le dispositif semble parfaitement adapté aux conditions climatiques de lîlle. Il est même possible de trouver des chaises à porteurs " de France, à une place, à glace et jalousies " ${ }^{75}$, comme en témoigne une annonce parue dans un journal en 1776. persiennes s'est sans doute développée peu après. Anne Pérotin-Dumont ${ }^{77}$ cite un acte notarial de 1777 concernant la vente d'une maison près de la Rivière des Pères à BasseTerre, dans lequel il est fait mention d'une "galerie basse fermée par un mur à hauteur d'appui et le reste en bois avec des jalousies". L'année suivante, on trouve dans les registres du notaire Nielly la vente d'une maison à Pointe-à-Pitre dont "les portes et fenêtres sur le devant de laditte maison sont garnies de jalousies " 78 .

$\mathrm{Au}$ début des années 1780, les maisons qui en sont dotées sont déjà nombreuses, comme en témoignent les actes notariés ou les annonces de ventes dans les journaux locaux de 
l'époque, aussi bien à Saint-Domingue qu'en Guadeloupe et en Martinique (fig. $\mathbf{n}^{\circ} 46$ et 47).

Figure 46

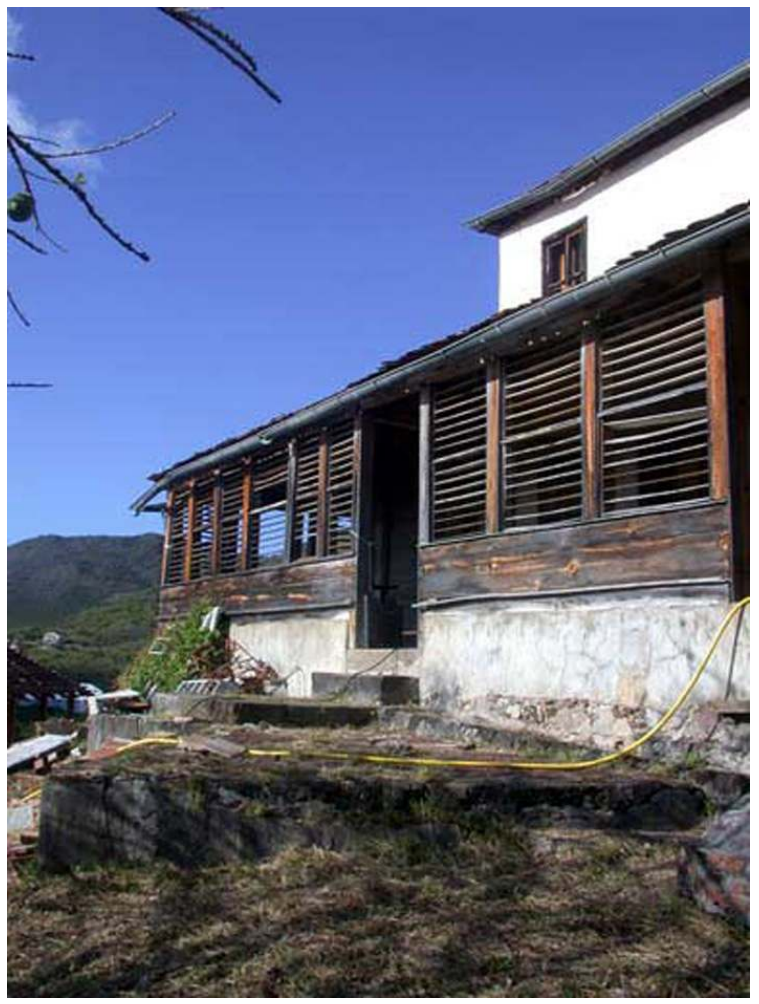

Maison de maître de l'habitation La Sucrerie aux Anses-D'Arlets (Martinique). Vue extérieure de la galerie garnie de persiennes

Phot. C. Charlery (c) C. Charlery, 2004 
Figure 47

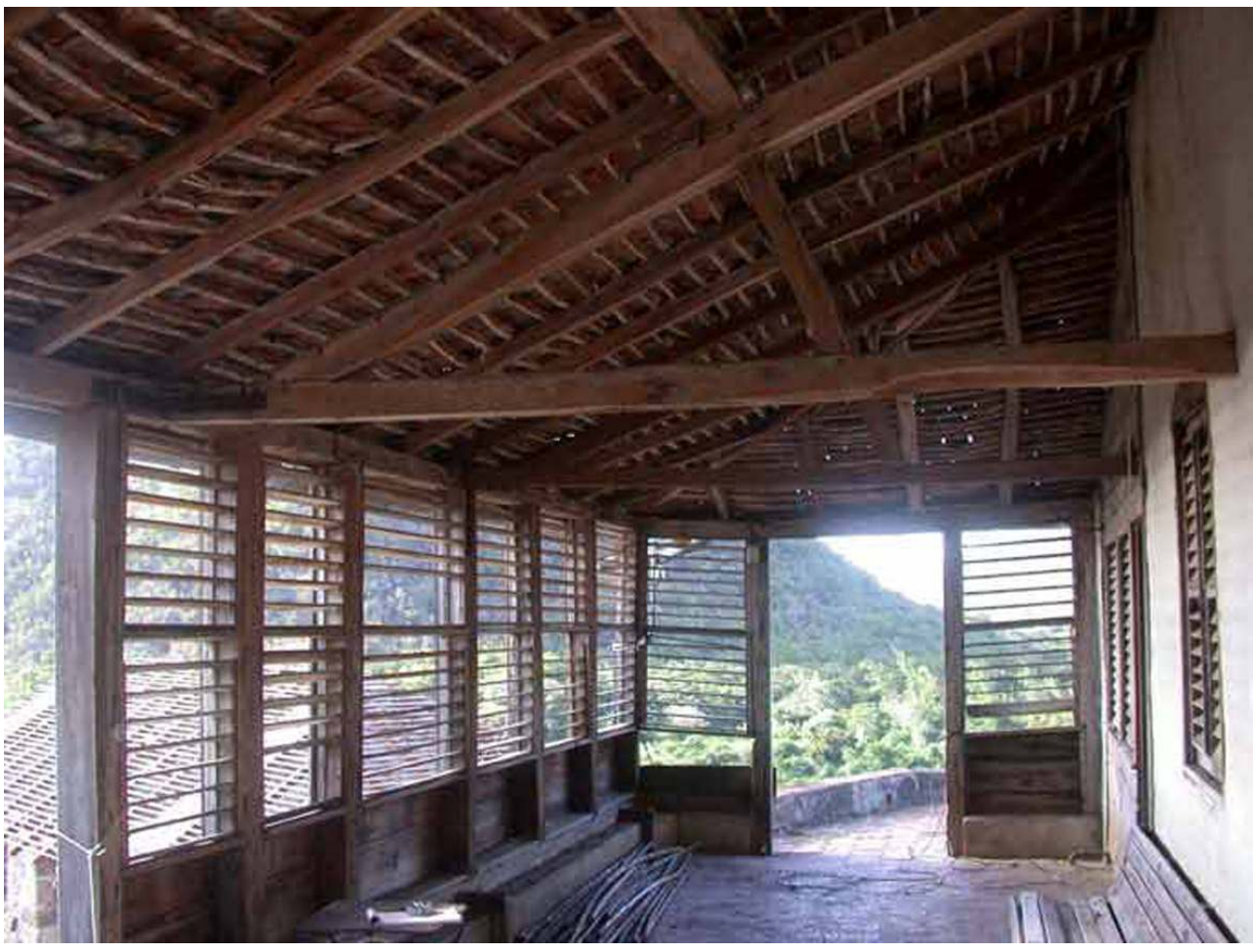

Maison de maître de l'habitation La Sucrerie aux Anses-d'Arlets (Martinique). Vue intérieure de la galerie garnie de persiennes

Phot. C. Charlery @ C C. Charlery, 2004

\section{Décor intérieur et ameublement}

\section{Décor intérieur}


Figure 48

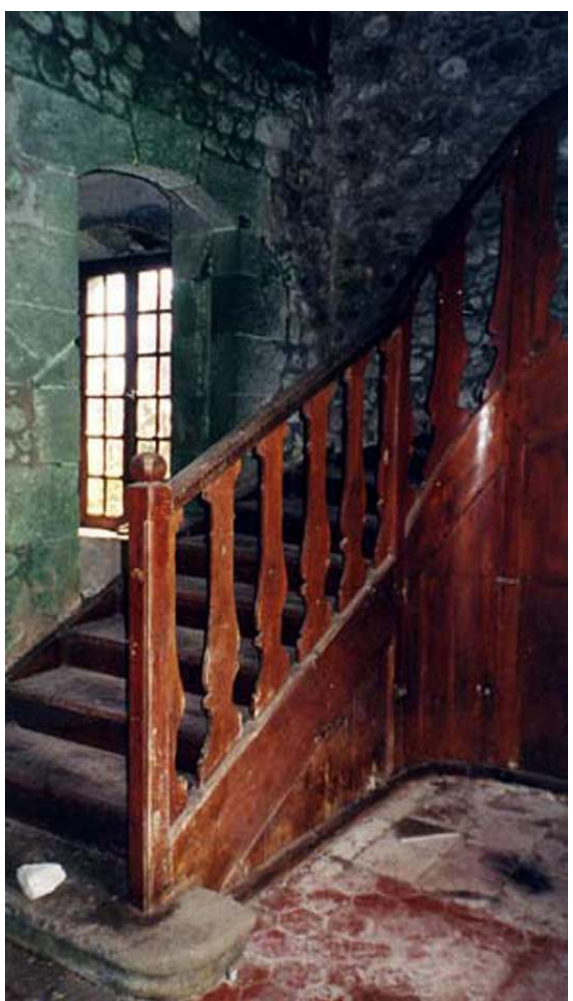

Maison de maître de l'habitation Leyritz à Basse-Pointe (Martinique). Détail d'un escalier du XVIIIe siècle

Phot. C. Charlery (c) C. Charlery, 2000

Il semble que le décor intérieur, même dans les plus riches demeures, reste souvent d'une grande sobriété. En témoigne la description du pavillon de l'habitation Charrier près de la ville du Cap, dans le nord de Saint-Domingue, où séjournent le prince de Rohan, puis le général Don Bernard Galvez: Moreau de Saint-Méry nous en livre une description à la fin du XVIII ${ }^{e}$ siècle: "Le pavillon, sans être très vaste, est fort commode. Une galerie ombrage ses deux façades est et ouest; des meubles élégants sans somptuosité; des peintures fraîches sans recherche ; un immense salon placé à angle droit et dans l'ouest du pavillon ; une grande terrasse ornée de treillages et de figues, à laquelle on arrive (fig. $\left.\mathrm{n}^{\circ} 48\right)$ par un superbe escalier " 79 . 
Figure 49

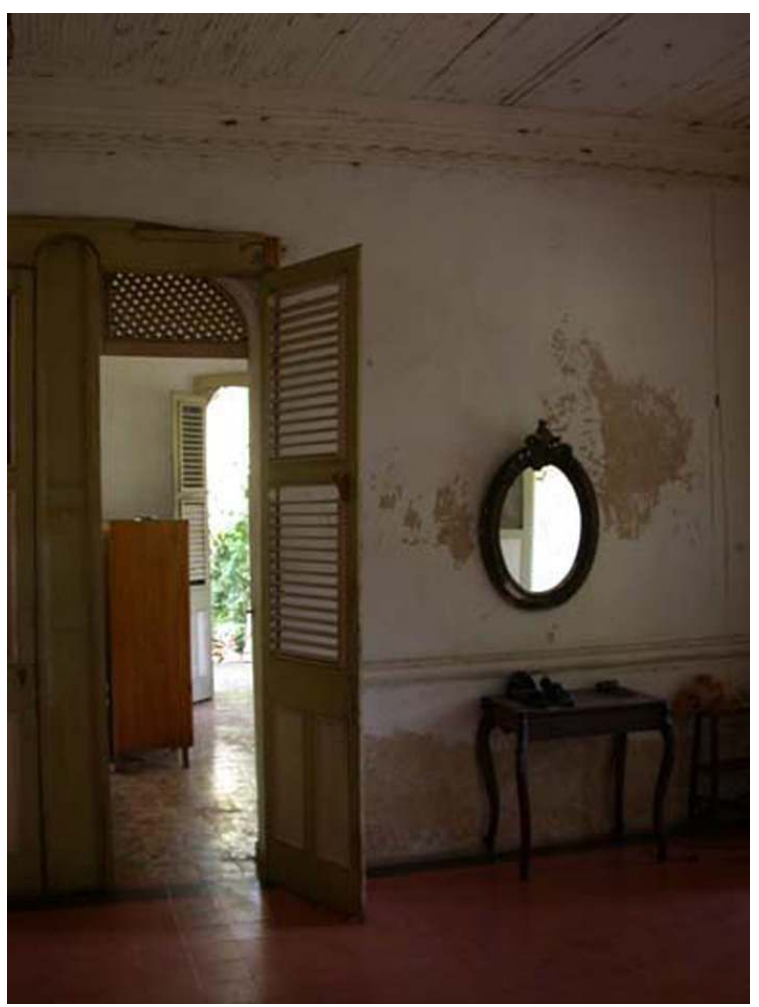

Maison de maître de habitation Goyard dans le quartier de Bel Air aux environs de Cap-Haïtien (Haïti). Détail du décor intérieur du salon, réalisé en 1911 dans un style Jugenstyl pour le président Cincinnatus Lecomte

Phot. C. Charlery (c) C. Charlery, 2003

Quelques années plus tard, au début du XIX ${ }^{\mathrm{e}}$ siècle, Robin donne une description très semblable du décor intérieur des maisons de riches planteurs situées autour de SaintPierre de la Martinique: "Les décorations en sont simples. Le pavé, ordinairement de marbre, est ce qui m'a paru de plus riche. Les murs y sont seulement blanchis, quelquefois peints ou boisés, ou garnis de papier. Grâce au climat, point de ces massives cheminées enfoncées [...] et par conséquent, point de magots et de lourds bronzes pour les décorer. Les glaces y sont rares : ce ne sont le plus souvent que ces miroirs à larges cadres [...]. On y connaît bien moins ces draperies richement frangées, ces meubles somptueux où se déroule le lampas aux brillantes couleurs, qu'étalent nos vaniteuses bourgeoises " ${ }^{80}$ (fig. $n$ $\circ 49$ ).

Dans l'Illinois, au nord de la Louisiane, les murs intérieurs étaient enduits puis chaulés et présentaient une couleur blanche caractéristique. La peinture était très peu employée et le bois gardait le plus souvent sa couleur naturelle ${ }^{81}$.

Les cheminées étaient rares, surtout aux îles. Le père du Tertre explique que "Comme il n'y a point d'hiver dans ces îles, il n'y a pas une seule cheminée dans toutes les maisons, excepté chez les gouverneurs, où elles sont un objet d'ornement plutôt que d'utilité "82. Cependant, dans certaines caféières construites en altitude à Saint-Domingue, mais aussi en Louisiane, où l'hiver peut être froid, des cheminées sont construites. 


\section{Ameublement}

90 Le mobilier est souvent rudimentaire et lorsque les meubles ont quelque apparence, ils viennent de France ou d'Amérique (fig. $\mathbf{n}^{\circ} 50$ et 51 ).

$91 \mathrm{Au} \mathrm{XVII}{ }^{\mathrm{e}}$ siècle, un coffre, une table, un lit et des bancs constituent tout l'ameublement des cases. Les personnes mariées ont des lits comme en France, mais les autres n'ont souvent que des hamacs en coton dans lesquels ils se couchent "comme les sauvages" Le hamac était en effet déjà couramment utilisé par les Indiens caraïbes.

Figure 50

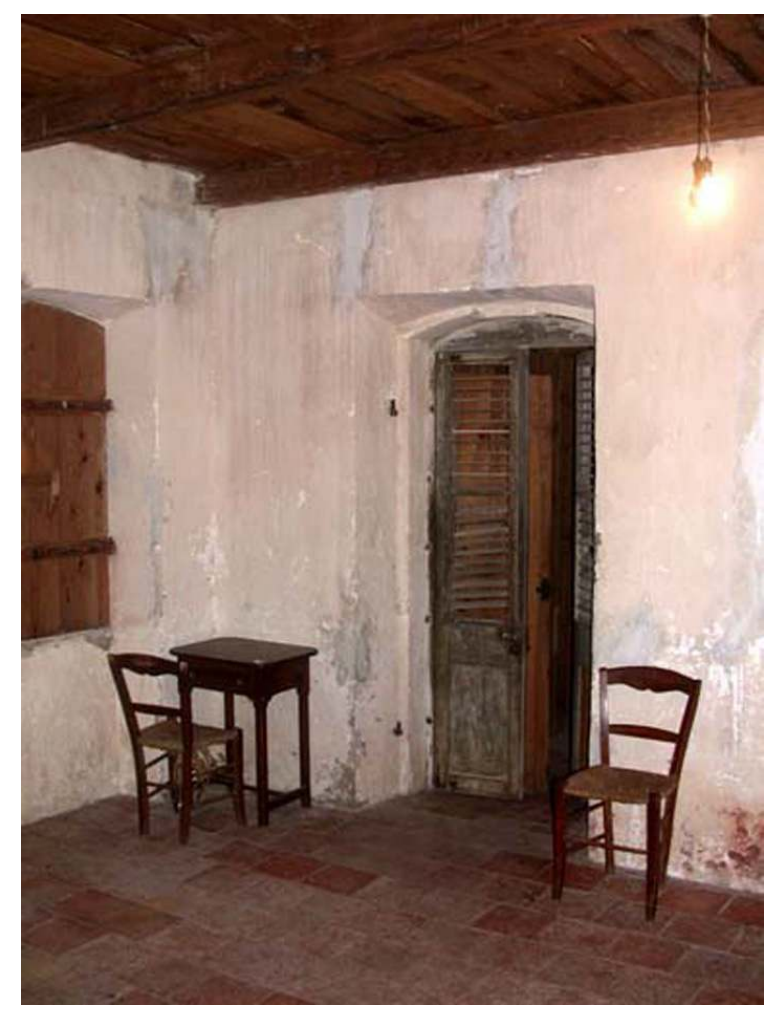

Maison de maître de l'habitation La Sucrerie aux Anses-D'Arlets (Martinique). Vue intérieure du salon tel qu'il devait être au XVIIII siècle : murs ayant reçu un badigeon à la chaux légèrement coloré et mobilier d'une grande simplicité

Phot. C. Charlery @ C C. Charlery, 2004 


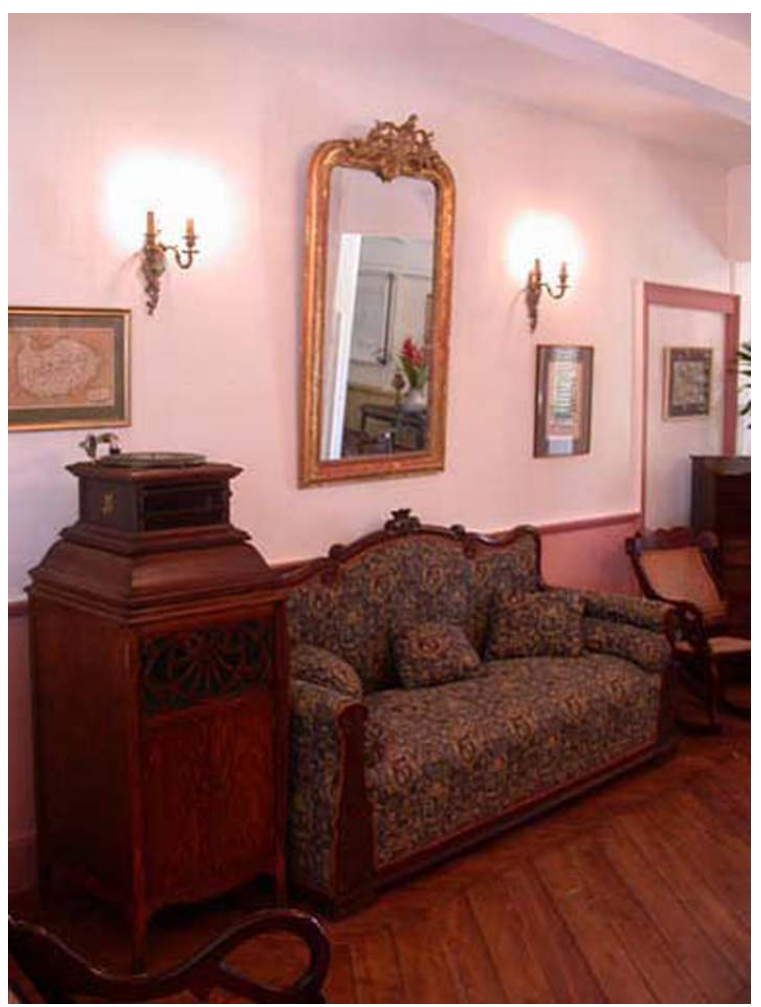

Maison de maître de l'habitation Acajou au François (Martinique). Détail du mobilier datant de la fin du XIX siècle

Phot. C. Charlery (C) C. Charlery, 2003

Nous ne tenterons pas de mener une étude exhaustive de l'évolution du mobilier dans les anciennes colonies d'Amérique, car le sujet est bien trop vaste. Nous avons choisi quelques exemples pour tenter d'évoquer l'ameublement qui garnissait les intérieurs dans les diverses couches de la société coloniale.

En 1699, la maison de maitre de l'habitation Islet à Saint-Claude en Guadeloupe possède, dans la salle principale, une "table sur son châssis pliant" avec ses huit chaises. Dans l'une des chambres, se trouvent une armoire d'acajou neuve, une couchette garnie d'un matelas et d'une paillasse et une "petite table sur son châssis tourné ". Dans la seconde chambre, il y avait une couchette sans matelas ${ }^{84}$.

Au milieu du XVIII e siècle, le mobilier n'est pas luxueux mais de bonne facture et n'a rien à envier à celui des fermes françaises. Un inventaire de 1743 décrit l'ameublement de la maison de maître de l'habitation de M. De Blaine, ancien colon, située sur la paroisse de Vieux-Habitants en Guadeloupe ${ }^{85}$. Il y a dans la salle à manger, une table et un buffet en acajou avec des pieds tournés et douze chaises empaillées en bois local. Dans l'office, un simple petit buffet en bois de rose avec un $1 / 2$ baril de sel " de France " et dans la chambre, un lit en bois du pays, " avec sa paillasse, son matelas de coton couverte de toille grise, 2 oreillers de plumes, avec leur tayes de toille blanche et la courte pointe d'indienne de Provence ". Il y a aussi une armoire en bois de rose, une petite table à tiroir, un coffre et un pot de chambre. Au grenier, une seconde chambre renferme un lit et un buffet en bois de rose. La vaisselle n'est pas particulièrement abondante et consiste en quelques pièces en faïence, telles une salière, un bol, une écuelle et un pot. Le reste est en terre cuite et en 
grès : quelques pots, terrines, plats et pichets. On trouve aussi deux jarres à eau, dont une fabriquée en Provence. Quelques objets ont un peu plus de valeur : cinq chandeliers de cuivre, une canne à pomme d'or, une longue vue, un petit cadre doré et quelques dizaines de couverts en argent avec leur "poinçon de Paris". Deux petits cadres dorés, dans lesquels se trouvaient les portraits du roi et de la reine, complètent l'inventaire.

A la fin du XVIII siècle, le mobilier n'a guère évolué, mais les ustensiles et la vaisselle sont plus recherchés, signe notable de l'enrichissement des colons à cette époque. Ainsi, en 1780, la maison de maître de l'habitation caféière de la veuve Bonneteau, située en Côte-sous-le-vent à la Guadeloupe, riche de quarante-trois esclaves, est ainsi meublée ${ }^{86}$ : dans la salle principale, se trouvent un buffet de bois de rose, quatorze chaises dont les sièges étaient en paille, quatre chaises hollandaises, deux tables en bois de mahogany, une table à plateau de marbre monté sur bois de rose et un miroir du même bois. Il y a aussi une paire de chandelier en argent, pour faire de la lumière le soir. A côté, dans l'office, se trouve un garde-manger, un chandelier en cuivre et la vaisselle, souvent ébréchée mais particulièrement abondante et presque luxueuse : quarante-huit assiettes en faïence, vingt-et-une en porcelaine, neuf plats, grands et petits, cinq soupières avec leurs plats, deux saladiers en faïence, quatre compotiers, une terrine et un cabaret avec six tasses, une théière, un petit "caffetier" et un sucrier, le tout en porcelaine. Les couverts, au nombre de soixante-dix-huit pièces, sont tous en argent. Il y a aussi du cristal : quatre salières dont les bords étaient dorés, deux portes huiliers avec leurs burettes, deux moutardiers, deux carafes et six verres à liqueur. Outre deux carafes supplémentaires en verre, on trouve un mortier de marbre avec son pilon. Enfin, dans la troisième pièce qui sert de chambre principale, se trouve un grand lit en bois de rose, garni " de sa paillasse, matelas, tour de lit, courtepointe d'indienne, traversin \& oreiller", un buffet en bois de mahogany, une table en bois de rose, un petit miroir et une "boete à commodité ". Il y a enfin une grande armoire en bois de courbaril qui renfermait le linge de maison, lui aussi abondant: onze nappes, cinquante-neuf serviettes, du tissu, neuf paires de draps, six hamacs en coton, qui peuvent sans doute servir de lits d'appoint et les habits de madame Bonneteau. L'armoire renferme enfin de nombreux objets en or, comme une tabatière, un étui, un cure-dent, une paire de boucles, une paire de boutons, un crochet, une montre et une paire de lunettes. Le galetas étant habitable, chaque chambre du haut est garni d'un lit. On voit que le mobilier en bois local était courant.

L'habitation des époux Lagarde, près de Basse-Terre en Guadeloupe, est moins luxueusement garnie, mais semble représentative de cette bourgeoisie de couleur qui a un pouvoir croissant au début du XIX ${ }^{\mathrm{e}}$ siècle. Le mobilier est assez abondant : deux tables, deux glaces, une armoire, un canapé et six chaises, un petit sofa, une table de toilette, un lit à deux dossiers garni de deux matelas, d'un traversin et d'un oreiller, ainsi qu'un peu de linge de maison. Cependant, la vaisselle ne consiste qu'en quelques pièces d'argenterie, principalement des couverts. Le couple possède tout de même trois esclaves pour aider aux tâches ménagères, dont une cuisinière ${ }^{87}$.

Enfin, au bas de l'échelle, il y a les petites habitations caféières ou vivrières des mulâtres ou des nègres libres, dont les maisons sont très simplement meublées. Celle que la jeune câpresse Céline achète dès son affranchissement en 1817 sur la paroisse de Rivière-Salée à la Martinique, est simplement garnie d'une " petite table en bois du pays, quatre chaises, quelques pièces de vaisselle et de ménage et une petite table de toilette " ${ }^{88}$. Céline ne dispose, pour l'aider sur cette petite habitation caféière, que d'une unique esclave. 


\section{Les cuisines}

Figure 52

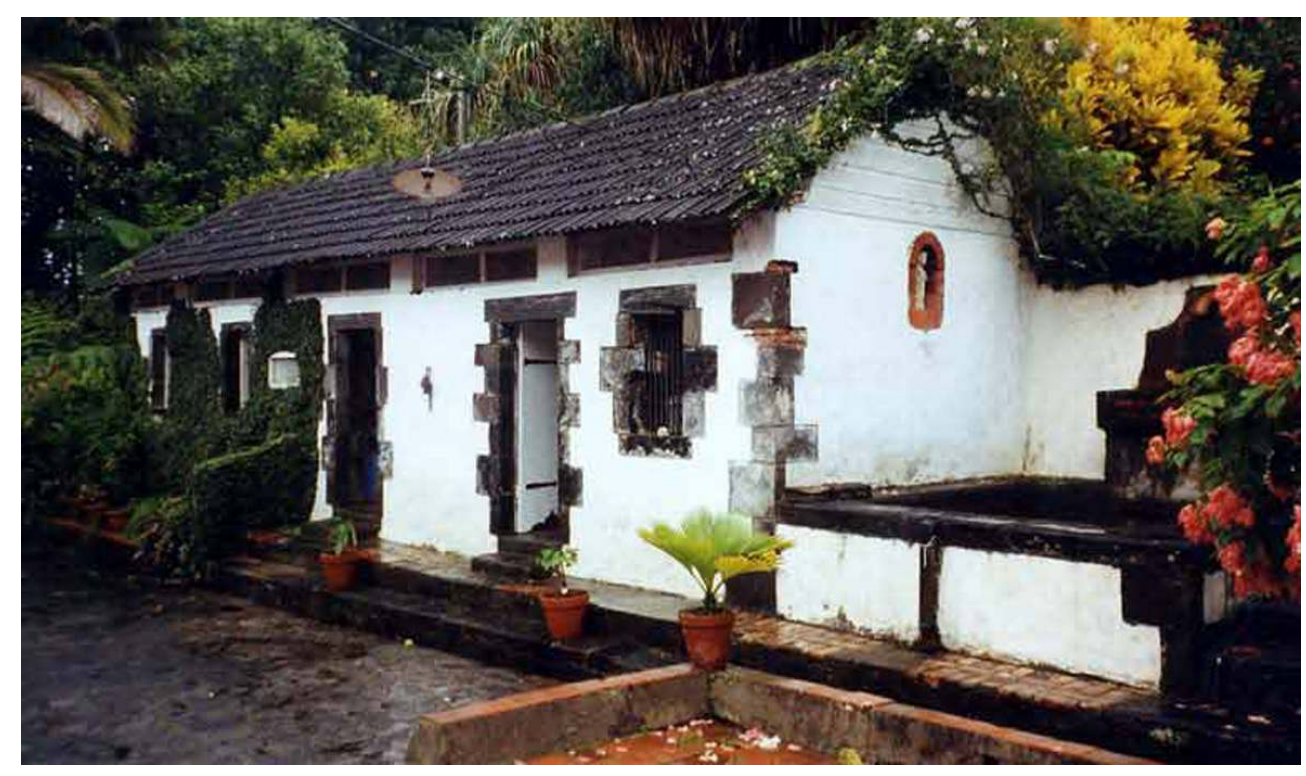

Cuisine de l'habitation sucrerie Beauséjour à Grand'Rivière (Martinique). Cette cuisine, séparée de la

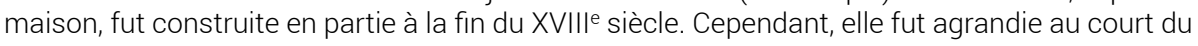
premier quart du XIX siècle. C'est de cette époque que date le grand bassin extérieur

Phot. C. Charlery (C) C. Charlery, 1999

La cuisine est presque toujours séparée et construite à distance de la maison principale (fig. $n^{\circ} 52$ ). Le risque $d^{\prime}$ incendie est sans doute pour beaucoup dans cette disposition, mais la volonté de dissocier des espaces sociaux différents semble évidente, car, dans bien des cas, la cuisine est réservée aux esclaves domestiques et une chambre à nègre lui est parfois adjointe.

$\mathrm{Au}$ début de la colonisation, le père du Tertre rapporte que "La cuisine est toujours séparée de la case. Elle est composée d'un petit appentis de cinq ou six pas au-dessous du vent. On pend la marmite avec un gros bâton posé sur deux fourches, et on fait cuire en commun chez les habitants de très moyenne condition toutes les viandes : mais chez les plus riches la cuisine est murée comme la case des particuliers "89 (fig. $\mathrm{n}^{\circ} 53$ ).

$100 \mathrm{Au} \mathrm{XVIII}{ }^{\mathrm{e}}$ siècle, la cuisine présentait souvent un plan carré. Contre le mur maçonné du fond se trouvait le massif du potager et le four dont le foyer circulaire était rejeté à l'extérieur, donnant une silhouette caractéristique à l'édifice. Il subsiste plusieurs exemples de telles dispositions, comme la cuisine de l'habitation Campry à Baillif (fig. $\mathrm{n}$ -54) ou celle d'une maison rurale située sur le morne Maillant, près de Basse-Terre, en Guadeloupe. En Guyane, sur l'habitation Maçaye à Rémire, construite vers 1735 et dont les fondations ont été mises au jour pendant une campagne de fouilles archéologiques, on retrouve un plan similaire.

101 Ces cuisines sont bien entendu équipées de quelques ustensiles comme en témoigne l'inventaire de la veuve Bonneteau en 1780 : il y a une chaudière, une poêle, un poêlon, un petit réchaud et un grand canari ${ }^{90}$ (fig. $n^{\circ} 55$ ). 
Figure 53

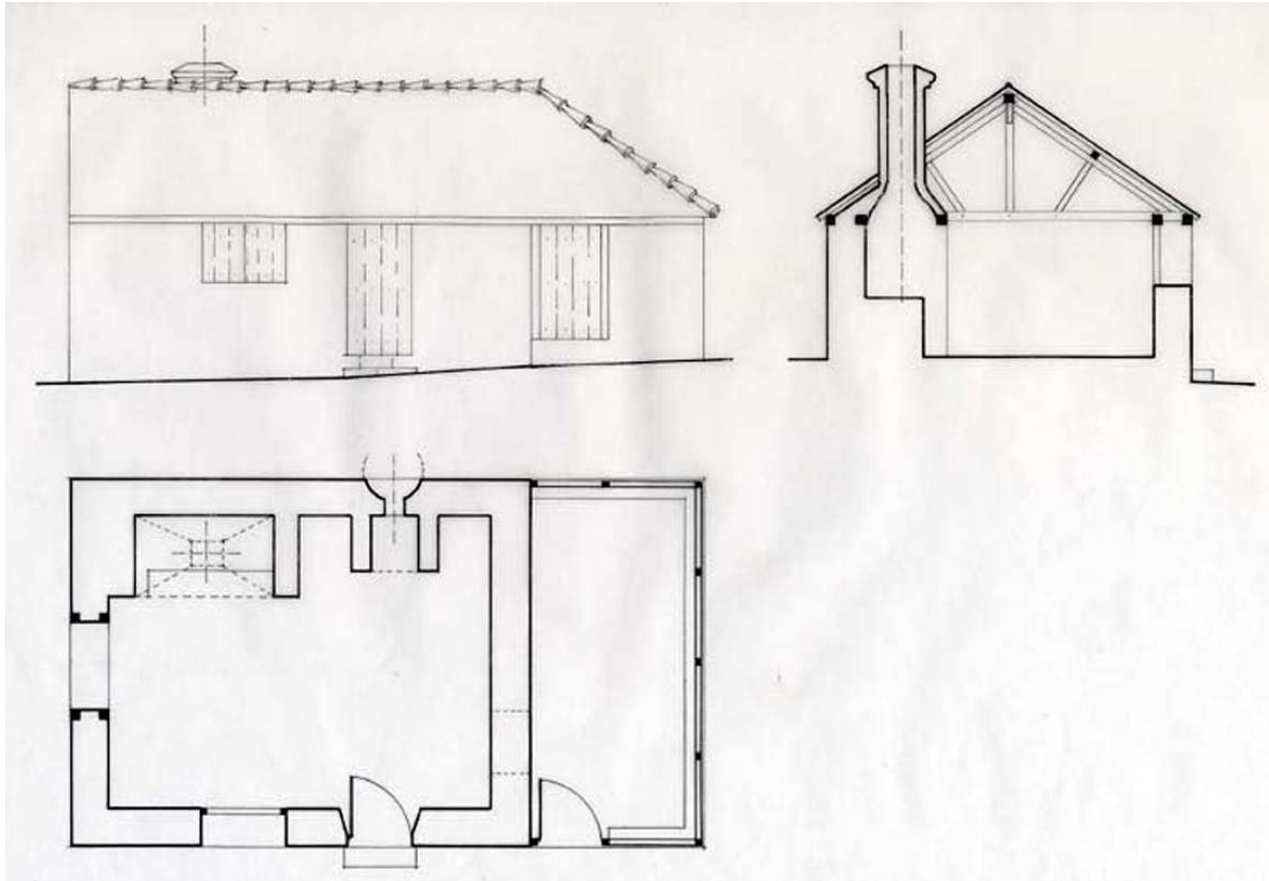

Plan, coupe et élévation de la cuisine de l'habitation La Sucrerie aux Anses-D'Arlets (Martinique). La cuisine fut construite à la fin du XVIII siècle. Cependant, une petite pièce lui fut adjointe au début du XIXe siècle, afin de servir de chambre pour les esclaves domestiques. Les vestiges d'un four ont été récemment découverts

Repro. C. Charlery (c) C. Charlery, 2004

Figure 54

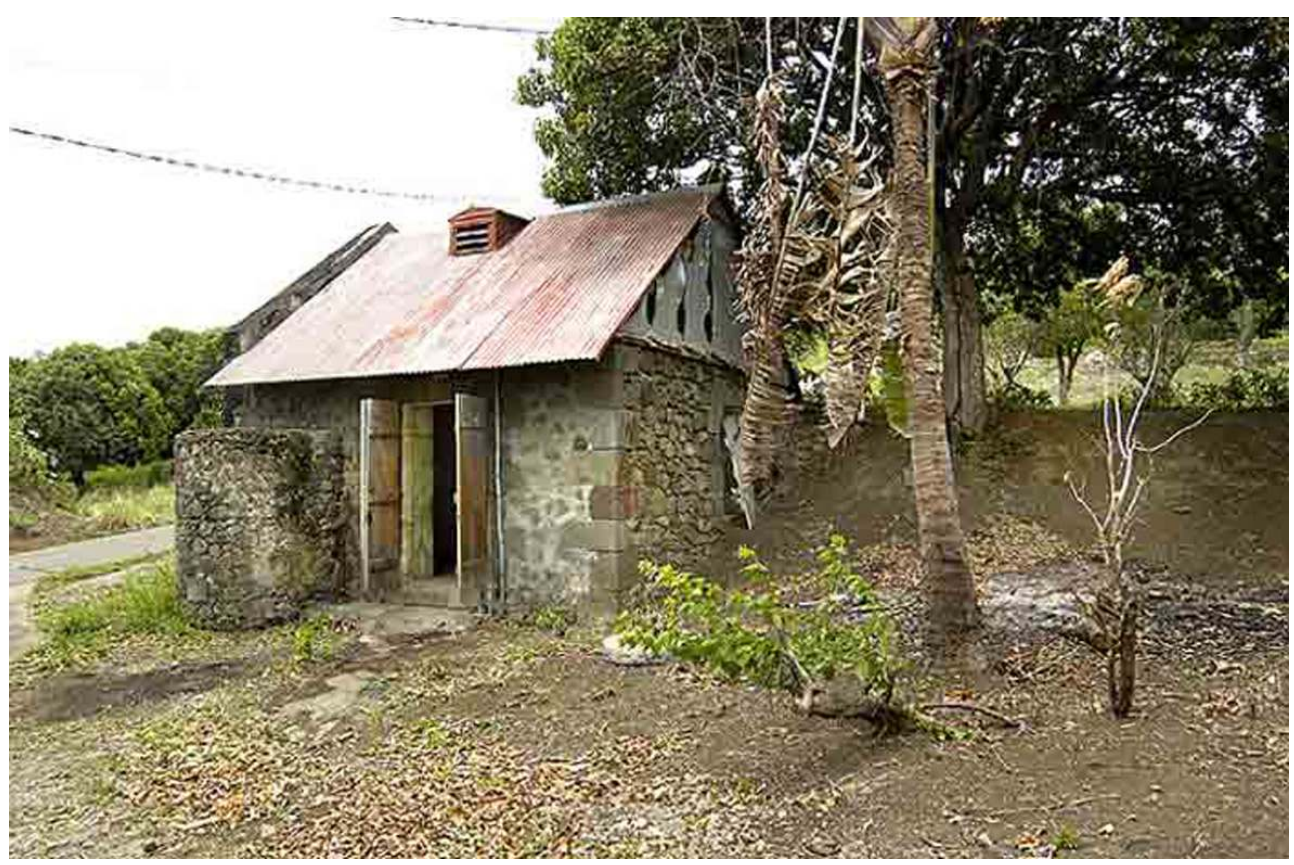

Cuisine de l'habitation sucrerie Campry à Baillif (Guadeloupe). Le four, visible depuis l'extérieur, est aujourd'hui encore conservé

Phot. Inv. M. E. Desmoulins @ Inventaire général, ADAGP, 2002 
Figure 55

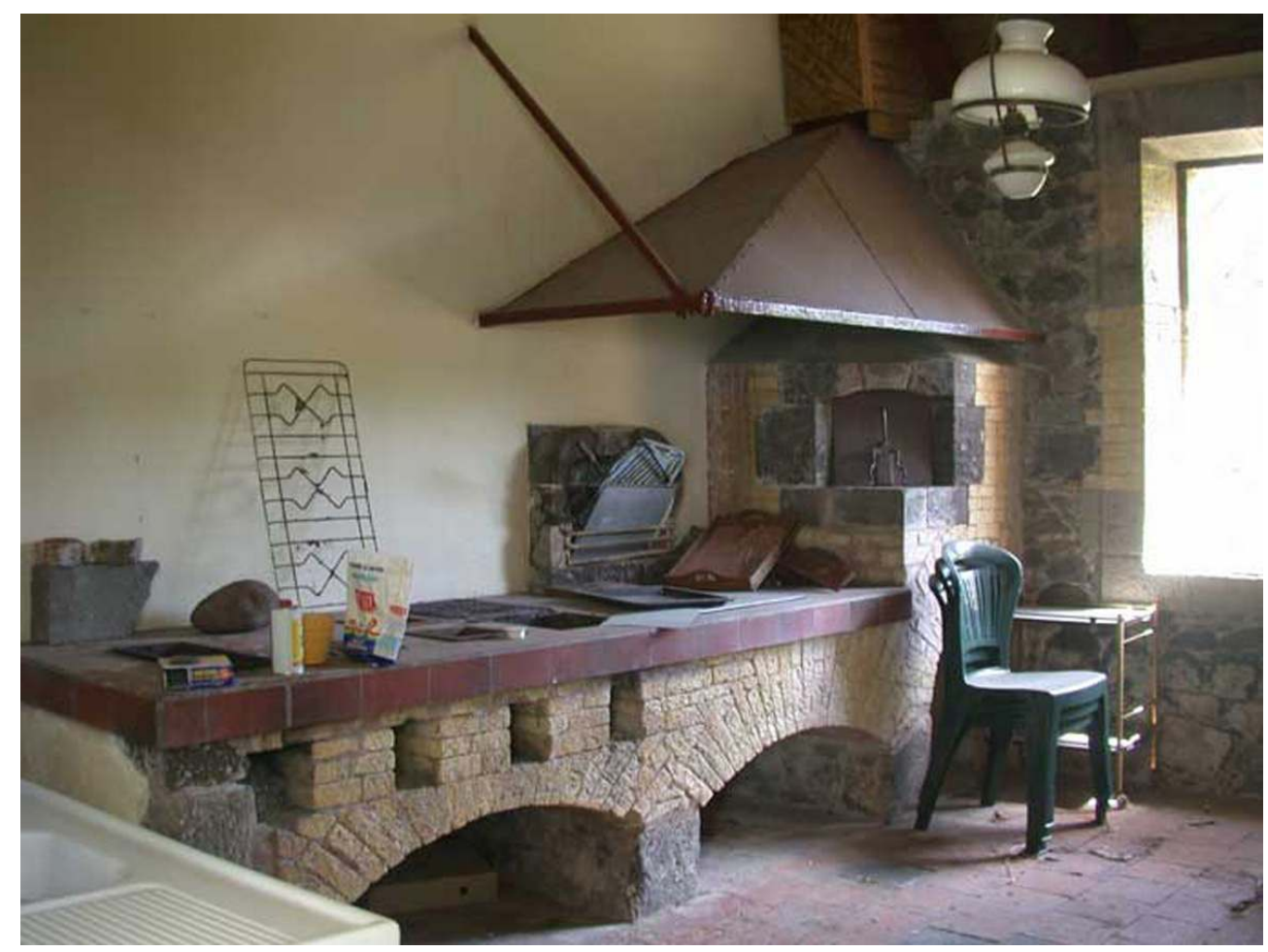

Cuisine de la maison du directeur du Génie à Basse-Terre (Guadeloupe). Vue de l'intérieur, du potager et du four, construit dans les années 1860

Phot. C. Charlery (c) C. Charlery, 2003

\section{Les jardins}

\section{La clôture}

La grandeur et la magnificence des habitations coloniales doit beaucoup aux grandes allées d'arbres qui bordent les propriétés ou qui séparent les cultures. Lors de son séjour aux îles à la fin du XVII ${ }^{e}$ siècle, le père Labat relève souvent la majesté de ces plantations. A Saint-Domingue, lorsqu'il arrive près de Léogane, il note: "Je fus bien satisfait de la beauté des terres et des chemins par lesquels nous passâmes pour y arriver. Il me semblait être dans les grandes avenues du parc de Versailles [...] Les habitations et les maisons que l'on trouve le long de ces magnifiques chemins ont de belles avenues de grands arbres, chènes ou ormes, plantés à la ligne et entretenus avec soin. "91. Parfois, ces allées peuvent être très longues, comme le rapporte Moreau de Saint-Méry dans les années 1780: "L'on aperçoit sur l'habitation Duplaa, une allée de 400 toises de long, garnie d'un double rang de chênes très élevés, et dans lesquels on remarque le long et constant effet de la brise d'est " ${ }^{\prime 2}$.

103 Cependant, à la fin du XVIII ${ }^{e}$ siècle, Moreau de Saint-Méry remarque que depuis les années 1750, les allées de citronniers dans la plaine du Cap ont été remplacées par des allées de campèches ${ }^{93}$ (fig. $\mathbf{n}^{\circ}$ 56).

104 Parfois, lorsque la plantation donne sur la route coloniale ou un grand chemin de communication, un immense portail en maçonnerie ou en pierre de taille est élevé, 
donnant un aspect particulièrement cossu à la propriété, même si la maison est modeste. C'est le cas de nombreuses habitations-sucreries de la plaine du Cap ou de Port-au-Prince ${ }^{94}$ (fig. $\mathbf{n}^{\circ}$ 57).

\section{Figure 56}

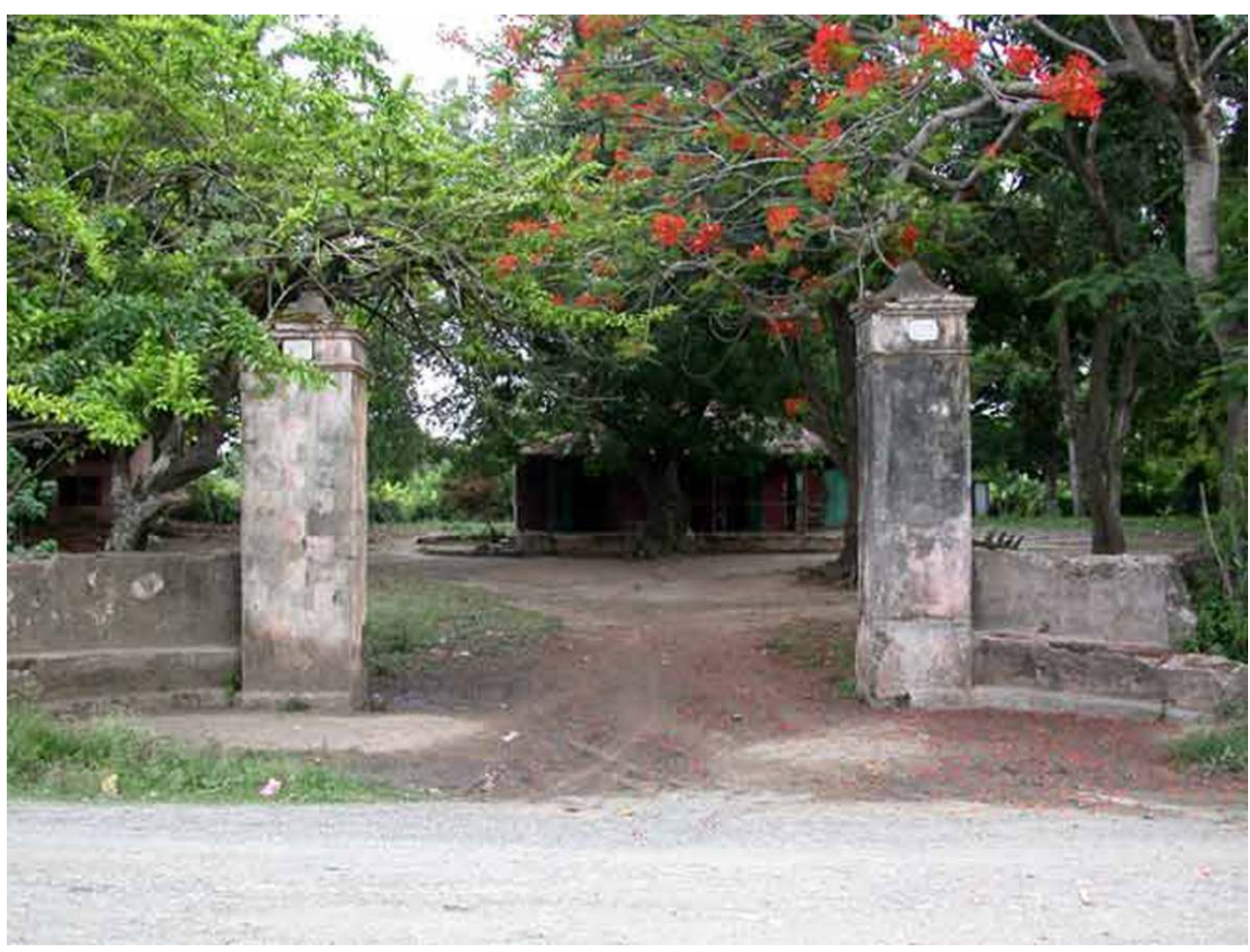

Portail d'entrée de l'ancienne habitation sucrerie Destreille, près du Cap-Haïtien (Haïti). Datant de la fin du XVIII siècle, ce portail a conservé son passage piéton adjacent. Une porte garnissait le portail à l'époque coloniale

Phot. C. Charlery @ C C. Charlery, 2003. 
Figure 57

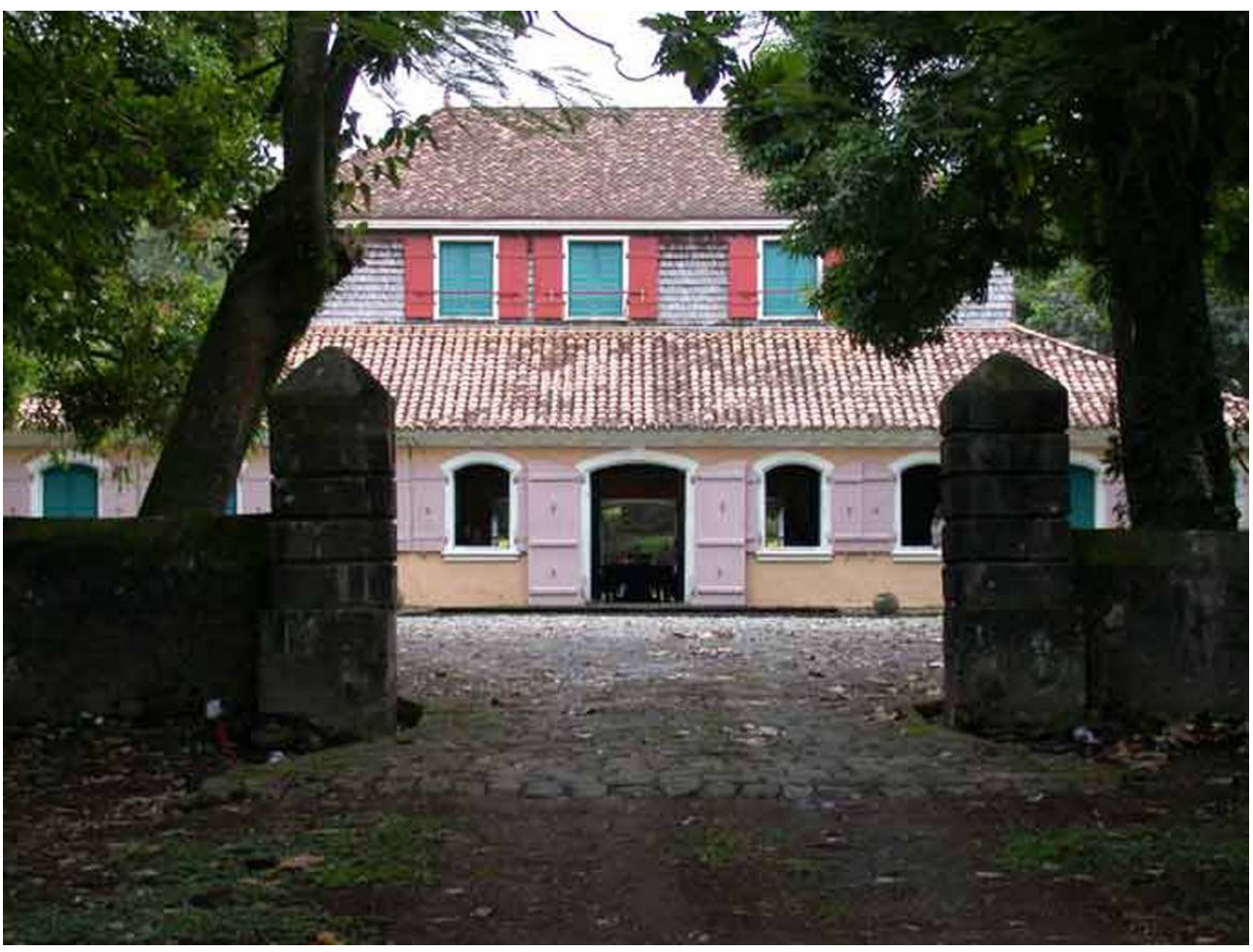

Portail d'entrée de l'habitation sucrerie Pécoul à Basse-Pointe (Martinique)

Phot. C. Charlery @ C. Charlery, 2003

\section{Jardins d'agrément}

Plusieurs cartes anciennes indiquent par ailleurs que les jardins sont assez réguliers, le plus souvent à la française (fig. $\mathbf{n}^{\circ} \mathbf{5 8}$ ).

106 Ils peuvent être agrémentés d'une fontaine ou d'un bassin animé d'un jet, comme à l'habitation Leyritz à la Martinique (fig. $\mathbf{n}^{\circ}$ 59). 
Figure 58

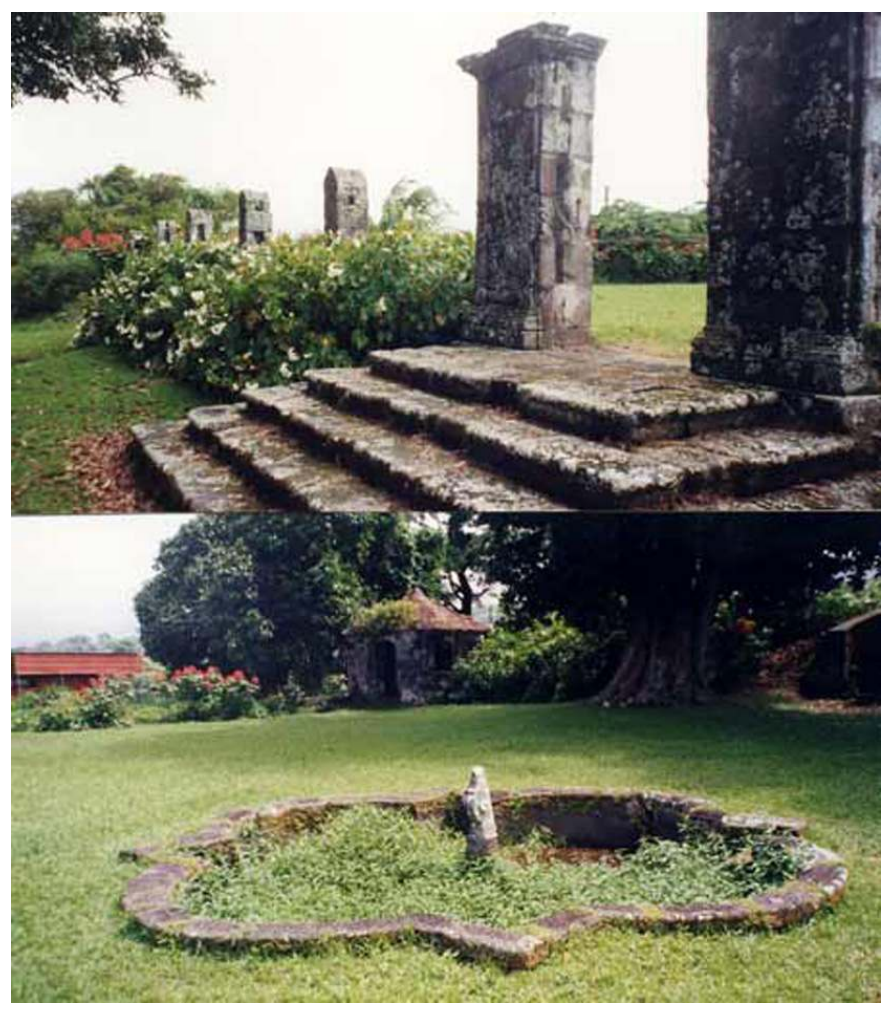

Jardin d'agrément de l'habitation sucrerie Leyritz à Basse-Pointe (Martinique). Ce jardin, probablement aménagé dans la seconde moitié du XVIII siècle, consistait en un grand carré clos, agrémenté d'un bassin, d'une fontaine et d'un lavoir. La grande symétrie de l'espace suggèrerait l'existence, jadis, d'un jardin à la française

Phot. C. Charlery (c) C. Charlery, 2000 
Figure 59

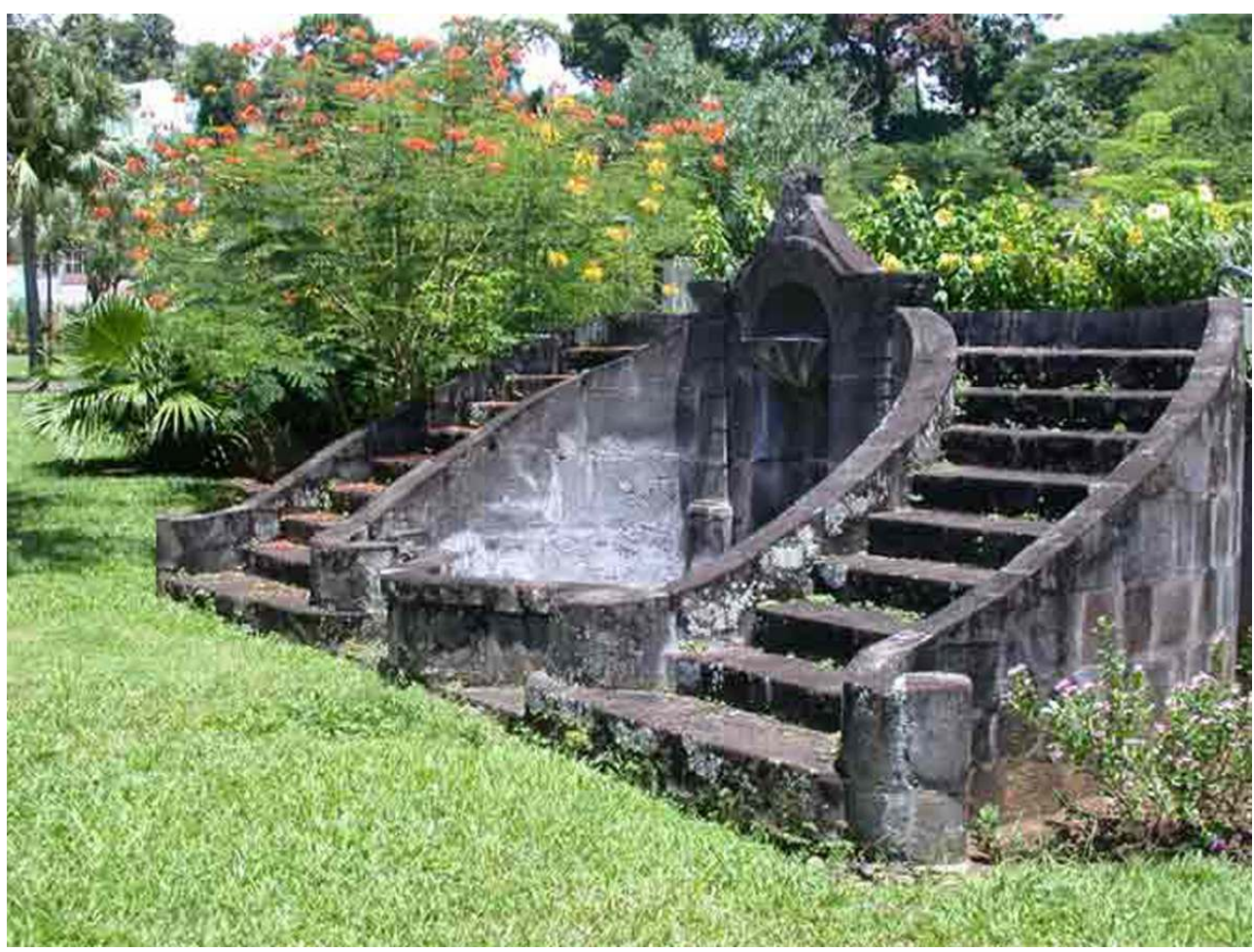

Fontaine de I'habitation Château-Sœurette à Trois-Rivières (Guadeloupe). Cette fontaine, encadrée d'un escalier à double volée, était à l'origine dans le jardin d'une habitation coloniale. Démontée il y a quelques années, la fontaine est aujourd'hui au centre du bourg

Phot. C. Charlery (c) C. Charlery, 2004

\section{Jardins potagers et fruitiers}

Dans bien des cas, le jardin potager et les vergers sont clos de murs, probablement afin de limiter les vols, d'empêcher que le bétail ne détruise les récoltes et que le vent ne casse les branches. Déjà en 1671, la description de l'habitation des Carmes, installée sur les pentes du Volcan dominant Basse-Terre en Guadeloupe, confirme l'ancienneté de ces dispositions: "Devant la caze il y a un joly jardin fort propre et commode qui est renfermé d'une muraille sèche "95. Plus tardif, mais non moins significatif, il faudrait citer le jardin de l'habitation Pécoul sur la paroisse de Basse-Pointe en Martinique, qui conserve, aujourd'hui encore, son haut mur autour du verger.

108 Il est malheureusement impossible, en l'absence d'étude sur le sujet, de retracer l'évolution des arbres fruitiers qui sont plantés, ni même de savoir avec précision quels sont les légumes récoltés dans les potagers.

\section{Le colombier}

Le colombier s'apparente, comme en France, à un symbole seigneurial. Dans les territoires français d'Amérique, où les colons n'appartenaient pas forcément à l'aristocratie, le colombier donnait plus simplement l'apparence d'un fief noble et symbolisait une certaine réussite. A la fin du XVIII ${ }^{\mathrm{e}}$ siècle, le colombier était encore un élément de richesse et marquait la prééminence des bourgeois ${ }^{96}$. Cependant, il ne faut pas 
oublier que l'élevage des pigeons procure une réserve de viande non négligeable et pratique, la petite taille des oiseaux facilement consommables évitant les problèmes de conservation.

Figure 60

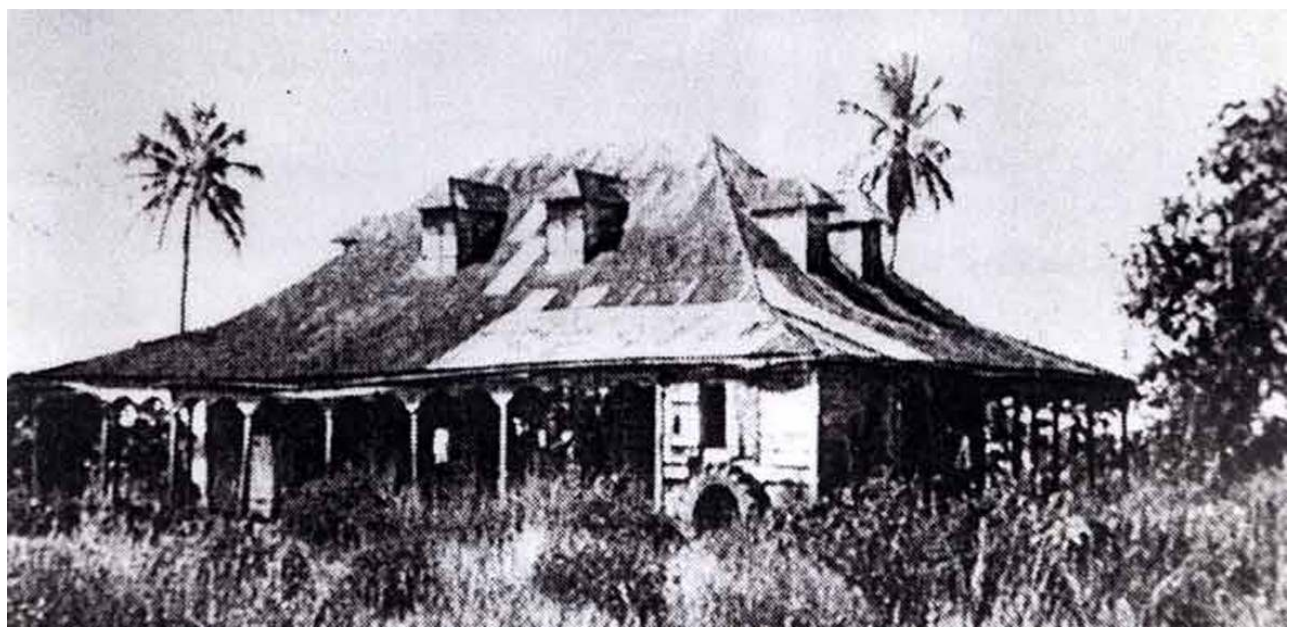

Vue de l'ancienne maison de maître de l'habitation sucrerie La Ramée à Sainte-Rose (Guadeloupe). Cette photo ancienne nous montre une maison coloniale, construite juste après le grand cyclone de 1928. Avec sa galerie, elle pourrait être considérée comme un archétype de la maison coloniale dans les territoires français d'Amérique. Elle fut malheureusement détruite par le cyclone Hugo en 1989

Repro. C. Charlery @ C C. Charlery, 2003

110 Si quelques colombiers furent construits en maçonnerie, beaucoup étaient en bois, à l'image de celui que l'on trouvait sur la plantation de la veuve Bonneteau en Guadeloupe et qui consistait en "un colombier de dix pieds quarrés aussi en charpente, en très mauvais état " ${ }^{97}$.

111 Il ne subsiste aujourd'hui que très peu de colombiers dans les anciennes colonies françaises de l'Amérique. Celui conservé sur l'habitation Pécoul, à la Martinique, est attesté dans un inventaire de 1764. Il consiste, à cette époque, en un pavillon à deux niveaux, de 16 pieds carrés, bâti à chaux et à sable, orné d'une génoise, couvert en tuiles, avec un cachot dans sa partie basse. Notons que cette disposition doit être assez commune, puisque déjà à la fin du XVII ${ }^{e}$ siècle, le père Labat décrivant le colombier du couvent des pères de Basse-Terre, précise que "le dessous servoit de prison pour leurs nègres $"{ }^{98}$ (fig. $\mathbf{n}^{\circ} \mathbf{6 0}$ ).

\section{Conclusion}

112 Au terme de cette étude, il nous semble évident qu'une architecture spécifique s'est développée en milieu rural dans l'ensemble des colonies françaises de l'Amérique tropicale et subtropicale. Dans l'état actuel des recherches, la compréhension du processus de sa diffusion reste incertaine, et l'on ne peut qu'émettre des hypothèses. Cependant, nous l'avons vu, la récurrence de certaines distributions intérieures semble écarter le simple fait du hasard, car dans toutes les couches de la société coloniale, des riches planteurs aux affranchis ayant acquis des micro-propriétés, les maisons avaient des plans très similaires. Bien entendu, la vie sur les propriétés variait énormément selon la condition sociale des propriétaires. 
113 Cette architecture, devenue emblématique dès la fin du XVIII ${ }^{\mathrm{e}}$ siècle, est aujourd'hui en voie de disparition: en effet, l'arrivée de matériaux modernes, comme le béton, et l'influence du modèle de la villa métropolitaine, ont mis à mal les traditions architecturales, notamment en matière de maîtrise du confort thermique et de la ventilation naturelle à l'intérieur des maisons.

\section{NOTES}

1. Petitjean-Roger, Jacques. Les premières habitations de la Martinique. Monuments historiques, Architecture d'outremer, Paris : Editions CNMHS, 1981, p. 37.

2. Moreau de Saint-Mery, Médéric-Louis-Elie. Description topographique, physique, civile, politique et historique de la partie française de Saint-Domingue; avec des observations générales sur la population, accompagnées de détails les plus propres à faire connaître l'état de la colonie à l'époque du 18 octobre 1789. Tome 1. Philadelphie, 1797, p. 11. MédéricLouis-Elie Moreau de Saint-Méry est né en 1750 à la Martinique et appartient à une veille famille créole installée sur l'île depuis le milieu du XVII ${ }^{e}$ siècle. Avocat, il s'embarque en 1776 pour l'île de Saint-Domingue et s'installe au Cap-Français. En 1781, il épouse une jeune femme créole originaire de la Louisiane qui le fait entrer dans le monde de la franc-maçonnerie, ce qui lui procure des alliances précieuses. Installé en France, il effectue dès 1787 un grand voyage aux Antilles et entreprend sa Description de la partie française de l'île de Saint-Domingue. Son ouvrage est capital et constitue une source inépuisable sur la colonie à la fin de l'Ancien Régime. Pris dans la tourmente de la Révolution française, il quitte la France en 1793 et s'exile aux Etats-Unis pendant cinq années. De retour à Paris, il reprend momentanément une place influente sous l'Empire, mais est révoqué en 1806. Moreau de Saint-Méry vit désormais dans la simplicité et il meurt à Paris en 1819.

3. Du TertrE, père Jean-Baptiste. Histoire générale des Antilles habitées par les Français. Fortde-France : E. Kolodziej - E.D.C.A., rééd. de 1978, tome 2, p 456-457. Le père du Tertre, dominicain, arrive aux Antilles dès les premières années de la colonisation; il débarque en Guadeloupe en 1640 et y séjourne sept ans. Il effectue un second voyage aux Antilles de 1656 à 1657. Son ouvrage est d'une importance capitale, car il porte sur une période généralement peu documentée: l'installation des premiers colons et la première moitié du XVII siècle.

4. Le Roux, Yannick. L'habitat guyanais sous l'Ancien Régime ; étude de la culture matérielle . Thèse non publiée, Ecole des hautes études en sciences sociales, Paris, 1995, p. 2-5.

5. Debien, G. Les Grand'cases des plantations à Saint-Domingue aux XVII ${ }^{\mathrm{e}}$ et $\mathrm{XVIII}^{\mathrm{e}}$ siècles. Annales des Antilles, bulletin de la société d'histoire de la Martinique. Fort-de-France, 1970, $\mathrm{n}^{\circ} 15$, p. 4 .

6. Lafleur, Gérard. Saint-Claude, histoire d'une commune de Guadeloupe. Paris : Karthala, 1993, p. 71.

7. Du Tertre, père Jean-Baptiste. Histoire générale des Antilles habitées par les Français. Fortde-France : E. Kolodziej - E.D.C.A., rééd. de 1978, tome 2, p. 457.

8. Lafleur, Gérard. Saint-Claude, histoire d'une commune de Guadeloupe. Paris : Karthala, 1993 , p. 15.

9. Moreau de Saint-Mery, Médéric-Louis-Elie. Description topographique, physique, civile, politique et historique de la partie française de Saint-Domingue ; avec des observations 
générales sur la population, accompagnées de détails les plus propres à faire connaître l'état de la colonie à l'époque du 18 octobre 1789. Tome 1. Philadelphie, 1797, p. 106.

10. Choelcher, Victor. Des colonies françaises : abolition immédiate de l'esclavage. 1842. Victor Schoelcher, un des plus ardents militants du combat anti-esclavagiste, est à l'origine du décret d'abolition de l'esclavage, finalement proclamé en 1848 dans les colonies françaises.

11. Arch. dép. Martinique. Notaire Gabourin, 16 octobre 1828 : Vente d'une habitation par Dessablon à Rémy, et Arch. dép. Martinique, Notaire Gardié, 7 novembre 1864 : donation d'une habitation par monsieur Rémy et dame Céline à leur fille.

12. Arch. dép. Martinique. Les libres de couleur et la société domingoise à la fin de l'Ancien Régime. Catalogue de l'exposition : Des constitutions à la description de Saint-Domingue, la colonie française en Haïti vue par Moreau de Saint-Méry. Fort-de-France, 2004, p. 13-25.

13. Labat, révérend père Jean-Baptiste. Nouveau voyage aux isles de l'Amérique, contenant l'histoire naturelle de ces pays, l'origine, les mœurs, la religion et le gouvernement des habitans anciens et modernes (édition de 1742). Saint-Joseph: Courtinard, rééd. de 1979, p. 225-226. Le révérend père Jean-Baptiste Labat, dominicain, effectue un long séjour aux Antilles, de 1694 à 1705. Il met sa grande connaissance au service de la colonie et propose de nombreux perfectionnements, en particulier sur la manière de fabriquer le sucre. Son ouvrage constitue une description précise des îles à la fin du XVII ${ }^{e}$ siècle, quelques dizaines d'années après le père du Tertre.

14. Labat, révérend père Jean-Baptiste. Nouveau voyage aux isles de l'Amérique, contenant l'histoire naturelle de ces pays, l'origine, les mœurs, la religion et le gouvernement des habitans anciens et modernes (édition de 1742). Saint-Joseph : Courtinard, rééd. de 1979, p 71-72.

15. Debien, G. Les Grand'cases des plantations à Saint-Domingue aux XVII ${ }^{\mathrm{e}}$ et XVIII ${ }^{\mathrm{e}}$ siècles. Annales des Antilles, bulletin de la société d'histoire de la Martinique. Fort-de-France, 1970, $n^{\circ} 15, \mathrm{p} 16$

16. Les Affiches Américaines. Bihebdomadaire, Le Cap Français (Saint-Domingue), samedi 9 mars 1776.

17. Liget, Louis. La nouvelle maison rustique... Paris, 1700.

18. Prefontaine, chevalier de. Maison rustique, à l'usage des habitants de la partie de la France équinoxiale connue sous le nom de Cayenne. Paris : C.-J.-B. Bauche, 1763.

19. De Wimpffen, baron Alexandre Stanislas. Voyage à Saint-Domingue, 1788, 1789 et 1790. Paris : chez Cocherie, an V-1797, p. 113. Le baron de Wimpffen, voltairien et épris de lumière, est issu de la noblesse allemande. Il entreprend un voyage à Saint-Domingue à la fin de l'Ancien Régime, de 1788 à 1790. Son ouvrage, bien plus court que celui de Moreau de Saint-Méry, reste une source importante sur les mœurs et habitudes de vie de la société coloniale dans l'ancienne colonie française.

20. Vitry, Urbain. Le propriétaire architecte, contenant des modèles de maisons de ville et de campagne. 1827, p. 8.

21. Cointeraux, François. Traité de la construction des manufactures et des maisons de campagne. Paris : l'Auteur, 1791, p. 113.

22. Cointeraux, François, Traité de la construction des manufactures et des maisons de campagne. Paris, l'Auteur, 1791, p. 122.

23. Vitry, Urbain. Le propriétaire architecte, contenant des modèles de maisons de ville et de campagne. 1827, p. 22-23.

24. Cointeraux, François. Traité de la construction des manufactures et des maisons de campagne. Paris : l'Auteur, 1791, p. 122.

25. Arch. dép. Guadeloupe. Notaire Mollenthiel, 10 octobre 1817, Inventaire des biens de Sieur de Blaine dressé le 19, 20 et 21 février 1743. 
26. De Wimpffen, baron Alexandre Stanislas. Voyage à Saint-Domingue, 1788, 1789 et 1790. Paris : chez Cocherie, an V-1797, p. 113.

27. Archives privées : Inventaire de l'habitation De Lislettes faite par Isac Duquerry, 4 août 1699.

28. Caom, E 163, 22 mai 1731, Habitation L'Islet.

29. Caom, E 276, 2 novembre 1765, Contrat de vente de l'habitation L'Islet.

30. Arch. dép. Guadeloupe. Notaire Hébert, 12 mai 1779, Habitation Verrone.

31. Arch. dép. Guadeloupe. Notaire Mollenthiel, 16 et 17 mai 1780, Inventaire des biens dépendant de la succession d'Angélique Bonneteau.

32. Le Roux, Yannick. Une habitation en Guyane au XVIII ${ }^{e}$ siècle. Cayenne: Inspection Académique de la Guyane, 1990, p. 20.

33. Lourdes, Rizo Aguilera. Arquitectura agroindustrial colonial cafetalera s. $X X^{e}$ en Santiago de Cuba. Thèse de doctorat, Université de Santiago de Cuba, 1990.

34. Robin. Voyage à l'intérieur de la Louisiane, de la Floride occidentale et dans les Iles de la Martinique et de Saint-Domingue. Paris : F. Buisson, 1807. Robin effectue un voyage vers les Amériques de 1802 à 1806. Il débarque d'abord à la Martinique, avant de poursuivre vers la Floride, la Louisiane et de remonter le Mississippi vers Saint-Louis.

35. Les Affiches Américaines. Hebdomadaire, Le Cap français (Saint-Domingue), 19 février 1766, (avis divers).

36. Plaw, John. Architecture rurale ou modèles de bâtiments, depuis la chaumière la plus simple jusqu'au plus élégant château, plusieurs desquels ont été exécutés par Monsieur John Plaw, 1800.

37. Wood, John. A serie of plans for cottages or habitations of labourer, either in husbandry, or the mecanic arts, adapted as well to town, as the country, rééd. 1792.

38. Charlery, Christophe. De l'habitat des esclaves aux cases deux-pièces. Actes du colloque PNR Architecture : Habiter son territoire (29 avril 2003). Pointe-à-Pitre, parution 2005.

39. Peterson, Charles. Early Sainte-Genevieve and its architecture. The Missouri Historical Review. Columbia: Floyd C Schoemaker, janvier 1941, p. 216.

40. Estienne, Charles, Liebault, Jean. L'agriculture et maison rustique. Lyon : pour Jacques du Puys, 1583.

41. Alexendroff, Georges, Alexendroff, Jeanne-Marie. Architectures et climats : Soleil et énergies naturelles dans l'habitat. Paris : Editions Berger-Levrault, 1982, p. 143-146.

42. Caom DFC Guadeloupe/Carton 35/n 1449 : Mémoire sur le projet de construction d'un logement pour le directeur des fortifications et les bureaux de la sous direction, 1863.

43. Goerg, Odile. La Guinée Conakry. Rives coloniales, architectures de Saint-Louis à Douala. Marseille : Ed. Parenthèses et Ed. de l'Orstom, 1993, p. 90.

44. Gibbs, James. Book of architecture containing designs of buildings and ornaments. Londres, 1728.

45. Morrison, Hugh. Early american architecture, from the first colonial settlements to the national period (édition de 1952). New York : Dover Publications Inc, 1987, p. 288.

46. Charlery, Christophe. De l'habitat des esclaves aux cases deux-pièces. Actes du colloque PNR Architecture : Habiter son territoire (29 avril 2003). Pointe-à-Pitre, parution 2005.

47. Perez Monta, Eugenio. Casas Coloniales de Santo Domingo. Barcelone : éditions Caspe, 1980. 48. Shat Vincennes, 7F62.

49. Charlery, Christophe. De l'habitat des esclaves aux cases deux-pièces. Actes du colloque PNR Architecture : Habiter son territoire (29 avril 2003). Pointe-à-Pitre, parution 2005.

50. Caran T1068.

51. Les Affiches Américaines. Bihebdomadaire, Le Cap Français (Saint-Domingue), 7 mai 1766, (avis divers).

52. La Gazette de la Martinique. Hebdomadaire. Saint-Pierre (Martinique), 17 août 1785, (avis divers). 
53. Rosci, Marco. Il trattato di architettura di Sebastiano Serlio e Il sesto libro delle habitationi di tutti li gradi huomini. Fac simile du manuscrit de 1537-1546, Milan, 1966.

54. Babelon, Jean-Pierre. Demeures parisiennes sous Henri IV et Louis XIII. Farigliano: Editions Hazan, 1991, p. 203-204.

55. Labat, révérend père Jean-Baptiste. Nouveau voyage aux isles de l'Amérique, contenant l'histoire naturelle de ces pays, l'origine, les mœurs, la religion et le gouvernement des habitans anciens et modernes (édition de 1742). Saint-Joseph : Courtinard, rééd. de 1979, tome 1, p. 225-226.

56. Labat, révérend père Jean-Baptiste. Nouveau voyage aux isles de l'Amérique, contenant l'histoire naturelle de ces pays, l'origine, les mœurs, la religion et le gouvernement des habitans anciens et modernes (édition de 1742). Saint-Joseph : Courtinard, rééd. de 1979, tome 1, p. 71-72.

57. Vitry, Urbain. Le propriétaire architecte, contenant des modèles de maisons de ville et de campagne. 1827, p. 9-13.

58. Cointeraux, François. Traité de la construction des manufactures et des maisons de campagne. Paris : l'Auteur, 1791, p. 113.

59. Les Affiches Américaines. Hebdomadaire, Le Cap français (Saint-Domingue), 19 février 1766, (avis divers).

60. Vitry, Urbain. Le propriétaire architecte, contenant des modèles de maisons de ville et de campagne. 1827, p. 11.

61. Du Tertre, père Jean-Baptiste. Histoire générale des Antilles habitées par les Français. Fort-de-France : E. Kolodziej - E.D.C.A., rééd. de 1978, tome 2, p. 458.

62. Goerg, Odile. La Guinée Conakry. Rives coloniales, architectures de Saint-Louis à Douala. Marseille : Ed. Parenthèses et Ed. de l'Orstom, 1993, p. 219.

63. Les Affiches Américaines, hebdomadaire, Le Cap français (Saint-Domingue), 7 mai 1766, (avis divers).

64. Aviler d'. Dictionnaire d'Architecture Civile et Hydraulique et des Arts qui en dépendent .Paris, réédition de 1755, p. 202.

65. Larousse, Pierre. Grand Dictionnaire Universel du XIXe siècle. 1990 (réimpression de l'édition de 1866-1876).

66. Polti. Les Persiennes de l'Hôtel de l'Intendance de Franche-Comté. Monuments Historiques de la France, 1939, p 19-21.

67. Charlery, Christophe. Histoire des persiennes : de Versailles aux Antilles. Parution 2005.

68. Diderot, Denis et Le Rond d'alembert, Jean. L'Encyclopédie. Neufchâtel, 1765, tome 12.

69. Albaret d'. Différents projets relatifs au climat et à la manière la plus convenable de bâtir dans les pays chauds et plus particulièrement dans les Indes Occidentales. 1776.

70. Supplément aux Affiches Américaines. Bihebdomadaire, Port-au-Prince (Saint-Domingue), 4 mai 1776, (avis divers).

71. Moreau de Saint-Mery, Médéric-Louis-Elie. Description topographique, physique, civile, politique et historique de la partie française de Saint-Domingue; avec des observations générales sur la population, accompagnées de détails les plus propres à faire connaître l'état de la colonie à l'époque du 18 octobre 1789. Tome 1. Philadelphie, 1797, p 301.

72. Moreau de Saint-Mery, Médéric-Louis-Elie. Description topographique, physique, civile, politique et historique de la partie française de Saint-Domingue; avec des observations générales sur la population, accompagnées de détails les plus propres à faire connaître l'état de la colonie à l'époque du 18 octobre 1789. Tome 1. Philadelphie, 1797, p 379.

73. Moreau de Saint-Mery, Médéric-Louis-Elie. Description topographique, physique, civile, politique et historique de la partie française de Saint-Domingue; avec des observations générales sur la population, accompagnées de détails les plus propres à faire connaître l'état de la colonie à l'époque du 18 octobre 1789. Tome 1. Philadelphie, 1797, p 320. 
74. Moreau de Saint-Mery, Médéric-Louis-Elie. Description topographique, physique, civile, politique et historique de la partie française de Saint-Domingue; avec des observations générales sur la population, accompagnées de détails les plus propres à faire connaître l'état de la colonie à l'époque du 18 octobre 1789. Tome 1. Philadelphie, 1797, p 354.

75. Larousse, Pierre. Grand Dictionnaire Universel du XIX ${ }^{\mathrm{e}}$ siècle. 1990 (réimpression de l'édition de 1866-1876). 10 juillet 1776.

76. Cointeraux, François. Traité de la construction des manufactures et des maisons de campagne. Paris : l'Auteur, 1791, p 113.

77. Perotin-Dumont, Anne. La ville aux îles, la ville dans l'île, Basse-Terre et Pointe-à-Pitre, Guadeloupe, 1650-1820. Paris : Karthala, 2000, p. 816.

78. Arch. dép. Guadeloupe. Notaire Nielly, 7 avril 1778, vente d'une maison par Honoré Maurel à Jean-Pierre Desmier.

79. Moreau de Saint-Mery, Médéric-Louis-Elie. Description topographique, physique, civile, politique et historique de la partie française de Saint-Domingue ; avec des observations générales sur la population, accompagnées de détails les plus propres à faire connaître l'état de la colonie à l'époque du 18 octobre 1789. Tome 1. Philadelphie, 1797, p 592.

80. Charlery, Christophe. De l'habitat des esclaves aux cases deux-pièces. Actes du colloque PNR Architecture : Habiter son territoire (29 avril 2003). Pointe-à-Pitre, parution 2005.

81. Goerg, Odile. La Guinée Conakry. Rives coloniales, architectures de Saint-Louis à Douala. Marseille : Ed. Parenthèses et Ed. de l'Orstom, 1993, p 220.

82. Du Tertre, père Jean-Baptiste. Histoire générale des Antilles habitées par les Français. Fort-de-France : E. Kolodziej - E.D.C.A., rééd. de 1978, tome 2, p 457.

83. Du Tertre, père Jean-Baptiste. Histoire générale des Antilles habitées par les Français. Fort-de-France : E. Kolodziej - E.D.C.A., rééd. de 1978, tome 2, p 457.

84. Arch. dép. Guadeloupe. Notaire Mollenthiel, 10 octobre 1817, Inventaire des biens de Sieur de Blaine dressé le 19, 20 et 21 février 1743.

85. Vitry, Urbain. Le propriétaire architecte, contenant des modèles de maisons de ville et de campagne. 1827, p. 22-23.

86. Les Affiches Américaines. Hebdomadaire, Le Cap français (Saint-Domingue), 19 février 1766, (avis divers).

87. Arch. dép. Guadeloupe. Notaire Henry, 12 juin 1822, Liquidation de la communauté des époux Lagarde.

88. Arch. dép. Martinique. Notaire Castel, 17 août 1817, Vente d'une habitation et mobilier par Athanaze à la née Céline.

89. Du Tertre, père Jean-Baptiste. Histoire générale des Antilles habitées par les Français. Fort-de-France : E. Kolodziej - E.D.C.A., rééd. de 1978, tome 2, p 457.

90. Les Affiches Américaines. Hebdomadaire, Le Cap français (Saint-Domingue), 19 février 1766, (avis divers).

91. Debien, G. Les Grand'cases des plantations à Saint-Domingue aux XVII ${ }^{\mathrm{e}}$ et XVIII ${ }^{\mathrm{e}}$ siècles. Annales des Antilles, bulletin de la société d'histoire de la Martinique. Fort-de-France, 1970, $\mathrm{n}^{\circ} 15, \mathrm{p} 7$.

92. Moreau de Saint-Mery, Médéric-Louis-Elie. Description topographique, physique, civile, politique et historique de la partie française de Saint-Domingue; avec des observations générales sur la population, accompagnées de détails les plus propres à faire connaître l'état de la colonie à l'époque du 18 octobre 1789. Tome 1. Philadelphie, 1797, p 236.

93. Moreau de Saint-Mery, Médéric-Louis-Elie. Description topographique, physique, civile, politique et historique de la partie française de Saint-Domingue; avec des observations générales sur la population, accompagnées de détails les plus propres à faire connaître l'état de la colonie à l'époque du 18 octobre 1789. Tome 1. Philadelphie, 1797, p 216. 
94. Debien, G. Les Grand'cases des plantations à Saint-Domingue aux XVII ${ }^{\mathrm{e}}$ et $\mathrm{XVIII}^{\mathrm{e}}$ siècles. Annales des Antilles, bulletin de la société d'histoire de la Martinique. Fort-de-France, 1970, $\mathrm{n}^{\circ} 15, \mathrm{p} 39$.

95. Lafleur, Gérard. Saint-Claude, histoire d'une commune de Guadeloupe. Paris : Karthala, 1993, p. 71.

96. Cointeraux, François. Traité de la construction des manufactures et des maisons de campagne. Paris : l'Auteur, 1791, p 113.

97. Les Affiches Américaines. Hebdomadaire, Le Cap français (Saint-Domingue), 19 février 1766, (avis divers).

98. Labat, révérend père Jean-Baptiste. Nouveau voyage aux isles de l'Amérique, contenant l'histoire naturelle de ces pays, l'origine, les mœurs, la religion et le gouvernement des habitans anciens et modernes (édition de 1742). Saint-Joseph: Courtinard, rééd. de 1979, chapitre XVIII, p 370.

\section{RÉSUMÉS}

Dans l'imaginaire collectif, la «maison coloniale » évoque une grande demeure, confortable et luxueuse, mais la réalité est souvent différente. De nombreuses maisons de maître restent somme toute assez modestes et ressemblent plus à des fermes françaises moyennes qu'à des châteaux. Il existe une multitude de plans de distribution intérieure, mais certaines analogies semblent indiquer que des plans type ont circulé, de la Guyane à la Louisiane, en passant par la Martinique, la Guadeloupe, Saint-Domingue et la partie orientale de l'île de Cuba. Cette étude typologique nous permettra aussi d'évoquer le processus d'adaptation au climat avec l'apparition des galeries et des persiennes et d'en comprendre le développement. Nous parlerons enfin des cuisines et des jardins, éléments indispensables à la vie domestique.

In everybody's imagination, the « colonial house » evoked a big, comfortable luxurious mansion. However, the reality was often different and most of such houses were rather modest and looked like our average French farms rather than our castles. There were various models of interior structures, but certain analogies seem to indicate that standard typologies circulated from Guyana to Louisiana, through Martinique, Guadeloupe, Santo Domingo and the eastern part of Cuba. The study of such typologies will allow us also to understand their development and highlight the adaptation process to the climate through the appearance of galleries and shutters. Finally we will quickly talk about the kitchens and the gardens which were essential elements of the domestic life in a colonial plantation.

\section{INDEX}

Mots-clés : habitation, architecture coloniale, Amérique tropicale, maison coloniale, maison de maître, galerie, ventilation, jalousie, persienne, mobilier colonial, colombier 


\section{AUTEUR}

\section{CHRISTOPHE CHARLERY}

Architecte du patrimoine, Direction régionale des affaires culturelles de Guadeloupe. christophecharlery@wanadoo.fr 